\title{
Encouraging the resumption of economic activity after COVID-19: Evidence from a large scale field experiment in China
}

\author{
Juan Palacios, ${ }^{1}$ Yichun Fan, ${ }^{1}$ Erez Yoeli ${ }^{2}$, Jianghao Wang ${ }^{1,3}$, \\ Yuchen Chai ${ }^{1}$, Weizeng Sun, ${ }^{4}$ David Rand,${ }^{2}$ and Siqi Zheng $* 1$ \\ ${ }^{1}$ Department of Urban Studies and Planning, Massachusetts Institute of Technology, MA, USA \\ ${ }^{2}$ Sloan School of Management, Massachusetts Institute of Technology, MA, USA \\ ${ }^{3}$ Institute of Geographic Sciences Natural Resources Research, Chinese Academy of Science, \\ China \\ ${ }^{4}$ School of Economics, Central University of Finance and Economics, China
}

Working Paper

February 3, 2021

\begin{abstract}
As the COVID-19 pandemic comes to an end, governments find themselves facing a new challenge: motivating citizens to resume economic activity. What is an effective way to do so? We investigate this question using a field experiment in the city of Zhengzhou, China immediately following the end of the city's COVID-19 lockdown. Using self-reports and GPS trajectory data from participants' phones, we assessed the effect of providing information about the proportion of participants' neighbors who have resumed economic activity. We find that informing individuals about their neighbors' plans to visit restaurants increases the fraction of participants visiting restaurants by 12 percentage points (37\%), amongst those participants who underestimated the proportion of neighbors who resumed economic activity. Those who overestimated did not respond by reducing restaurant attendance, so the intervention yielded no 'boomerang' effect. We explore moderators, risk perceptions, and a placebo intervention for parks. All of these analyses suggest our intervention worked by reducing the perceived risk of going to restaurants.
\end{abstract}

Keywords: COVID-19, descriptive norms, field experiment, voluntary economic resumption, policy. 
The respiratory syndrome-coronavirus 2 (SARS-CoV-2) virus and the policies implemented to reduce its transmission (1, 2) have sent the global economy into its deepest recession since the Great Depression (3). In the second quarter of 2020, the US economy alone exhibited its greatest GDP reduction in modern history due to the COVID-19 pandemic (4). Although mandatory government shutdowns are commonly thought to be the cause of reduced activity, there is mounting evidence that most of the reduction in economic activity was voluntary, spurred by fears of the virus (5, 6). At the time of writing, there are high rates of COVID-19 in most countries, but some countries (e.g., Korea, Japan, China) have successfully contained the virus via low rates of community transmission, and others (e.g., the United Kingdom, the United Sates, and Israel) are ramping up vaccine distribution $(7 ; 8,9)$. Governments are thus devoting increasing attention to reopening their services and the economy more broadly. In the United States, for instance, President-Elect Joe Biden has given prime billing to reopening schools and economic recovery as he prepares to take over the office of the President (10). However, economic recovery will remain stymied so long as the public remains skeptical that it is safe to engage in normal economic activity (11)-a skepticism that is exacerbated by concerns over the safety of vaccines (12) and general distrust of government (13). As former chair of the Council of Economic Advisors Austan Goolsbee recently said, after unemployment numbers surged alongside virus cases in December 2020, "Jobs day lesson 1 million: The virus is the boss." (14) Can government officials and others effectively communicate when it is safe for individuals to resume normal economic activity? There has been almost no research on this question to date (15), and, to the best of our knowledge, no work that measures the effect of messaging on actual behavior rather than just self-report intentions.

In this study, we explore the effect of 'descriptive norms' on individuals' willingness to resume economic activity in the aftermath of a COVID-19 lockdown. Descriptive norm interventions provide information about how common a behavior is, with the goal of encouraging people to behave in the way others are behaving (e.g., to engage in the behavior if the norm states that most other people do, and to avoid the behavior if the norm states that few people are engaging in it). Descriptive norms are a commonly employed 'nudge,' and have been successfully used to influence a variety of behaviors, including reducing alcohol consumption (16), improving tax compliance (17), increasing the reuse of hotel towels (18), conserving energy (19), reducing smoking and engaging in other health-related behaviors (20). Descriptive norms are thought to be effective messages because others' behavior can inform whether it is beneficial to engage in a behaviorwhether the behavior is, e.g., safe, helpful, or expected (21). Further, conforming to others' behavior is a fundamental feature of how people learn, and an important driver of human cultural evolution (22). Descriptive norms are also appealing from a pragmatic perspective because they are inexpensive to implement: It is virtually costless to include descriptive norms messages with 
other outgoing messages, and usually relatively low cost to collect the requisite data on how common a behavior is.

Descriptive norms, however, do not always generate large behavioral effects (23, 24, 25, 26) and can sometimes even backfire amongst people with relatively high prior beliefs on how common the behavior is (27), a phenomenon sometimes called 'the boomerang effect'. In the context of resuming economic activity following a pandemic, there is another particularly powerful reason to fear that descriptive norms will backfire: the more people go to public spaces like restaurants, the higher the objective risk of being infected if one joins them. If descriptive norm information causes people to believe that more people are going out, this could quite rationally lead them to be discouraged from visiting such spaces due to risk avoidance (28; 29). Thus, it is unclear ex-ante whether descriptive norms will help or hurt the resumption of economic activity.

\section{Experimental design}

We test the impact of descriptive norms in a field experiment in the Chinese city of Zhengzhou (population 10.1 million), just after the end of a government-mandated COVID-19 shutdown (Fig. 1a). We recruited 622 subjects from the city's residents who work in the central business district of the city. Recruitment was done via text messages, phone calls and advertisements on social media. Subjects received the intervention the week they were recruited, with recruitment lasting a total of five weeks (see section Methods Section and Supplementary Table F.1 for a detailed description of the recruitment procedure and statistics of sample attrition and new participants recruited by time). Each participant received a recruitment text message with instructions to install the smartphone app, which we designed especially for the study. The app is able to collect the GPS coordinates of participants during the study period, send tailored questionnaires, and pay 'red-pocket' money, a commonly used form of payments in China.

Figure $1 \mathrm{~b}$ displays an overview of the core experimental design. For each subject, on the first full week following their recruitment, we performed a survey on Wednesday, in which we collected whether they plan to go to a restaurant in the coming weekend and their belief on the percentage of their neighbors who plan to do so. Belief elicitation was incentive compatible: subjects received a small (2 Chinese Yuan, equivalent to roughly 0.30 USD; see Table G.2 for a description of monetary compensations to participants) bonus if their guess was within two percentage points of the truth.

Then, on Friday of that week, we informed subjects in the treatment group of the true proportion of their neighbors who were planning to go to restaurants over the weekend, based on the results of our Wednesday survey. The true proportion was computed synthesizing the results from the Wednesday survey, together with results from an extra survey we did on a random sample of another 500 citizens living in the same neighborhoods (i.e. urban district) 
as our participants. After that, we re-elicited subjects' beliefs about the percentage of their neighbors who will actually go to restaurants over the weekend. Besides the descriptive norm intervention, all materials were identical across the treatment and control groups (see Section D.1 in Supplementary Information for the wording and display of intervention). Finally, on Sunday evening, we asked the respondents to report their restaurant visitation over the weekend. We also collect GPS data from their smart phones to cross-validate the stated behaviors. Further details of the experimental design can be found in the Methods Section

Besides the main outcomes, we collected a rich set of participant characteristics, preferences, beliefs, and attitudes to understand which factors moderate the effectiveness of descriptive norms in our setting. Specifically, we collected 13 moderators at the recruitment date, including demographics (age, gender, having kids or not, education, income), economic preferences (general and health-specific risk preferences, time preference, altruism), knowledge about coronavirus, pre-COVID activity frequency, community and media trust (see supplementary Table D.5 for how each dimension was measured).

Prior to the intervention, our subjects reported a meaningfully curtailed baseline level of restaurant visits: $49.1 \%$ of subjects in the control group reported attending restaurants every week on average before the pandemic, but this number was just $31.18 \%$ at the time our intervention began, a 17.92 percentage point (or 57.47\%) decline (supplementary Table H.1). Our primary hypotheses were that subjects in the treatment group who underestimated others' behaviors (i.e., whose beliefs that others planned to visit restaurants were below the true percentage) would respond to the descriptive norms intervention by increasing these beliefs and modifying their behavior. We pre-registered these hypotheses as well as our 13 moderators (RCT ID: AEARCTR-0005644) and tested these hypotheses by comparing treated individuals with people in the control group with similar prior beliefs.

\section{Results}

Our main result is that the descriptive norm intervention effectively corrected subjects' beliefs about others' restaurant visits, and that these corrections translated into large increases in their own restaurant visits. Specifically, for those subjects with initial beliefs below the true value, the treatment shifted beliefs upwards by 4.64 percentage points [95\% CI: 0.97 to $8.31, P=0.013$ ], with greater increases associated with more downward-biased initial beliefs (Fig. 2a). These subjects were subsequently 12.5 percentage points [95\% CI: 1.54 to $23.3, P=0.025$ ] more likely to report visiting a restaurant over the weekend (Fig. $2 \mathrm{~b}$ ) relative to the control group, a $37.0 \%$ increase. Meanwhile, subjects whose beliefs were above the truth also corrected their beliefs, decreasing them in response to the intervention by 10.9 percentage points [95\% CI: -15.46 to $-6.52, P<0.001]$. However, these subjects did not alter their visits to restaurants almost at all 


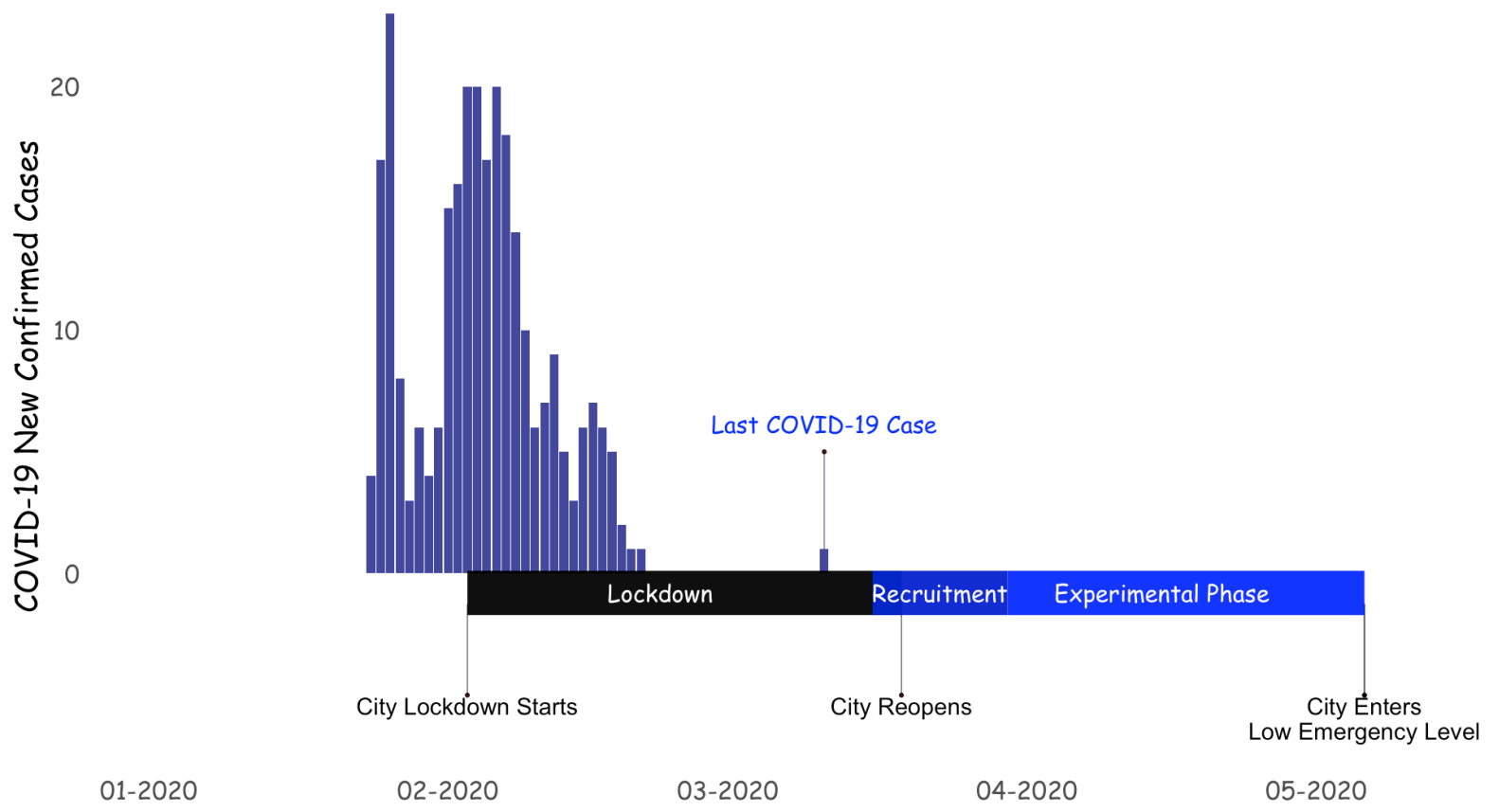

b

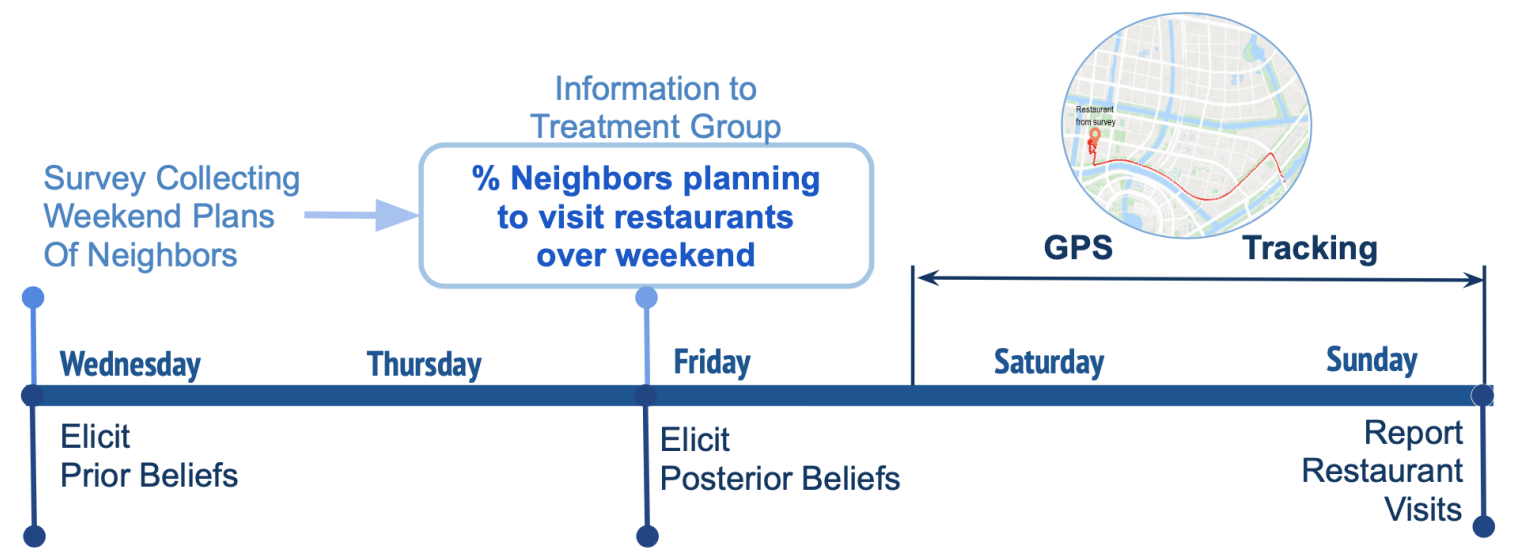

Notes: Panel a presents the study timeline of the study. Panel $\mathbf{b}$ displays the outline of questionnaires, messages and GPS tracking time in an experimental week. The full description of the data collection and construction of the descriptive norm intervention is presented in Methods Section The exact wording of the descriptive norm is "For each 100 people filling the questionnaire living in your urban district, [[Information Descriptive Norm]] plan to a restaurant this weekend." The full display of the intervention is described in section D.1 in Supplementary Information.

$[\beta=-1.25,95 \% \mathrm{CI}:-13.70$ to $11.18, P=0.842]$. Thus, a boomerang effect was not present in our intervention. In Supplementary Information Sec. A.2 and A.1. we confirm the robustness of these results using a variety of parametric and non-parametric specifications. We also show that the effect of the descriptive norms intervention on beliefs lasted several weeks (see Supplementary Figure I.1).

Next, we perform three secondary analyses that, in combination, suggest that our intervention worked by increasing subjects' perception that restaurants are safe. The first of these analysis focuses on the moderating role of risk preferences. In this analysis, we looked for evi- 
Figure 2: Changes in beliefs and behavior associated with descriptive norm

a
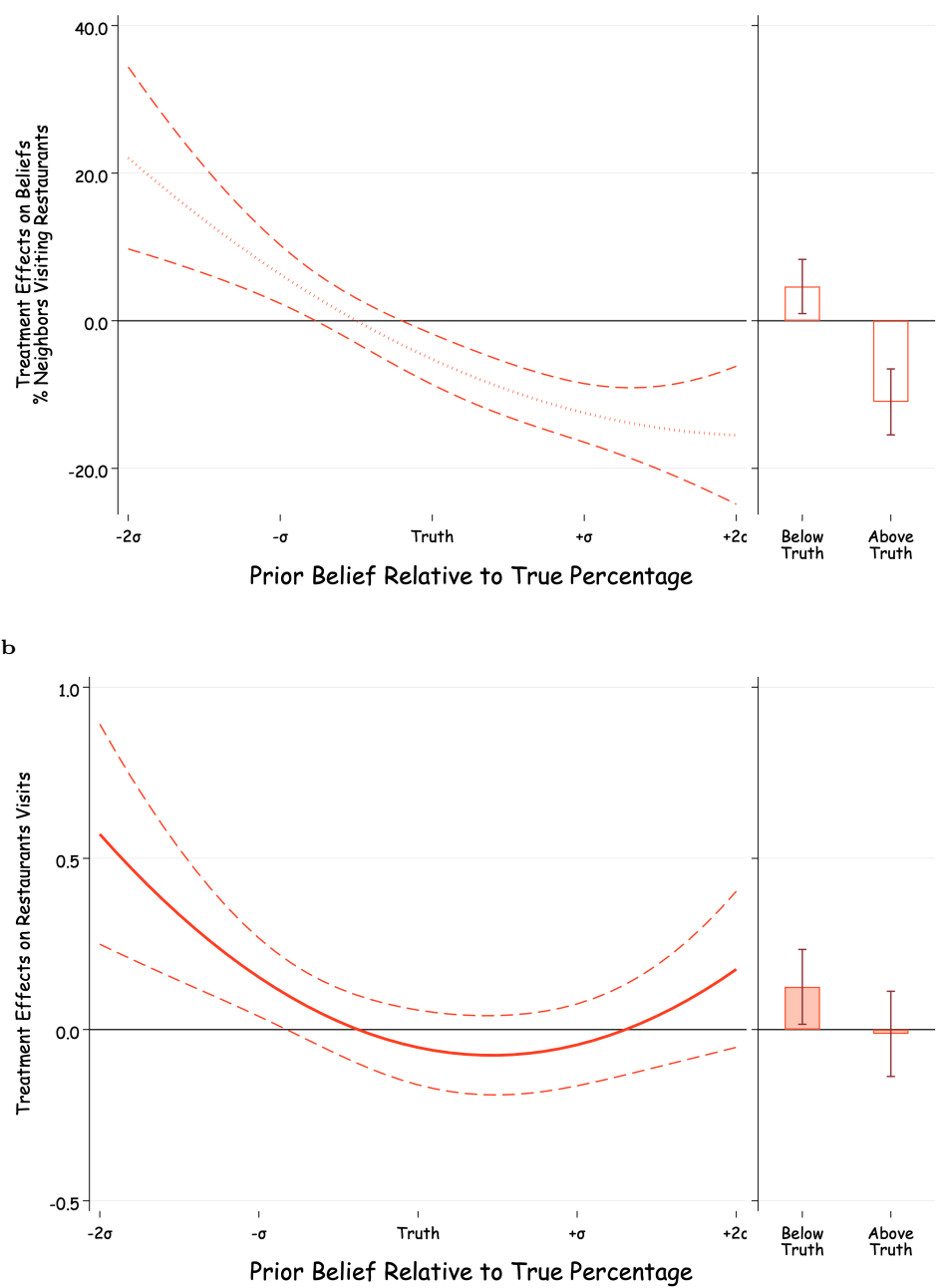

Notes: i) The vertical axes in Panel a displays the change in subjects' beliefs from Wednesday (prior) to Friday (posterior) regarding the percentage of neighbors who are actually going to go to restaurants over the weekend. The horizontal axes display the bias in beliefs on prior to our intervention, computed by subtracting subjects' prior beliefs regarding the percentage of neighbors that are planning to go to restaurants from the true percentage of neighbors planning to go to restaurants. The true percentages, used to build the descriptive norm information, are computed from the proportion of individuals that reported in our Wednesday questionnaire to have plans to go to restaurants over the weekend. The sample includes only responses of individuals that were treated for the first time, and control subjects that were in the sample for one week. The dotted line represents the average differences between treatment and control group calculated in a regression analysis interacting the treatment dummy with a polynomial form of the bias in prior beliefs. Section A.3 in Supplementary Materials describes the polynomial regression used to construct the figure. Dashed lines represent the 95-percent confidence interval. ii) The bar graphs included in the right hand side of Panel a indicate the average change in posterior beliefs for individuals with prior beliefs below and above the truth, separately; the error bars describe the $95 \%$ confidence intervals. Non-parametric comparisons between treatment and control group displayed in Figure A.1

iii) Panel b describes the change in subjects' visits to restaurants, after our first intervention, as a function of their bias in initial beliefs relative to the intervention information (i.e. prior belief - true percentage). The solid line represents the average differences between treatment and control group, calculated in a regression analysis interacting the treatment dummy with a polynomial form of the bias in prior beliefs. Section A.3 in Supplementary Materials describes the polynomial regression used to construct the figure. Dashed line represents the 95-percent confidence interval. iv) The bar graphs included in the right hand side of Panel $b$ indicate the average change in real visitation rate for individuals with prior beliefs below and above the truth, separately; the error bars describe the $95 \%$ confidence intervals. The estimated treatment effects on behavior based on Logit and Probit regressions show the similar levels of statistical significance, as reflected by the P-values associated with the coefficients of interest (Table A.1). Non-parametric comparisons between treatment and control group displayed in Figure A.4

dence of moderation by the characteristics, preferences, beliefs, and attitudes that we collected in our surveys on the recruitment date. We found that only one meaningfully moderated the 
effect of the intervention: subjects' risk tolerance. Fig. 3a shows that risk averse individuals did not adjust their behaviors when they learned that more people than they expected were going to restaurants (general risk: $0.18 \mathrm{pp}, \mathrm{CI}:-15.03$ to $15.39 \mathrm{pp}, P=0.981$; health risk: $0.42 \mathrm{pp}, \mathrm{CI}$ : -14.93 to $15.76 \mathrm{pp}, P=0.958)$, whereas risk tolerant people increased restaurant visits substantially (general risk: $21.0 \mathrm{pp}$, CI: 4.05 to $37.95 \mathrm{pp}, P=0.017$; health risk: $21.5 \mathrm{pp}$, CI: 5.47 to 37.53 pp, $P<0.01)$. As can be seen in Supplementary Fig. A.10 subjects' belief adjustment did not depend on their risk tolerance, but whether this adjustment translated to a change in behavior very much did: only subjects who were relatively risk tolerant were more likely to visit restaurants. Once again, we undertook a number of tests to assess the robustness of the results (see Supplementary Information Sec. A.4).

Second, we consider the effect of the intervention on subjects' stated perceptions of the risk associated with visiting a restaurant. On each Friday, immediately after our intervention, we asked individuals the question, "How would you rate the infectious risk of dining out in restaurants nearby?". Subjects recorded their replies with a 7-point Likert scale. We found that subjects who received the descriptive norms intervention reported somewhat lower perceived risk than those in the control, though this result is, only marginally significant [Standardized Coefficient $=-0.160,95 \%$ CI: $-0.35,0.026, p=0.093$ ] (Supplementary Table C.10).

Third, and finally, we contrast the impact of our intervention with a placebo treatment that repeated the descriptive norms intervention in the same sample of participants, but for parks instead of restaurants. Visiting parks is far less risky than visiting restaurants (30). Parks are open-air spaces where social interactions can take place at a distance, resulting in much less risk of transmission than in restaurants. Subjects' own perceptions of the relative risks conform with this: $82.8 \%$ of participants considered visiting local restaurants riskier than visiting parks in the neighborhood (Supplementary Fig. H.1). Accordingly, park visitation returned to normal very quickly in the aftermath of the pandemic: Within the control group, $33.3 \%$ of subjects reported going to parks once a week on average before the pandemic; this number was $37.63 \%$ at the time our intervention began, a 4.6 percentage point (or 13.92\%) increase (supplementary Table H.1). All this suggests that the descriptive norm intervention would be unlikely to change subjects' beliefs about risk and behaviors, since they already viewed parks as relatively safe and this was reflected in their behavior.

Indeed, we found that the effect of the descriptive norm intervention for parks was, at most, muted. For those subjects with prior beliefs below the truth, the treatment also successfully shifted beliefs upwards by 7.33 pp [95\% CI: 2.92 to 11.73 pp, $P<0.001$ ] (see Fig.3p). Yet unlike restaurant, knowing more people going to parks did not translate into behavioral change: we only observe a non-significant $3.39 \mathrm{pp}$ increase in park visits [95\% CI: -6.7 to $13.51 \mathrm{pp}, P=0.511$ ] (see Fig. 3 c). In Supplementary Information Sec. A.2, we show that these results are robust to 
Figure 3: The moderating effect of risk preferences and results of a placebo outcome a

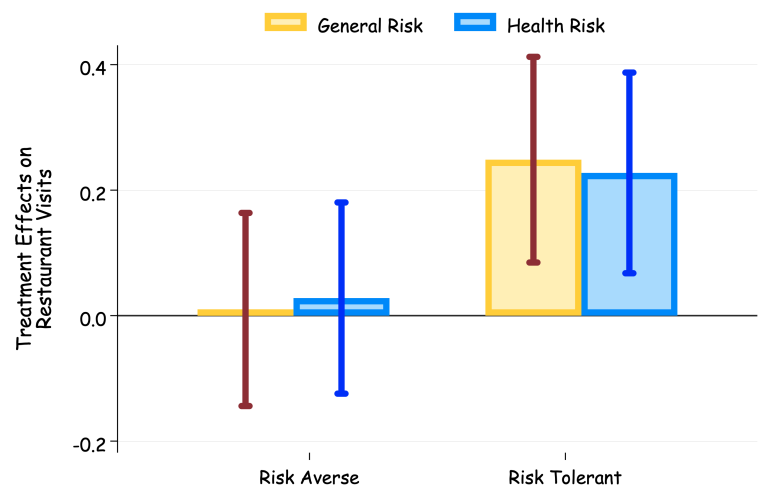

b

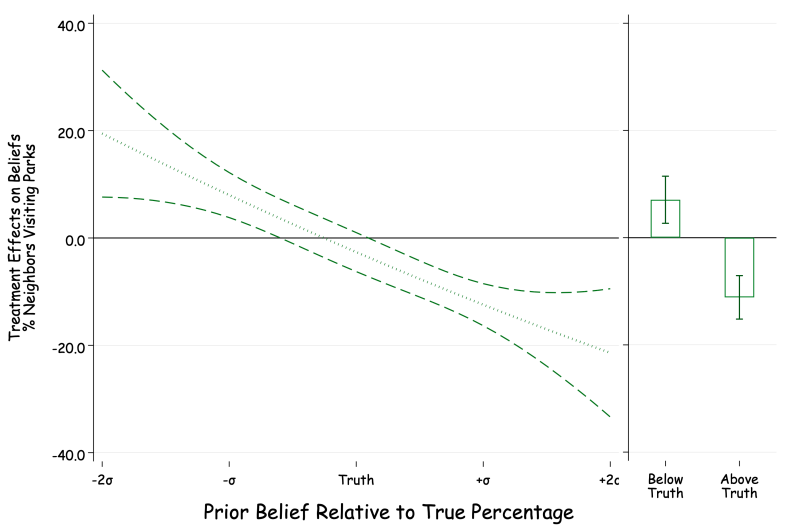

c

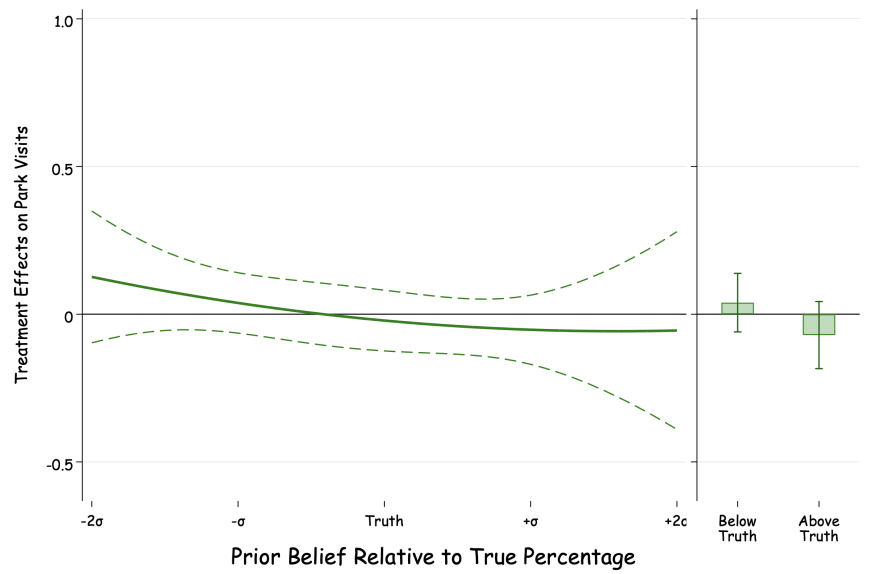

Notes: i) Panel a displays the treatment effects for individuals with low (below median) and high (above median) risk tolerance separately. We display the results for both the general and health-specific risk aversion. Dots describe point estimates and the darker (lighter) bars describe the 90\% (95\%) confidence intervals. There are significant differences of the treatment effect across the risk averse and risk tolerance sub-groups (cross-model Wald tests considering the covariance across estimators give $\mathrm{P}=0.058$ and $\mathrm{P}=0.048$ for general and health risk respectively). The results are consistent with those based on interaction terms (Equation 2, using continuous rather than group indicator of risk (Supplementary Figure A.7), and after adjusting for multiple hypothesis testing (Supplementary Table A.3). This moderator analysis has been pre-registered at the American Economic Association Registry for randomized control trials (RCT ID: AEARCTR-0005644).

ii) Panel b. Describes the treatment effect of descriptive norms on beliefs regarding the percentage of neighrbors visiting a park visitation green reported in our Friday survey. Section A.3 in Supplementary Materials describes the polynomial regression used to construct the figure. The dotted line represents the average differences between treatment and control group calculated in a regression analysis interacting the treatment dummy with a polynomial form of the bias in prior beliefs. Section A.3 in Supplementary Materials describes the polynomial regression used to construct the figure. Dashed lines represent the 95-percent confidence interval. The bar graphs included in the right hand side of Panel $\mathrm{b}$ indicate the average change in posterior beliefs for individuals with prior beliefs below and above the truth, separately; the error bars describe the $95 \%$ confidence intervals. Non-parametric comparisons between treatment and control group displayed in Figure A.1

iii) Panel c displays the differences in treatment effects across the distance between individuals' prior beliefs and the true percentage of neighbors planning to go to parks (used to construct the descriptive norm intervention). The sample includes only responses of individuals that were treated for the first time, and control subjects that were in the sample for one week. The solid line represents the average differences between treatment and control group calculated in a regression analysis interacting the treatment dummy with a polynomial form of the bias in prior beliefs. Section A.3 in Supplementary Materials describes the polynomial regression used to construct the figure. Dashed lines represent the 95-percent confidence interval. The bar graphs included in the right hand side of the figure indicate the average change in park visits for individuals with prior beliefs below and above the truth, separately; the error bars describe the $95 \%$ confidence intervals. Regression tables with different model specifications displayed in A.2 and non-parametric comparisons between treatment and control group are included in Figure A.4

employing additional regression specifications.

Our field experiment included an additional intervention that informed subjects of nearby 
restaurants who participated in a certification program created by the largest restaurant online portal in China, that affirmed these restaurants employed best practices for reducing virus transmission. The treatment effect of this intervention was positive. However, its estimated magnitude was roughly half that of our descriptive norm intervention, and it was not statistically significant. This is true even when restricting to only on individuals whose beliefs were below average $[\beta=0.06,95 \%$ CI: $-2.62,13.64 \mathrm{pp}, P=0.184$, Supplementary Table B.5]. In our view, the results for this intervention, which is similar to interventions that have been employed practice (31), further emphasize just how powerful was the descriptive norm intervention (For a complete description of all the interventions and some additional results, please refer to Supplementary Information Sec. B. C).

To mitigate concerns about self-reporting biases, we used the GPS coordinates of participants who agreed to share their data with the research team to evaluate its correspondence with self-reported visits $[\mathrm{N}=175]$. GPS Validation reaffirms the quality of the self-reported outcomes, showing a high correspondence between the reported restaurant visited and the GPS coordinates of participants. The complete description of the validation exercise is in Supplementary Information Sec. J.

\section{Discussion}

Overall, our experiment suggests that descriptive norms can serve as an effective tool for motivating a return to normal economic activity by reducing people's fear that such activity is unsafe. By conducting a randomized controlled trial, and combining self-reported data with GPS validations, we provide high-quality evidence of the causal effect of social norms on the resumption of economic activity. We hope our experiment informs politicians' and policy-makers' efforts to motivate a return to normal activity in the aftermath of COVID-19.

Our field experiment also provides a particularly detailed look into how descriptive norms worked in a particularly challenging setting. Because individual actions carry substantial health risks both for participants and for those people around them, and because objective infection risk increases with the number of others going out, this is a context where descriptive norms could reasonably be expected not to work as intended. Interestingly, however, learning that others planned to resume activity led participants to think that this behavior was actually safer, rather than more dangerous. This speaks to the power of social norms to change beliefs even in uncertain times, even in the face of countervailing forces.

\section{Supplementary Material}

Supplementary Information is available for this paper. 


\section{References}

[1] Solomon Hsiang, Daniel Allen, Sebastien Annan-Phan, Kendon Bell, Ian Bolliger, Trinetta Chong, Hannah Druckenmiller, Andrew Hultgren, Luna Yue Huang, Emma Krasovich, Peiley Lau, Jaecheol Lee, Esther Rolf, Jeanette Tseng, and Tiffany Wu. The Effect of LargeScale Anti-Contagion Policies on the Coronavirus (COVID-19) Pandemic. Nature, page 2020.03.22.20040642, jan 2020.

[2] Seth Flaxman, Swapnil Mishra, Axel Gandy, H Juliette T Unwin, Thomas A Mellan, Helen Coupland, Charles Whittaker, Harrison Zhu, Tresnia Berah, Jeffrey W Eaton, Christl A Donnelly, Steven M Riley, Michaela A C Vollmer, Neil M Ferguson, and Lucy C Okell. Estimating the effects of non-pharmaceutical interventions on COVID-19 in Europe. Nature, 2020 .

[3] World Bank. Global Economic Prospects. Technical Report June, Washington, DC, 2020.

[4] BEA. Gross Domestic Product, 2nd Quarter 2020 (Advance Estimate) and Annual Update, 2020.

[5] Austan Goolsbee and Chad Syverson. Fear, lockdown, and diversion: Comparing drivers of pandemic economic decline 2020. Journal of Public Economics, 193:104311, 2021.

[6] Raj Chetty, John N Friedman, Nathaniel Hendren, and Michael Stepner. How did covid-19 and stabilization policies affect spending and employment? a new real-time economic tracker based on private sector data. Technical report, National Bureau of Economic Research, 2020 .

[7] Kathleen Dooling. The advisory committee on immunization practicesâ updated interim recommendation for allocation of covid-19 vaccineâunited states, december 2020, 2020.

[8] The Times of Israel. Israel aims to vaccinate $25 \%$ of population in a month; 250,000 had shots so far, 2020.

[9] Melissa Eddy and Marc Santora. E.U. Starts Effort to Vaccinate 450 Million, 2020.

[10] Biden-Harris Transition. The Biden-Harris plan to beat COVID-19, 2020.

[11] Thiemo Fetzer, Lukas Hensel, Johannes Hermle, and Christopher Roth. Coronavirus perceptions and economic anxiety. The Review of Economics and Statistics, pages 1-36, 2021.

[12] Jeffrey V Lazarus, Scott C Ratzan, Adam Palayew, Lawrence O Gostin, Heidi J Larson, Kenneth Rabin, Spencer Kimball, and Ayman El-Mohandes. A global survey of potential acceptance of a covid-19 vaccine. Nature medicine, pages 1-4, 2020.

[13] Thiemo Fetzer, Marc Witte, Lukas Hensel, Jon Jachimowicz, Johannes Haushofer, Andriy Ivchenko, Stefano Caria, Elena Reutskaja, Christopher Roth, Stefano Fiorin, et al. Perceptions of an insufficient government response at the onset of the covid-19 pandemic are associated with lower mental well-being. PREPRINT, 2020.

[14] Austan Goolsbee. Twitter. https://twitter.com/austangoolsbee/ status/ 1347548098978062336, 08-January 2021.

[15] Nancy H.L. Leung, Daniel K.W. Chu, Eunice Y.C. Shiu, Kwok Hung Chan, James J. McDevitt, Benien J.P. Hau, Hui Ling Yen, Yuguo Li, Dennis K.M. Ip, J. S.Malik Peiris, Wing Hong Seto, Gabriel M. Leung, Donald K. Milton, and Benjamin J. Cowling. Respiratory virus shedding in exhaled breath and efficacy of face masks. Nature Medicine, 26(5):676-680, 2020.

[16] H. Wesley Perkins and Alan D Berkowitz. Perceiving the community norms of alcohol use among students: Some Research implications for campus alcohol education programming*. Substance Use and Misuse, 21(9-10):961-976, 1986.

[17] Michael Hallsworth, John A List, Robert D Metcalfe, and Ivo Vlaev. The behavioralist as tax collector: Using natural field experiments to enhance tax compliance. Journal of public economics, 148:14-31, 2017.

[18] Noah J Goldstein, Robert B Cialdini, and Vladas Griskevicius. A room with a viewpoint: Using social norms to motivate environmental conservation in hotels. Journal of consumer Research, 35(3):472-482, 2008. 
[19] Kimberly S. Wolske, Kenneth T. Gillingham, and P. Wesley Schultz. Peer influence on household energy behaviours. Nature Energy, 5(3):202-212, 2020.

[20] Robert C. Dempsey, John McAlaney, and Bridgette M. Bewick. A critical appraisal of the social norms approach as an interventional strategy for health-related behavior and attitude change. Frontiers in Psychology, 9(NOV):1-16, 2018.

[21] J.J.; et al VanBavel. Using social and behavioural science to support COVID-19 pandemic response. Nature Human Behaviour, pages 1-50, 2020.

[22] Michael Muthukrishna, Thomas J H Morgan, and Joseph Henrich. The when and who of social learning and conformist transmission. Evolution and Human Behavior, 37(1):10-20, 2016.

[23] John Beshears, James J Choi, David Laibson, Brigitte C Madrian, and Katherine L Milkman. The effect of providing peer information on retirement savings decisions. The Journal of finance, 70(3):1161-1201, 2015.

[24] Christina Annette Gravert and Linus Olsson Collentine. When nudges aren't enough: Incentives and habit formation in public transport usage. CEBI WORKING PAPER SERIES, Working Paper 10/19, ISSN 2596-44TX, 2019.

[25] Ariella S Kristal and Ashley V Whillans. What we can learn from five naturalistic field experiments that failed to shift commuter behaviour. Nature Human Behaviour, 4(2):169$176,2020$.

[26] Mark A Andor, Andreas Gerster, Jörg Peters, and Christoph M Schmidt. Social norms and energy conservation beyond the us. Journal of Environmental Economics and Management, $103,2020$.

[27] P Wesley Schultz, Jessica M Nolan, Robert B Cialdini, Noah J Goldstein, and Vladas Griskevicius. The constructive, destructive, and reconstructive power of social norms. Psychological science, 18(5):429-434, 2007.

[28] Eli P. Fenichel. Economic considerations for social distancing and behavioral based policies during an epidemic. Journal of Health Economics, 32(2):440-451, 2013.

[29] Eli P. Fenichel, Carlos Castillo-Chavezb, M. G. Ceddiac, Gerardo Chowellb, Paula A. Gonzalez Parrae, Graham J. Hickling, Garth Holloway, Richard Horan, Benjamin Morin, Charles Perrings, Michael Springborn, Leticia Velazquez, and Cristina Villalobos. Adaptive human behavior in epidemiological models. Proceedings of the National Academy of Sciences of the United States of America, 108(15):6306-6311, 2011.

[30] Seth Benzell, Avinash Collis, and Christos Nicolaides. Rationing Social Contact During the COVID-19 Pandemic: Transmission Risk and Social Benefits of US Locations. Proceedings of the National Academy of Sciences, pages 2-4, 2020.

[31] Daisy Dai and Michael Luca. Digitizing Disclosure: The Case of Restaurant Hygiene Scores. American Economic Journal: Microeconomics, 12(2):41-59, 2020.

[32] Jon M. Jachimowicz, Salah Chafik, Sabeth Munrat, Jaideep C. Prabhu, and Elke U. Weber. Community trust reduces myopic decisions of low-income individuals. Proceedings of the National Academy of Sciences of the United States of America, 114(21):5401-5406, 2017.

[33] Armin Falk, Anke Becker, Thomas Dohmen, Benjamin Enke, David Huffman, and Uwe Sunde. Global evidence on economic preferences. The Quarterly Journal of Economics, 133(4):1645-1692, 2018.

[34] Davide Cantoni, David Yang, Noam Yuchtman, and Jane Zhang. Protests as strategic games: Experimental Evidence from Hong Kong's Authoritarian Movement. The Quarterly Journal of Economics, 134(2):1021-1077, 2019.

[35] John A. List, Azeem M. Shaikh, and Yang Xu. Multiple hypothesis testing in experimental economics. Experimental Economics, 22(4):773-793, 2019.

[36] George Loewenstein, Cass R. Sunstein, and Russell Golman. Disclosure: Psychology Changes Everything. Annual Review of Economics, 6(1):391-419, 2014. 


\section{Methods}

Study Context. Our study was conducted in Zhengzhou, the capital city of Henan province in central China, which is 500 kilometers from the city of Wuhan where the first outbreak of the COVID-19 was documented. The city had a total of 158 infected confirmed COVID cases, with the last case reported on March 11th. The city-government imposed strict lockdown measures on citizens from January 26th to March 19th, 2020. During the city lockdown, non-essential businesses were closed, and citizens were not allowed to leave their homes, except for essential purchases or health reasons. In addition, participants' residential communities imposed a series of measures on residences to avoid the spread of the virus (e.g. limiting access to the property).

Starting from March 19th, restaurants and parks in the city could start to reopen (Fig. 1a displays the timeline of the study, together with the number of daily COVID-19 cases evolution). However, customers were obliged to take extensive precautionary measures imposed by the city government or their residential community when leaving their homes. Customers going to restaurants must wear masks and show their health certificates, a color scheme embedded in citizen's smartphones to signal infection levels based on their presence in areas of high infection risk (e.g. Wuhan). Individuals that had fever, cough and other COVID related symptoms were not allowed to enter the dining area. Starting from May 6th 2020, the measures to control the coronavirus spread in the city were further relaxed (end date of our experiment), the city started the loosening of the remaining restrictions and requirements for citizens in public spaces (e.g. lifting requirements to wear masks in public spaces). We implemented our experimental intervention for the first time on March 30th, ten days after the local government began to loosen the lockdown measures and dining out services were allowed to re-open in the city. At that time, around 50 percent of restaurants were opened, based on data from a sample of 5,000 restaurants collected from the restaurant portal Dianping.com (Chinese version of Yelp.com). Over the five weeks of the experiment, the percentage of restaurants re-opening increased to nearly 70 percent. Our last round of intervention took place on May 1st, the last weekend before the loosening of COVID precautionary policies in the city.

Recruitment. Our main recruitment started on March 16 and finished on March 22 (See Fig. 17 for study timeline). In addition, we refreshed the sample every week during the experiment to keep the sample size stable (see Supplementary Table F.1 for an overview of the number of participants over the experimental weeks). In total, we recruited valid 622 residents working around the central business district of the city via text messages and phone calls to participate in the study. Each participant received a recruitment text message with instructions to install the smartphone app designed for the study, and a description of the compensation to be part of the experiment (see Supplementary Table G.2 for a description of all monetary compensations). 
When they agreed to participate and signed the informed consent, a group of local assistants explained the study purpose in more detail, answered general questions about the experiment, supported individuals with technical difficulties to install the smartphone app and asked the participants to complete a short screening questionnaire. The smartphone app developed for the study is able to collect the precise GPS coordinates of participants during the study period, send tailored questionnaires, and pay red-pocket money. We used the GPS data collected from the app to validate the self-reported weekend plans of individuals (results from validation exercise reported in Supplementary Materials Section J).

Participants completed two pre-treatment surveys measuring detailed individual information, including their socio-demographic characteristics, perception and knowledge towards the COVID-19 pandemic, pre-COVID habits to go to parks and restaurants, perceived social norms and community trust (32). In addition, we include the survey instruments from the Global Preference Survey (33), a globally representative dataset with experimentally validated measures of risk attitude, altruism and time preferences (questionnaires attached to Questionnaire File). These measures serve as important controls and factors to be used for heterogeneity analysis, as pre-specified in our pre-registered analysis plan (RCT ID: AEARCTR-0005644). At the end of the experiment, participants received again the same questions about attitudes, norms, and economic preferences to test for any changes during the experiment.

Experimental Design. In this study, we manipulate the beliefs of our participants regarding the proportion of neighbors that are visiting restaurants over the weekend. We follow the design introduced by (34), to provide a random subset of individuals in our sample with truthful information intended to shift beliefs regarding others' restaurant visitation. The treatment consists of providing truthful personalized information regarding the proportion of neighbors planning to restaurants, plausibly affecting beliefs regarding the number of neighbors actually going to restaurants over the weekend.

Following the timeline of Fig. 1 $\mathrm{b}$, we implemented the descriptive norm treatment as follows:

- From Tuesday to Thursday:

(i). We elicited the individuals' plans to visit restaurants in the upcoming weekend to build our information treatment. We asked them to report whether they intended to go to a restaurant in the upcoming weekend.

(ii). Prior belief on planned behavior: We elicited subjects' prior beliefs regarding the percentage of their neighbors who were at that point planning to go to restaurants over the weekend. 
(iii). Prior belief on actual behavior: We also elicited subjects' beliefs regarding the percentage of neighbors that will actually go to restaurants.

All participants of our experiment were incentivized to make the right guess by receiving monetary compensations for each accurate guess (within two percentage points' differences to the real proportion of neighbors; Table G.2 describes all monetary compensations in the study). The monetary compensation of 2 Chinese Yuan for right guesses were given at the end of the experiment to avoid biasing participants during the experiment. Prior beliefs about planned and actual behavior of neighbors are highly correlated (Supplementary Figure A.3).

To enhance the representativeness of the treatment information, we complemented the information from our experimental sample with a survey of a random sample of 500 citizens living in the same neighborhoods as our participants, who also reported their plans for the weekend (i.e., we have about 1,000 individuals per week answering their plans in total). The percentage of neighbors planning to go to restaurants over the weekend for each neighborhood (i.e. urban district) are used to construct our information treatment.

The sample's average prior belief regarding the percentage of neighbors going out was quite close to the truth but with substantial variations across individuals. The standard deviation for restaurant beliefs was 23 percentage points, full distribution of priors and posteriors displayed in Supplementary Fig. A.2.

- On Friday morning, just before the weekend starts:

(i). Reminder of priors: Everyone in our sample was reminded of their prior beliefs regarding the number of people that will actually go to restaurants over the weekend, as reported in the survey on mid-week survey.

(ii). Main treatment intervention: People in the treatment group were informed about the actual proportion of neighbors who planned to go to restaurants in the following weekend.

(iii). Posterior belief: We re-elicited beliefs regarding the proportion of neighbors who will actually go to restaurants over the weekend. Again, all participants of our experiment were incentivized with to make the right guess (Table G.2 describes all monetary compensations in the study).

Responses from our mid-week survey indicated that an average of 38\% (51\%) of all subjects planned to go to restaurants (parks) over the weekend across the five urban districts (see Tables D.2 and D.3 for the exact percentages computed for each urban district and week separately for restaurants and parks). 
- Over the weekend:

(i). The GPS coordinates of participants were monitored from Friday afternoon to Sunday evening for those subjects that granted the app designed for the study access to their GPS data.

(ii). On Sunday night, all participants reported whether they have been to any restaurants or parks during the weekend and if so, the time and name of the place they went to. We cross-validate the self-reported weekend behaviors with the GPS data retrieved from the smartphone of participants via our study APP (see Supplementary Section J for a detailed description of the validation exercise).

For parks, our placebo treatment, we repeated the entire procedure described above, with identical questions, and incentives.

Randomization Strategy We used a block randomization strategy, where individuals are randomly assigned to each experimental arm, stratified by geographical area of their home address (i.e., five urban districts in the city) and pre-COVID frequency of restaurant visits for leisure (i.e., a dummy variable indicating going to restaurants at least once a week or less). We randomized individuals across experiment arms within each of the 10 strata. Individuals remain in the same experimental arm in the entire study, with no shifts over weeks. The balance tests between control and treatment subsamples show the randomization was well executed (Supplementary Table E.1 for balance tests). From week 1 to 4 in the experiment, participants are randomly assigned to 4 experimental arms with equal probability:

(i). Experimental arm 1: Control arm.

(ii). Experimental arm 2: Descriptive norm only.

(iii). Experimental arm 3: Restaurant certificate only.

(iv). Experimental arm 4: Descriptive norm and restaurant certificate.

Main Econometric Analysis. We implement a series of regression analyses to examine changes in beliefs and behavior associated with our treatment interventions. We run the following regression separately for restaurant and park activities:

$$
Y_{i}=\alpha T_{i}+\beta T_{i} \times \text { AboveTruth }_{i}+\delta \text { AboveTruth }_{i}+X_{i} \Gamma+\epsilon_{i t}
$$

where $Y_{i t}$ includes the two main outcomes of interest $\left\{\right.$ PosteriorBelie $_{i}$, Behavior $\left._{i}\right\}$. The variable Posterior Belief $f_{i}$ is individual $i$ 's belief about the proportion of neighbors who will actually go to the restaurants elicited on Friday post-treatment survey. Behavior $i$ is a dummy 
variable indicating if individual $i$ visits a restaurant on the weekend. $T_{i}$ is a dummy variable taking a value of one for people who receive the descriptive norm treatment information and zero otherwise; AboveTruth $i$ is a dummy variable indicating whether individual $i$ 's pre-treatment belief on Wednesday regarding proportion of neighbors planning to go to restaurants is higher than the actual percentage; $X_{i}$ describes the set of control variables. To calculate the main treatment effects on behavior $\left(\right.$ Behavior $\left._{i}\right)$, the list control variables include the strata variables (neighborhood fixed effects and a dummy variable indicating whether the individual went to restaurants at least once a week before the COVID pandemic), whether the individual reported to have plans to go to a restaurant in our Wednesday survey, individual's education level, and calendar week fixed effects. The coefficients of interest, $\alpha(\alpha+\beta)$, capture the impact of the treatment on an individual's PosteriorBelief $f_{i t}$ and Behavior ${ }_{i t}$ for individuals with beliefs below (above) the truth. Our main estimation of treatment effects focus on the week when people enter our experiment for the first time to avoid the confounding impacts of the previous weeks' information treatment. For the two additional preregistered information treatments (i.e., restaurant certificate and expanded prosocial norm), similar regression models have been run. Results reported in Supplementary sections B and C.

Moderator analysis. To understand how the treatment effects were moderated by individual risk preferences, we decomposed individuals into two sub-samples: risk averse and risk tolerant, with median level as splitting point. We then estimate the treatment effect of descriptive norm by each subgroup respectively using Equation 1 .

As robustness check, we also conducted interaction analysis with both discrete (dummy variable indicating individual is above median risk tolerance) or continuous definition of risk preferences using the following modified version of Equation 2

$$
Y_{i}=\alpha T_{i}+\beta T_{i} \times R_{i}+\gamma R_{i}+X_{i} \Gamma+\epsilon_{i}
$$

Here $R_{i k}$ denotes the value of the risk preference moderator for individual $i$. Our parameter of interest $\beta$, denotes whether people who are more risk tolerance responded significant differently to our treatment. A more detail description of our moderation analysis, together with extra robustness checks included in A.4. Results of moderator analysis for the full set of variables can be found in Supplementary Figure A.8 and A.9.

Ethics Statement. This project has human subjects' approval from the Committee on the Use of Humans as Experimental Subjects at Massachusetts Institute of Technology (protocol 2002000100). 


\title{
A behavioral intervention for encouraging the resumption of economic activity after COVID-19 lockdowns end: Evidence from a large scale-field experiment in China Supplementary Information
}

\author{
Juan Palacios, ${ }^{1}$ Yichun Fan, ${ }^{1}$ Erez Yoeli ${ }^{2}$, Jianghao Wang ${ }^{1,3}$, \\ Yuchen Chai ${ }^{1}$, Weizeng Sun, ${ }^{4}$ David Rand, ${ }^{2}$ and Siqi Zheng $* 1$ \\ ${ }^{1}$ Department of Urban Studies and Planning, Massachusetts Institute of Technology, MA, USA \\ ${ }^{2}$ Sloan School of Management, Massachusetts Institute of Technology, MA, USA \\ ${ }^{3}$ Institute of Geographic Sciences Natural Resources Research, Chinese Academy of Science, \\ China \\ ${ }^{4}$ School of Economics, Central University of Finance and Economics, China
}




\section{Contents}

\begin{tabular}{|l|l|}
\hline A Robustness checks and supplementary analyses & 1
\end{tabular}

A.1 Non-parametric comparisons of treatment and control group . . . . . . . . . . . . 1

A.1.1 Changes in beliefs . . . . . . . . . . . . . . . . . 1

A.1.2 Distribution of Prior and Posterior Beliefs . . . . . . . . . . . . . . . . 1

A.1.3 Correlation between beliefs regarding planned and actual behavior . . . . 1

A.1.4 Changes in behavior . . . . . . . . . . . . . . . . . . 4

A.2 Regression Tables with different model specifications . . . . . . . . . . . . 5

A.3 $\quad$ Treatment effects as a function of bias in prior beliefs $\ldots \ldots \ldots \ldots$

A.4 Moderator Analysis . . . . . . . . . . . . . . . . . . . . . . . . . 10

A.5 Multiple Hypothesis Testing Heterogeneous Treatment Effects . . . . . . . . . . . 13

\begin{tabular}{ll}
\hline B Extra Manipulation I: Restaurant Certification & 16
\end{tabular}

B.0.1 Construction information treatment . . . . . . . . . . . . . . . . . 16

B.0.2 Effects of restaurant certifications on individual behavior . . . . . . . . 20

C Extra manipulation II: Social Preferences, Perceived Norms and Precaution$\begin{array}{ll}\text { ary Behaviors } & 22\end{array}$

C.1 Manipulation perceived prosociality of neighbors . . . . . . . . . . . . . 22

\begin{tabular}{|l|l|l|l|l|l}
\hline D Supplementary Notes & 32
\end{tabular}

D.1 Display Treatment Information $\ldots \ldots \ldots$. . . . . . . . . . . . . . 33

D.2 Percentages used to construct descriptive norm . . . . . . . . . . . . . . 37

D.3 Description Moderating Scales f . . . . . . . . . . . . . . . . . . 38

\begin{tabular}{|ll}
\hline E Summary Statistics And Balance tests & 40
\end{tabular}

\begin{tabular}{|ll|}
\hline F & Recruitment and sample attrition
\end{tabular}

\begin{tabular}{|l|l}
\hline G Compensation Participants & 44
\end{tabular}

\begin{tabular}{ll}
\hline H Comparison Parks and Restaurants & 45
\end{tabular}

H.1 Comparison restaurant and park visits relative to Pre-COVID . . . . . . . . . . 45

H.2 Initial Risk Perception to Visit Public Spaces . . . . . . . . . . . . . . . . . 45

\begin{tabular}{lll}
\hline I Prior beliefs over weeks & 47
\end{tabular}

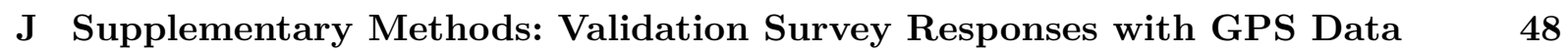

J.1 Restaurant Validation . . . . . . . . . . . . . . . . . . . . . . . . . . . . . . 48 


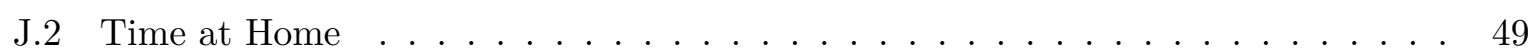




\section{A Robustness checks and supplementary analyses}

In the main text, we describe the treatment effects based on a ordinary least square regression. In this section, we present the non-parametric comparisons between control and treatment group, specification checks (testing the treatment effects in non-linear models (i.e. Logit and Probit). In addition, we show the high correspondence in participants' prior beliefs regarding planned and actual behavior of neighbors on our Wednesday survey. Finally, we also include the regression analysis which examines the differences in treatment effect over the distribution of participants' bias in prior beliefs.

The results of the tests provides supportive evidence showing that the intervention worked by encouraging individuals with prior beliefs below the truth to visit restaurants, and was specially strong for those in the lowest part of the distribution of beliefs.

\section{A.1 Non-parametric comparisons of treatment and control group}

\section{A.1.1 Changes in beliefs}

\section{A.1.2 Distribution of Prior and Posterior Beliefs}

Figure A.2 shows the distribution of the difference between the posterior beliefs regarding the proportion of neighbors going to restaurants (parks) over the weekend and the true percentage included in the information treatment. The sample is restricted to the first week the participant was part of the experiment. The treatment group is substantially more compressed around the truth (zero bias) than the control group in their responses to our Friday questionnaire, after receiving the percentage of neighbors planning on going to restaurants and parks. This indicates that subjects in the treatment group believed that the information provided was truthful.

\section{A.1.3 Correlation between beliefs regarding planned and actual behavior}

The goal of our experimental design is to isolate the causal effect of variation in beliefs regarding neighborsâ restaurant visits on oneâs own restaurant visitation. A challenge we face is that such information must be provided prior to the weekend, before we know the actual visit decisions others.

We solve this problem following the experimental design by (34). We collect information on individualsâ beliefs about othersâ planned visits to restaurants, as well as beliefs about othersâ future actual turnout at restaurants.

With this design, we are able to elicit planned restaurant visitation (as opposed to actual visitation) prior to the weekend. This allows us to provide truthful information regarding othersâ planned visitation to restaurant, plausibly affecting beliefs regarding othersâ actual protest 
Figure A.1: Changes in beliefs associated with descriptive norm

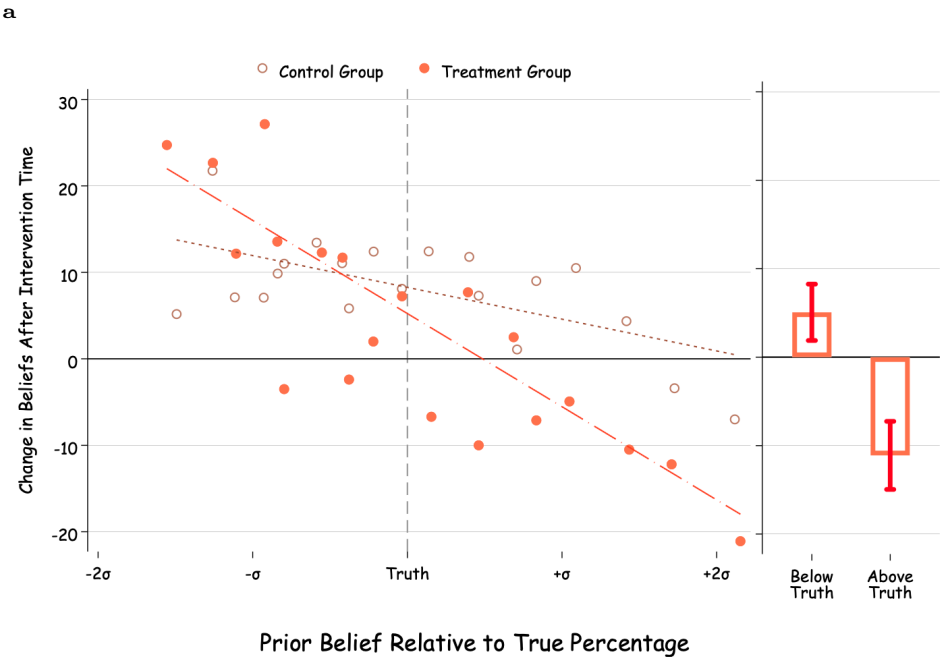

b

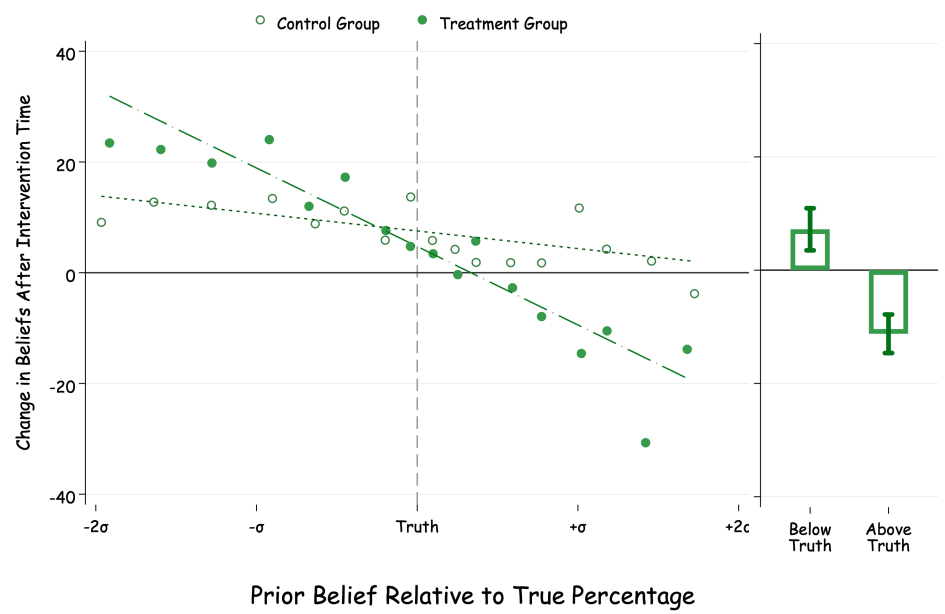

Note: i) The vertical axes in Panel display the change in subjects' beliefs from Wednesday (prior) to Friday (posterior) regarding the percentage of neighbors who are actually going to go to restaurants (panel a) and parks (panel b) over the weekend. The horizontal axes display the bias in beliefs on prior to our intervention, computed by subtracting subjects' prior beliefs regarding the number of neighbors that are planning to go to restaurants from the true percentage of neighbors planning to go to restaurants. The true percentages, used to build the descriptive norm information, are computed from the proportion of individuals that reported in our Wednesday questionnaire to have plans to go to restaurants over the weekend. The sample includes only responses of individuals that were treated for the first time, and control subjects that were in the sample for one week. Dots represent the change in subjectsâ beliefs about the \% of others who are going out to restaurants, after our intervention, as a function of their bias prior to the intervention (prior belief - true percentage). The steeper the fitted line, the more subjects with beliefs different from the truth adjusted those beliefs; a -45 degree line would mean that our intervention had perfectly corrected beliefs. ii) The bar graph included in the right hand side of Panel A and Panel B indicate the average changes effects in beliefs for individuals with prior beliefs below and above the truth, separately; the error bars are the $95 \%$ confidence intervals.

participation. Figure A.3 shows the high correspondence between beliefs regarding neighbors' planned and actual behavior. 
Figure A.2: Distribution of Prior Beliefs and Posterior Beliefs Regarding the Actual Percentage of Neighbors going to Parks or Restaurants

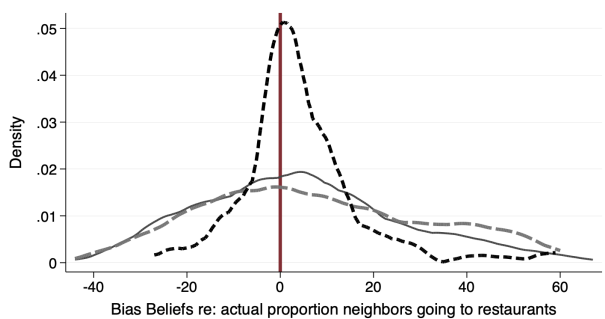

- Bias prior

-- Bias posterior (control group)

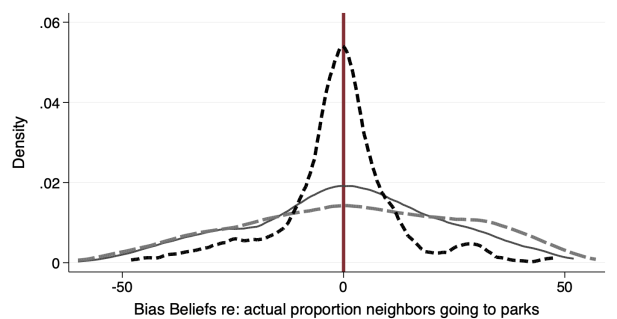

- Bias prior

-- Bias posterior (control group)

Biss posterior (treatment group)

Sample restricted to the first week individuals took part in the experiment.

Figure A.3: Distribution of Prior Beliefs Regarding Planned And Actual Behavior of Neighbors
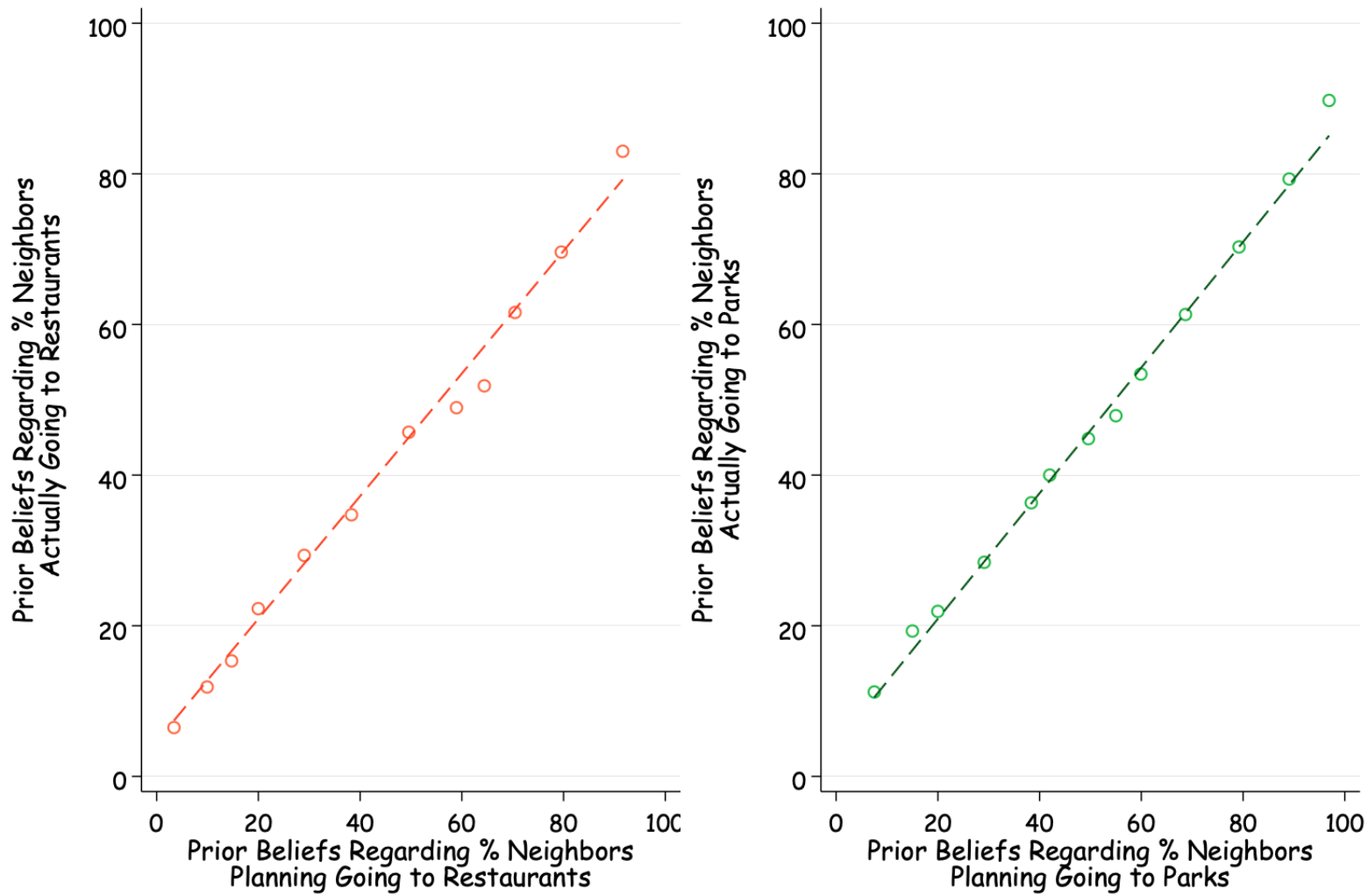

The bin scatter plots displays the relationship between prior beliefs regarding planned ( $\mathrm{x}$-axis) and actual ( $\mathrm{y}$-axis) behavior of neighbors, for the restaurant (left) and park (right) setting.

As in our main results, the sample is restricted to the first week individuals took part in the experiment. Pearson correlation coefficients in beliefs regarding planned and actual behavior is 0.83 for restaurants and 0.86 for parks. 


\section{A.1.4 Changes in behavior}

Figure A.4: Changes in behavior associated with descriptive norm

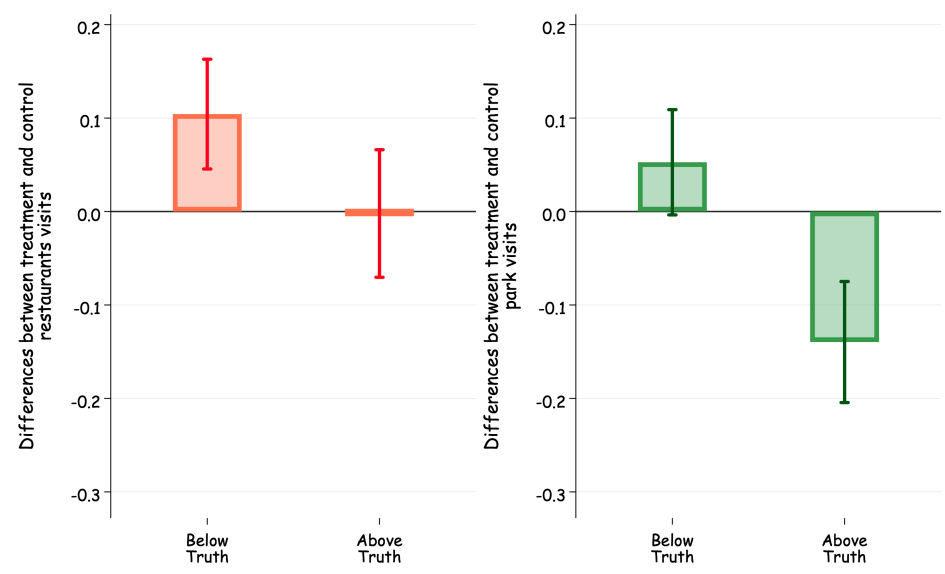

Note: The figure shows the average differences in propensity to visit a restaurant between treatment and control group disaggregated by the distribution of prior beliefs regarding the number of neighbors planning to go to restaurants (relative to the true percentage used to construct the treatment information). Error bars describe mean \pm standard error. Sample restricted to the first week individuals took part in the experiment.

Figure A.5: Changes in behavior across treatment group

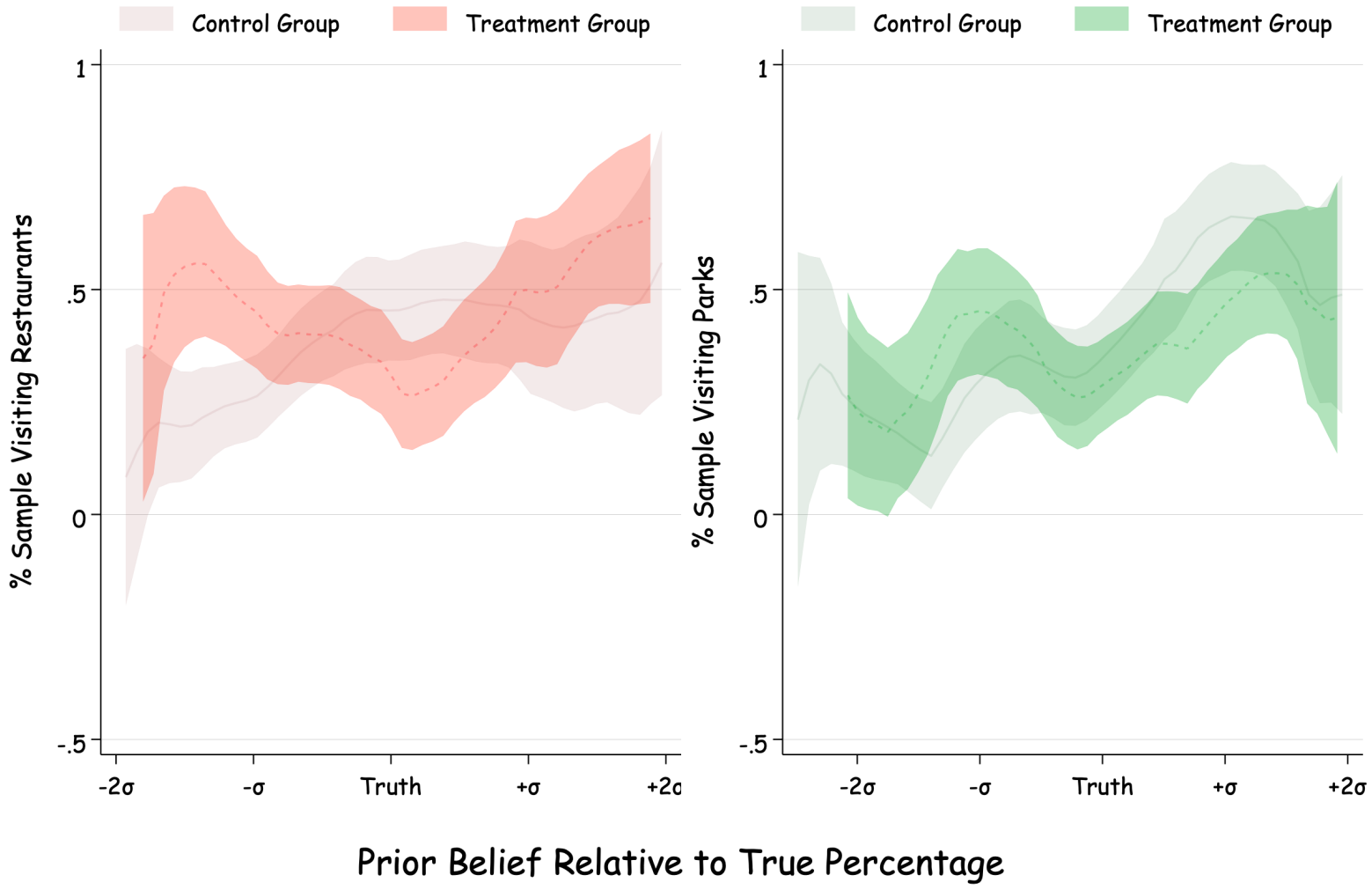

Note: The figure shows the comparissons of treatment and control group in visits to restaurants (left) and parks (right) using local polynomial smooth plots (non-parametric). Shadowed area describe the 95 confidence interval. Sample restricted to the first week individuals took part in the experiment. Control group describes individuals receiving no information, treatment group describes individuals receiving descriptive norms. 
A.2 Regression Tables with different model specifications 


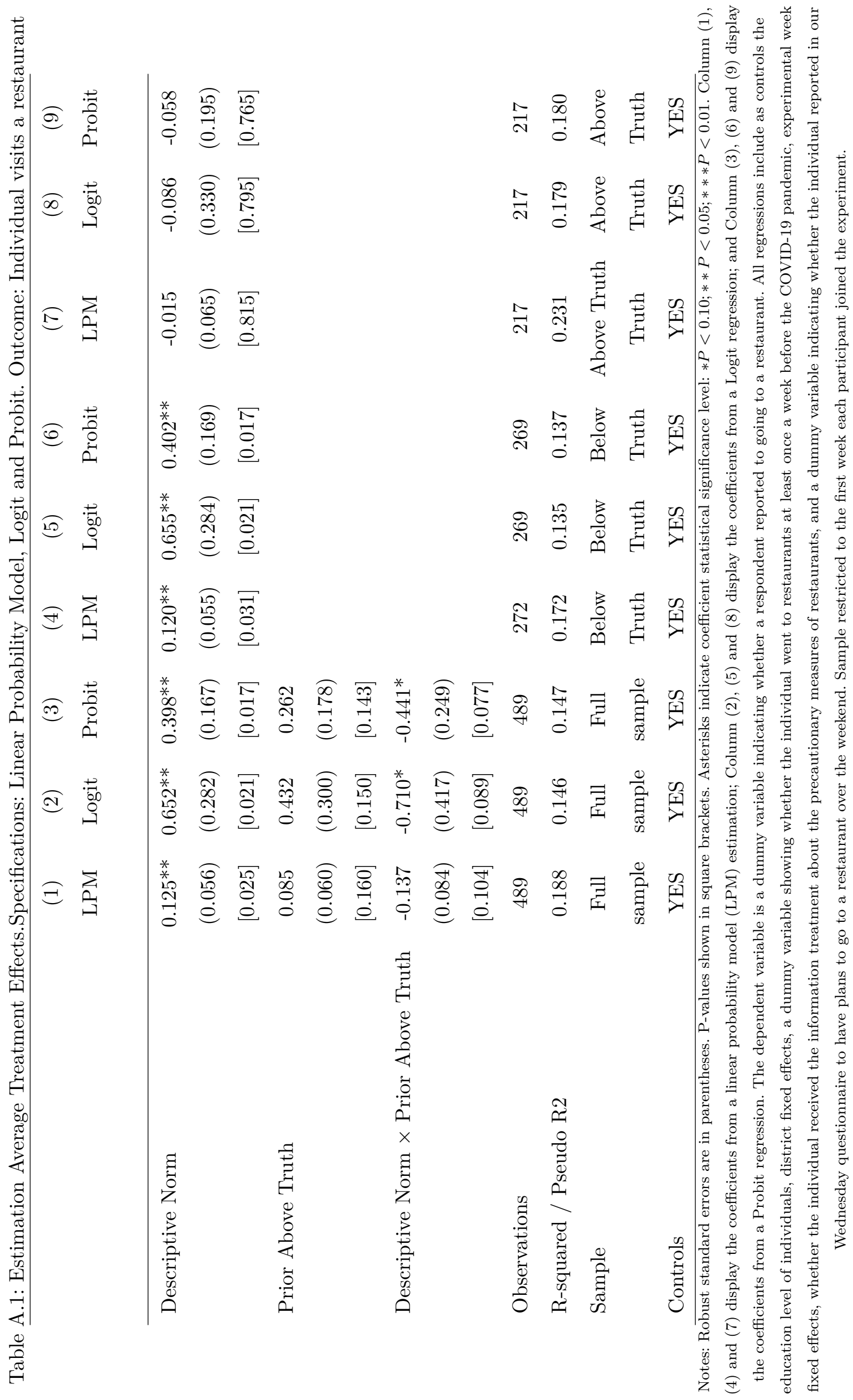




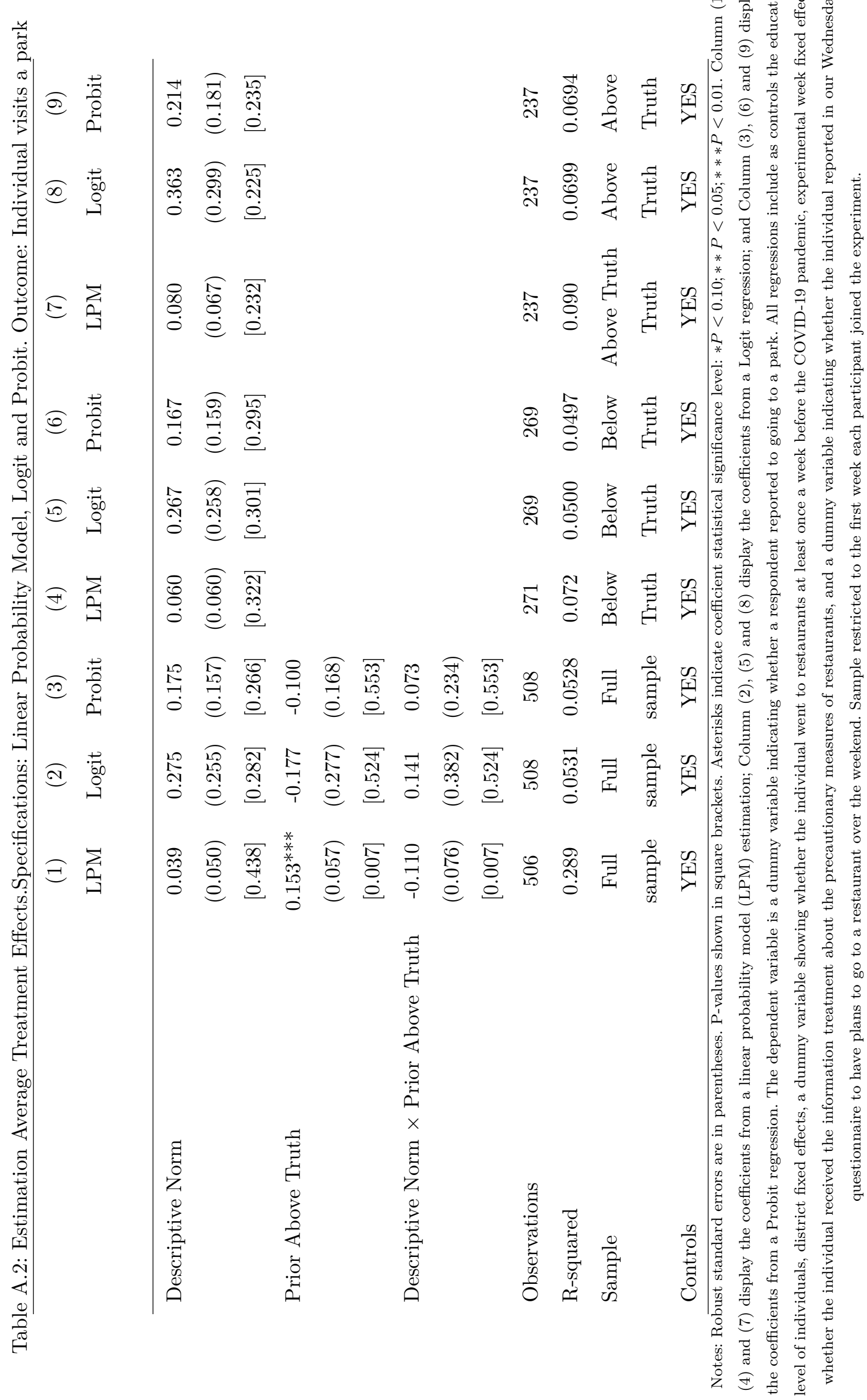




\section{A.3 Treatment effects as a function of bias in prior beliefs}

Figure 2 displays the differences in posterior beliefs and behavior between treatment and control group. The figure is based on the following regression model:

$$
Y_{i t}=\alpha T_{i}+\beta_{1} T_{i} \times \text { bias }_{i}+\beta_{2} T_{i} \times \text { bias }_{i} \times \text { bias }_{i}^{2}+\delta_{1} \text { bias }_{i}+\delta_{2} b i a s_{i}^{2}+X_{i} \Gamma+\epsilon_{i t}
$$

where $Y_{i t}$ includes the two main outcomes of interest $\left\{\right.$ PosteriorBelief $f_{i t}$, Behavior $\left._{i t}\right\}$. The variable PosteriorBelief $f_{i t}$ is individual $i$ 's belief about the proportion of neighbors who will actually go to the restaurants (or parks) elicited on Friday post-treatment survey in week $t$. Behavior $_{i t}$ is a dummy variable indicating if individual $i$ visits a restaurant (or park) on the weekend of week $t . T_{i}$ is a dummy variable taking a value of one for people who receive the descriptive norm treatment information and zero otherwise; bias $i_{i t}$ is a continuous variable indicating the difference between $i$ 's pre-treatment belief on Wednesday regarding proportion of neighbors planning to go to restaurants (or parks) and the actual percentage; $X_{i}$ describes the set of control variables. To calculate the main treatment effects on behavior (Behavior $\left.{ }_{i t}\right)$, the list control variables include the planned behavior variable (measured on Wednesdays, taking the value of 1 if individual plans to visit a restaurant), strata variables (neighborhood fixed effects and a dummy variable indicating whether the individual went to restaurants at least once a week before the COVID pandemic), and education level (below college dummy indicator). 
Figure A.6: Coefficient interaction terms associated with bias in prior beliefs

Panel a. Posterior Beliefs

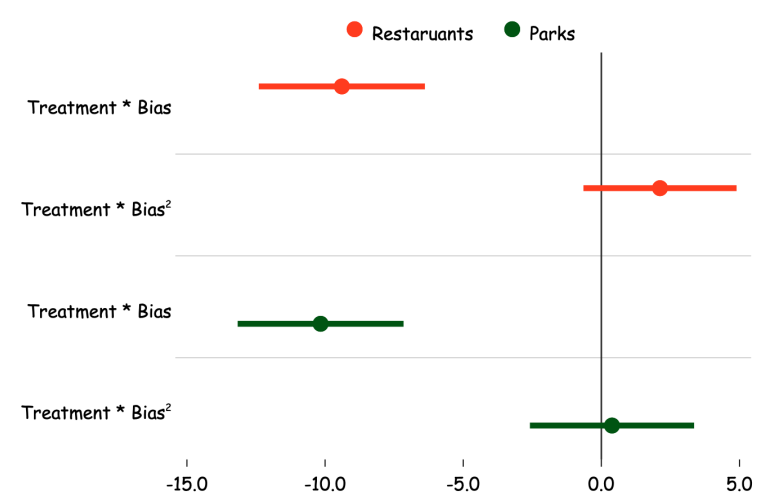

Panel b. Behavior

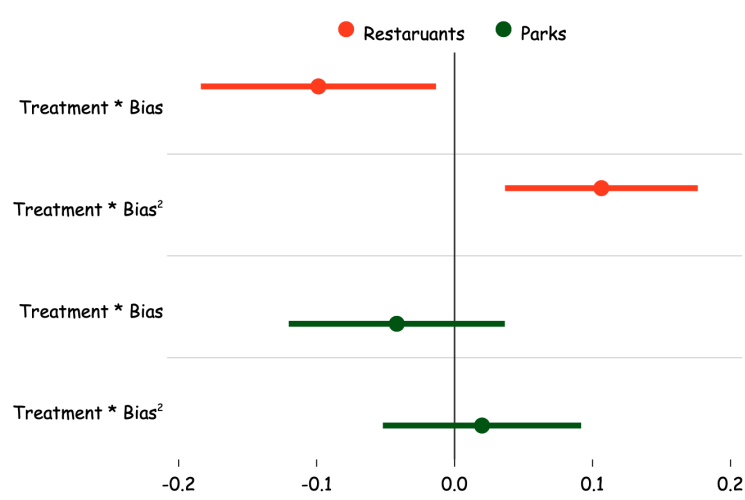

Note: Dots describe the point estimates and bars describe the 95 confidence interval. Figure A.6 shows the coefficients associated with the interaction terms between the treatment indicator, the bias in individual's prior beliefs (standardized), and the quadratic term of individuals' previous beliefs.

i) Panel a describes the coefficients in the regression predicting individual posterior beliefs, and Panel b describes the regression of predicting individual behavior. We estimate separately the regressions for parks and restaurants. The coefficients in Panel a show the similarities between parks and restaurants. The interaction between individual's bias in prior belief is negative and significantly different from zero. The interaction between the treatment indicator and the quadratic transformation of the bias is not statistically different from zero in restaurants and parks.

ii) Panel $b$ shows the coefficients of predicting behavior. There are clear differences between parks and restaurants. In the restaurant regression, both coefficients are statistically different from zero. The two coefficients in parks are not statistically different from zero. 


\section{A.4 Moderator Analysis}

In our main text, we show the differential effect of the descriptive norm intervention between risk averse and risk tolerant participants. This section presents a series of checks to ensure that those differences are robust. This section presents the decomposition of treatment effects based on interaction terms as well as sub sample split. The interaction terms are tested in a discrete (dummy indicating individual is above median in risk tolerance) and continuous (standardized scale).

For completeness, we included the full moderation analysis for all the pre-specified moderators, showing that risk tolerance stands out as the only significant moderator, together with education. Finally, we correct for multiple hypothesis testing. Across all specifications and checks, risk tolerance stands out as key moderator of the treatment effects of the descriptive norm intervention.

Robustness checks of risk moderator. The results of how risk preference moderates treatment effect presented in the main text are based on sub-group analysis. Here, we add multiple robustness checks by adding interaction terms on the original analysis, instead of running separate regressions by subgroups. The regression formula is described in Equation 2 , Methods Section. Since the treatment effect mainly took place within the subgroup who have initial beliefs below the truth (i.e., underestimated the number of neighbors going to restaurants), we focus on this group for the analysis of risk moderator.

First, we use a dummy variable to represent whether an individual is risk tolerant (i.e., risk tolerance score above median) and estimate the coefficient associated with the its interaction with the treatment dummy. Supplementary Figure A.7 displays the estimation results. The results show that, no matter we measure risk in general realm or health related realm, treatment effect of descriptive norm is significantly larger for people who are more risk tolerance in the general domain (interaction effect general risk: $\beta=24.7 ; 95 \%$ CI: 2.36 to $47.04 ; P=0.031$ ) and health-specific domain (interaction effect health risk: $\beta 22.2 ; 95 \%$ CI: 0.25 to $44.15 ; P=0.048$ ).

Second, we estimate Equation 2 with a continuous and standardize measure of risk tolerance. Results displayed in Supplementary Figure A.7. The estimation results suggest that one standard deviation increase in general risk tolerance increases the treatment effect by 14.3 (95\% CI: 3.5 to $25 ; P<0.01)$. Similarly, one standard deviation increase in risk tolerance in health-related realm increases the treatment effect by 10.4 (95\% CI: 0 to $21.2 ; P=0.058)$.

Full set of moderator analysis In our pre-analysis plan (RCT ID: AEARCTR-0005644), we specified several key moderators affecting people's perceptions and preferences of risk towards going out, with socio-demographics (age, gender, having kids or not, education, income), 
Figure A.7: Moderating effect of risk preferences

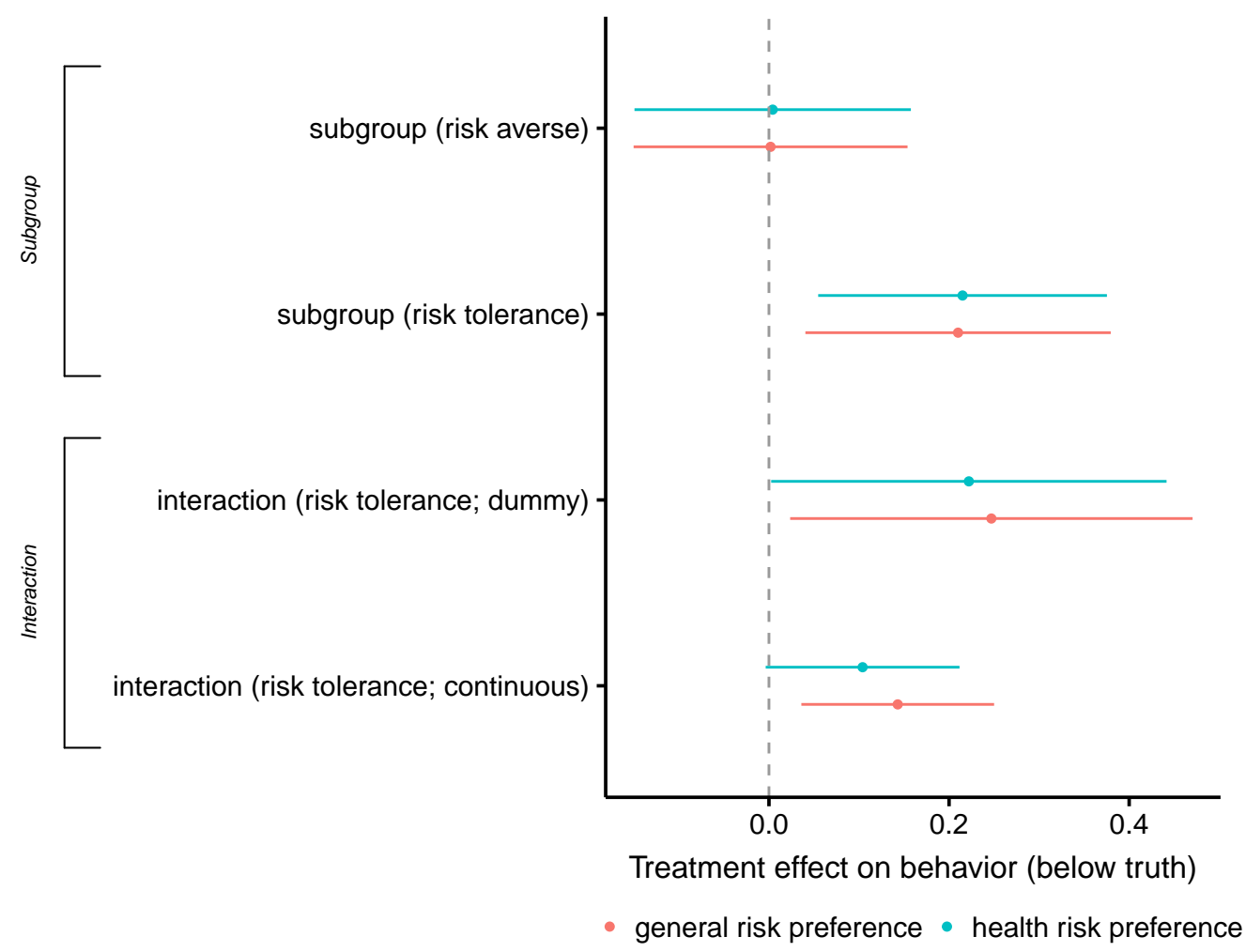

Note: The figure presents the results of differences in treatment effects over risk preferences. The sample is restricted to those subjects whose prior beliefs were below the true percentage (i.e., underestimated number of neighbors planning to go to restaurants).

i) The first two rows display the results of the subgroup analysis in which the main regression (Equation 1 was run separately for risk averse (below median) and risk tolerant (above median) subjects.

ii) The last two rows presents the results of the analysis based on interaction terms, as described in Equation 2 In the interaction term analysis, we first interact the treatment dummy with a dummy variable taking the value of one if the subject stated a level of risk tolerance above the median of the sample.

iii) Second, we include use the interact the treatment dummy with the standardized scale of risk tolerance.

Blue and red dots show the results for general and health related risk preferences respectively. Error bars reflect $95 \%$ confidence intervals. Error bars reflect $95 \%$ confidence intervals.Results are robust when adjusting for multiple hypothesis testing (Supplementary Table A.3.

economic preferences (risk preference, time preference, altruism), knowledge about coronavirus, and community trust as most important dimensions we wish to test on. In total, we consider 13 potential moderators and denote each moderator with a dummy variable indicating high or low value in that specific dimension based on their median values, except for categories with specific meanings like education (i.e., college educated), gender, having kids at home.

To estimate the heterogeneous treatment impacts moderated by all these variables, we first decompose individuals into two sub-samples according to whether they have higher or lower prior belief (i.e., the value of AboveTruth ${ }_{i t}$ in Eq.11). Second, we run 13 separate regressions for 
each moderator by estimating the following modified version of Equation 4

$$
Y_{i}=\alpha T_{i}+\beta^{k} T_{i} \times M_{i k}+\gamma^{k} M_{i k}+X_{i} \Gamma+\epsilon_{i}
$$

Here $M_{i k}$ denotes the value of the $k^{\text {th }}$ moderator for individual $i$. Our parameter of interest $\beta^{k}$, denotes whether people who have higher value in the $k^{\text {th }}$ moderator respond significant differently to our treatment. Again, we restrict the analysis to the week when people enter our experiment for the first time to avoid the confounding impacts of the previous weeks' information treatment.

Among participants with prior beliefs below the truth, only individuals with high (above median) level of risk tolerance in the general and health-specific domains increased their restaurant visits $[\beta=22.21,95 \%$ CI: 2.28 to $47.18 ; P=0.031]$ after receiving the treatment (Figure A.8p). Education also acts as an important moderator. Low educated (no college education) did not adjust their behavior when learning that more neighbours than they believed planned to dine out, while college graduates were 30.59 percentage points [95\% CI: 2.98 to $55.22 ; P=0.015$ ] more likely to adjust behaviors in respond to the treatment.

For people who overestimated the percentage of their neighbors going out, prosociality stands out as the most important moderator (Figure A.8p). More prosocial participants (above median) reduced their visits to both restaurants and parks when learning that fewer neighbors than they believe are planning to visit such places. In contrast, people with weak (below median) social preferences did not adjust their behaviors.

Results are similar when we use standardized continuous indicators of the moderators as interaction terms (Figure A.9p). However, the treatment effect as well as the moderating effect of prosociality becomes non-significant for participants with prior beliefs above the truth.

In addition, we implemented a subgroup analysis, dividing the sample into two groups (above vs below median values) for each moderator and estimating separately eq. 1. The results show similar patterns. When adjusting for multiple hypothesis testing (35), results are robust for education and risk preferences while weaker for social preferences; which is non-significant after the adjustment of standard errors (Supplementary Table A.3)

Subgroup moderator analysis The results from our moderation analysis show that participants' education and risk attitudes play an important role moderating the treatment effects of our main treatment. Here, we present the subgroup analysis of the impact of the descriptive norm treatment on both beliefs and behaviors of individuals with low and high education levels (i.e. with a college degree), and high and low risk tolerance (median delineation).

Figure A.10 show the estimated coefficients in Equation 1 describing the changes associated with our treatment dummy $\mathrm{T}_{i}$ on posterior belief (panel a) and behavior (panel b) for the 
Figure A.8: Heterogeneous treatment effects on restaurant visits (dummy moderators)

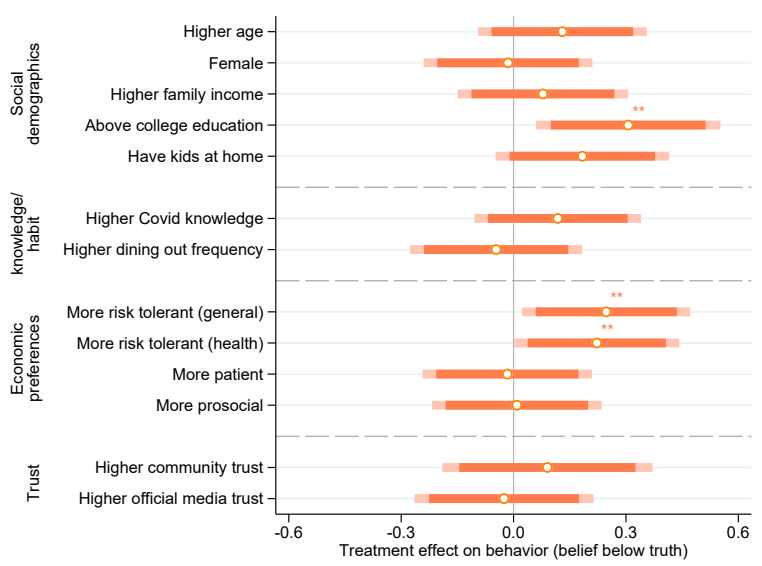

b

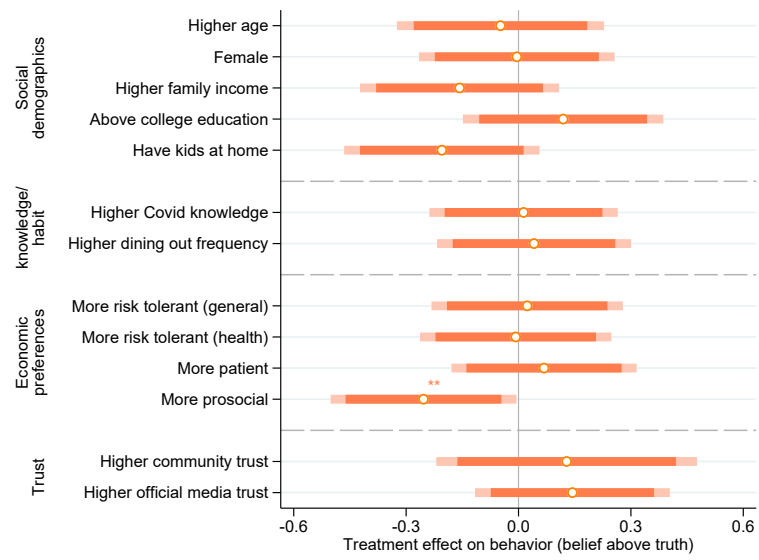

Note: The figure displays the estimated coefficients of the interaction term between the moderator dummy and treatment indicator in Eq. 4 The effects of all moderators are obtained through separate regressions. Dots describe point estimates and the darker (lighter) bars describe the $90 \%$ (95\%) confidence intervals.

Figure A.9: Heterogeneous treatment effects on restaurant visits (continuous moderators)

a

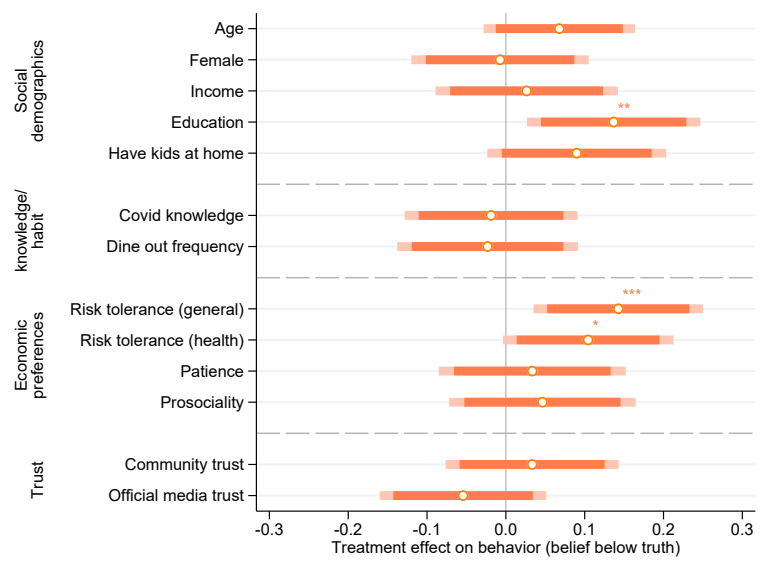

b

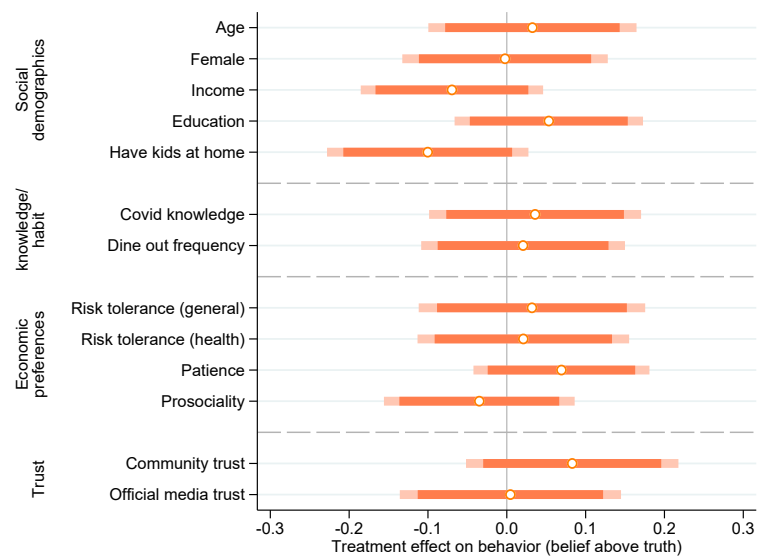

Note: The coefficients display the interaction term between the continuous indicators of moderators (standardized) and treatment indicator in Eq. 4 The effects of all moderators are obtained through separate regressions. Dots describe point estimates and the darker (lighter) bars describe the $90 \%$ (95\%) confidence intervals.

different subsamples of risk and education status. The results indicate that all subgroups updated their beliefs to a similar extent, yet the beliefs did not translate into actual behavior for all. Specifically, only higher educated and more risk tolerant people changed behavior after adjusting their beliefs that more people are dining out.

\section{A.5 Multiple Hypothesis Testing Heterogeneous Treatment Effects}

Table A.3 presents the p-values adjusted for multiple hypothesis testing. The multiple hypothesis testing is based on (35). The point estimates are slightly different from the figures presented since the correction procedure of (35) is not applicable to analysis including covariates thus the 
Figure A.10: Treatment Effects on Posterior Belief and Behavior for Different Education and Risk Tolerance groups
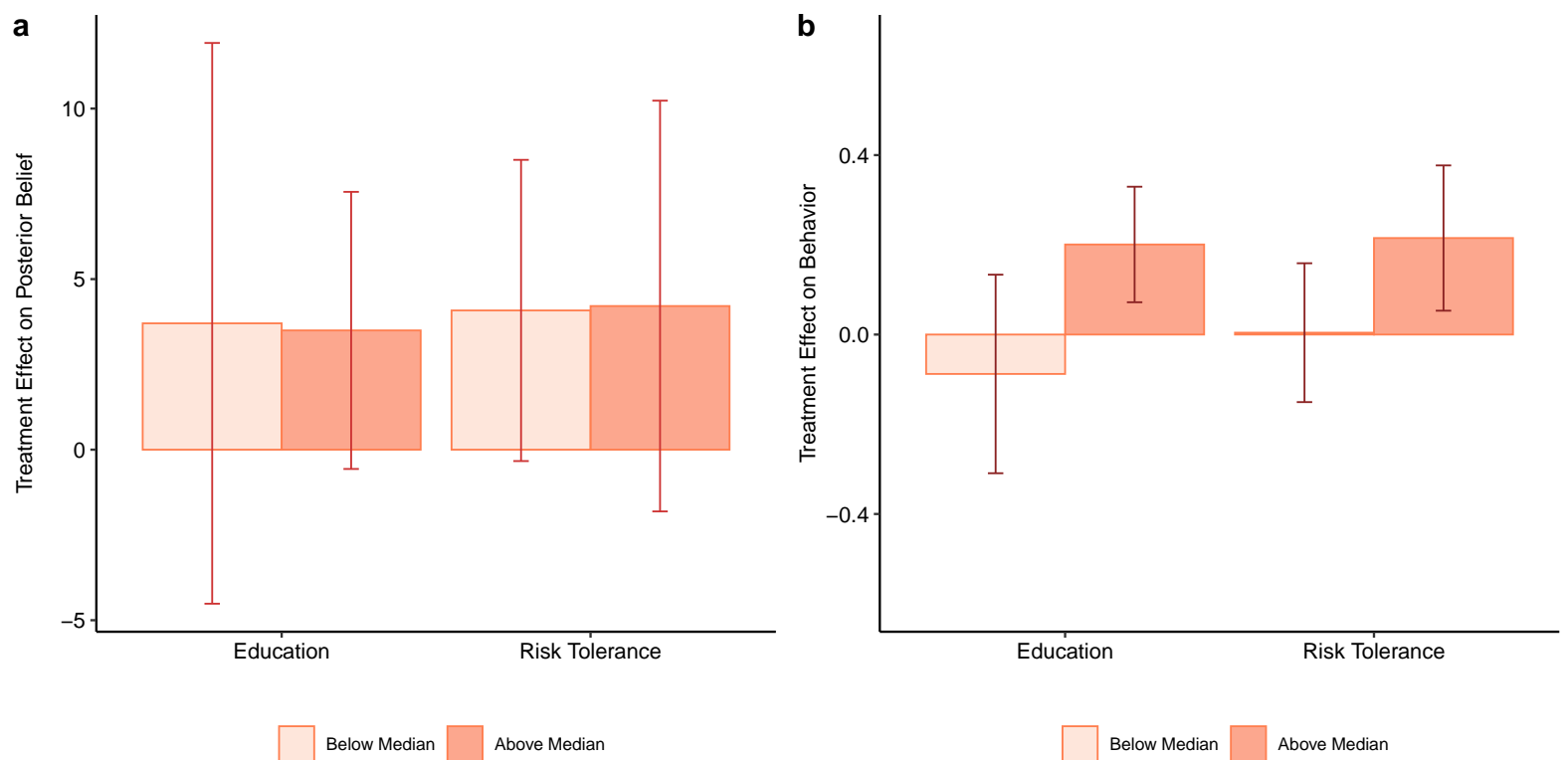

The figures investigate the differences in the average treatment effect of our intervention on belief and actual behavior for people with different education levels and risk tolerance. Sample restricted to individuals with prior belief below the truth. (a) shows the treatment effect on belief about other's behaviors, and (b) shows the treatment effect on actual dining out behavior. The error bars describe the $95 \%$ confidence intervals.

pure comparisons between treatment and control are presented in the table. 


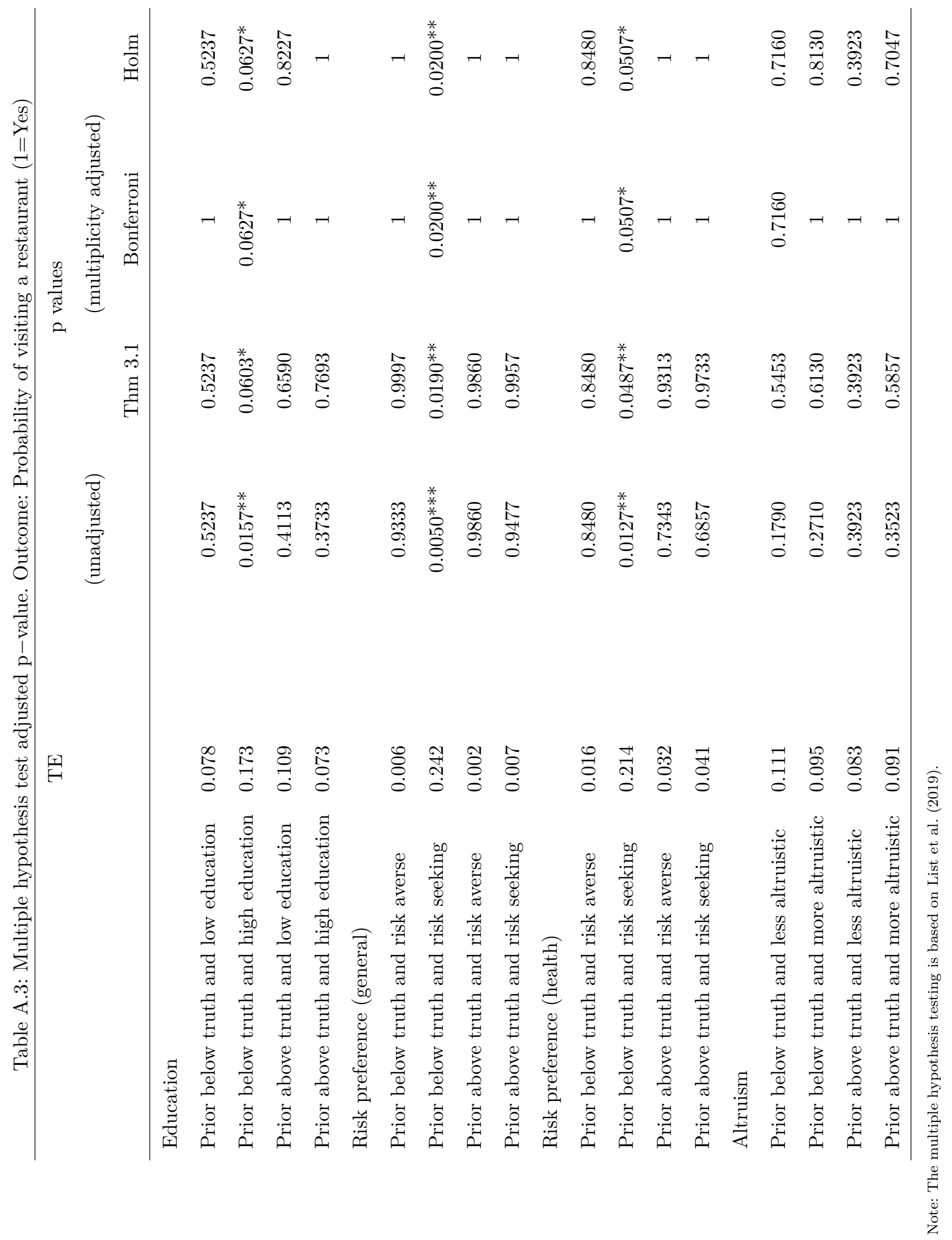




\section{B Extra Manipulation I: Restaurant Certification}

As described in the main text, we tested an additional intervention which highlights the measures of restaurants to minimize the transmission of the virus. This section describes the intervention in detail, and displays the main results, together with the interaction with our main treatment (descriptive norm). The results show that the intervention generated a positive, but non-significant effect on restaurant visits.

\section{B.0.1 Construction information treatment}

On February 20th 2020, the largest restaurant portal in China, Dianging.com (Chinese version of Yelp), created a voluntary certification program (The Meituan Safe Dining Certificate) for restaurants to signal clients that they take extensive precautionary measures to minimize the risk of infection to COVID-19 among their customers.

Restaurants need to fulfill the "Standards for Online Disclosure of Health Service Information of Catering Merchants" published by Dianping, take pictures, and upload to the Dianping to go through the reviewing process. After getting approved, the certification will appear on the main page of Dianping.com in the format of a yellow tag. Restaurants can lose their certification status if they stop sending the daily reports to Dianping, or a customer is filing a complaint about the safety of the restaurant. The measures that restaurants must take to get the certificate include the disinfection dining space, kitchen, and restaurant equipment daily; temperature testing and recording for all employees, allowing them to work only if their temperature is normal; ensuring that all employees must wear face-mask and gloves at all times; and have appropriate table location setting the appropriate distance between dining tables and chairs (See below the full list of requirements to be "Meituan Safe Dining Certificate").

We constructed a database of the 5,000 most popular restaurants in the city, including their location, opening and safe-dining certification status. In our sample, $18 \%$ of restaurants in the city are certified, remaining stable over the five weeks of the experiment. Every Friday, during the experiment, individuals in the treatment group were informed about the presence of certified restaurants in the neighborhood (i.e. urban district) of their place of residence through the app. In addition, we constructed a website where participants in the treatment group could see the name of restaurants in the city, their location, and whether the restaurant was certified as a "Meituan Safe Dining Certificate" at the time of the visit (Figure B.11).

\section{Requirements or obtain "Meituan Safe Dining Certificate":}

(i). Publish disinfection record: Disinfect dining space on a daily basis and publish disinfection records. 
Figure B.11: Restaurant website designed for the study

\section{“安心餐厅”认证情况参考表}

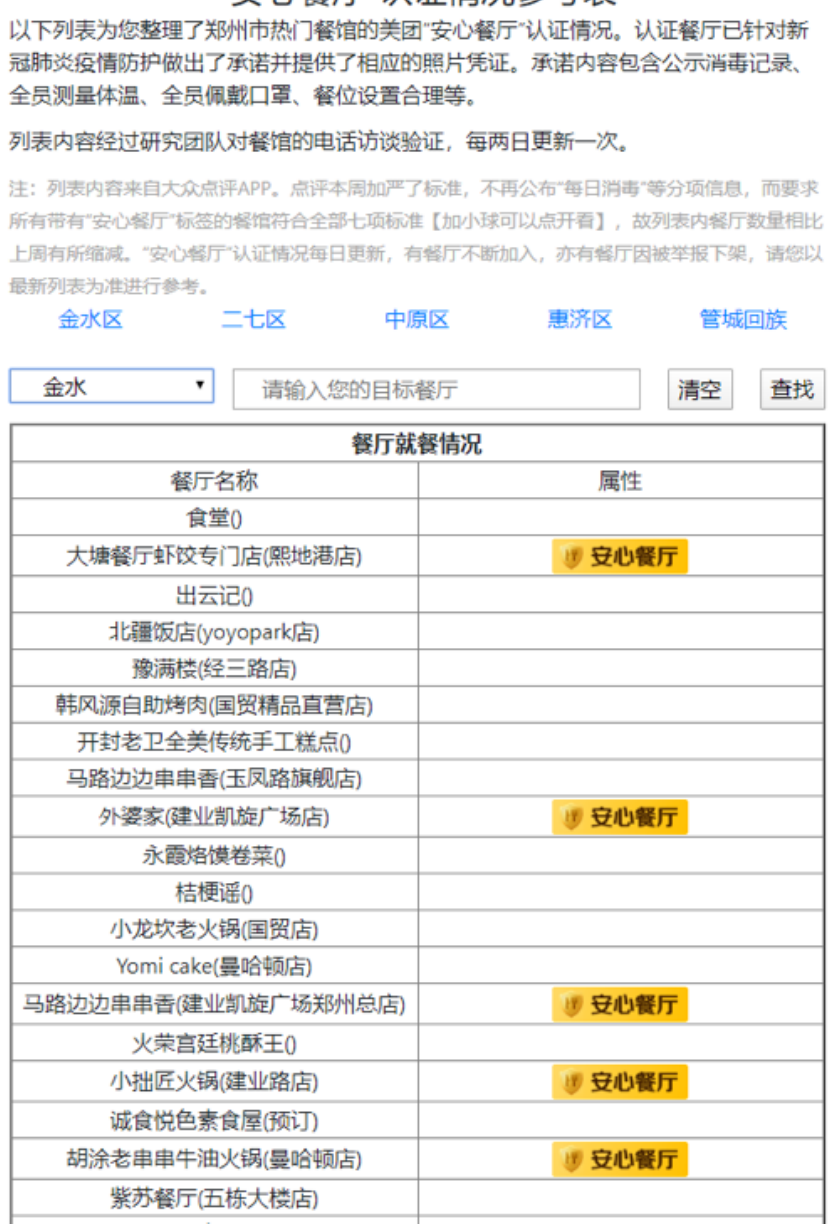

(ii). Temperature testing for all members: Temperature testing and recording for all employees and only allow working if temperature is normal.

(iii). All members must wear face-mask: All employees must wear face-mask; When serving the customers, both sides need to wear face-mask

(iv). Appropriate table location setting: Appropriate distance between dining tables and chairs. Tidy dining environment.

(v). Clean kitchen environment: Kitchen utensils such as cooking equipment, dining equipment, and cloth must be clean and properly disinfected.

(vi). Isolated food serving: Food servers must wear face-masks and gloves, and dishes need to be covered by a lid or plastic sheet.

(vii). Disinfect equipment.

Before our experiment, Dianping had already made the certificate publicly available on its 
Figure B.12: Certificate requirements
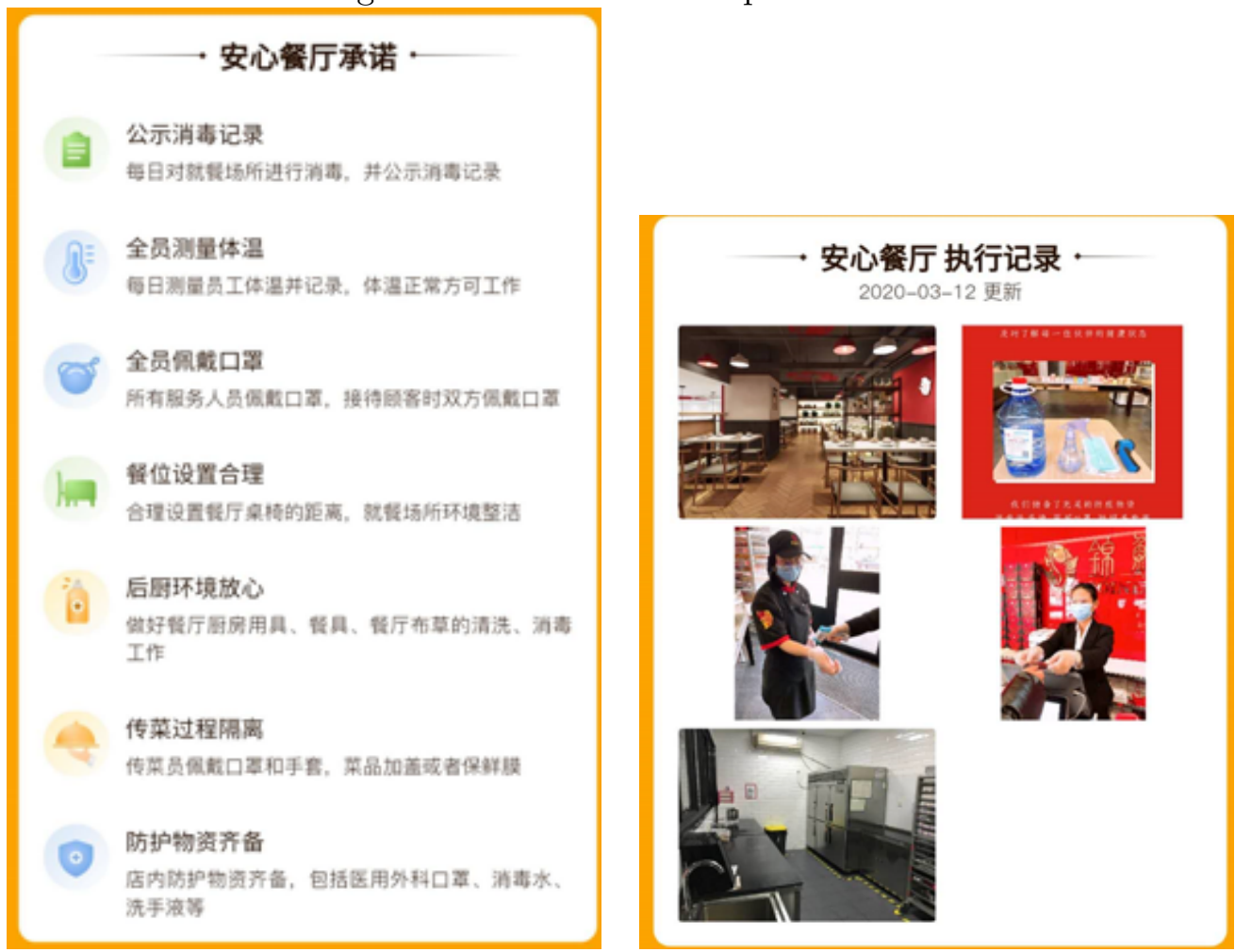

website. The information is thus publicly accessible to all our participants. However, our treatment reduces the information processing costs and increases the attention to the safety features of restaurants in the post-pandemic period. The results from the end of the survey questionnaire indicate that the intervention was indeed successful in providing new information to participants. In the final week, we include a set of questions to test how many of our participants knew about the "Meituan Safe Dining Certificate". The results indicate that only $24 \%$ percent of the control group knew about the certificate (Table B.4). In the treatment group, $75 \%$ of individuals were aware of the certificate used to construct our treatment.

Previous studies in the literature on behavioral economics using similar information saliency treatments indicate that the impact of disclosure depends on the saliency of information to individuals (31, 36). In the last two weeks of the experiment, we use images to increase the saliency of each of the precautionary measures and inform individuals about the costs for restaurants to maintain the certificate. 
Table B.4: Knowledge about safe-dining certificate used in the experiment for the construction of information treatment
$(1)$
$(2)$
(3)

\begin{tabular}{llll} 
& Treatment & Control & t-test \\
& Mean/SD & Mean/SD & $(1)-(2)$ \\
\hline Use Meituan to get safe dining information $(1=$ Yes $)$ & 0.36 & 0.30 & 0.23 \\
Know Meituan safe dining certificate (1=Yes) & {$[0.48]$} & {$[0.46]$} & \\
& 0.74 & 0.24 & $0.00^{* * *}$ \\
& {$[0.44]$} & {$[0.43]$} &
\end{tabular}

Observations

204

205

Notes: Column 1 and 2 reports mean values, with standard deviations in brackets. Column (3) the t-statistic of differences in means between the control and treatment group. Asterisks indicate coefficient statistical significance level:

$$
* P<0.10 ; * * P<0.05 ; * * * P<0.01 \text {. }
$$




\section{B.0.2 Effects of restaurant certifications on individual behavior}

The treatment did not increase the propensity to visit a restaurant [95\% CI: $[-2.62,13.64]$, $P=0.184$ ] (Table B.5). When presented together with the descriptive norm, the information about the restaurant certificate reinforced slightly the impact of the descriptive norm among the participants that joined the experiment with low priors (Table B.5. 


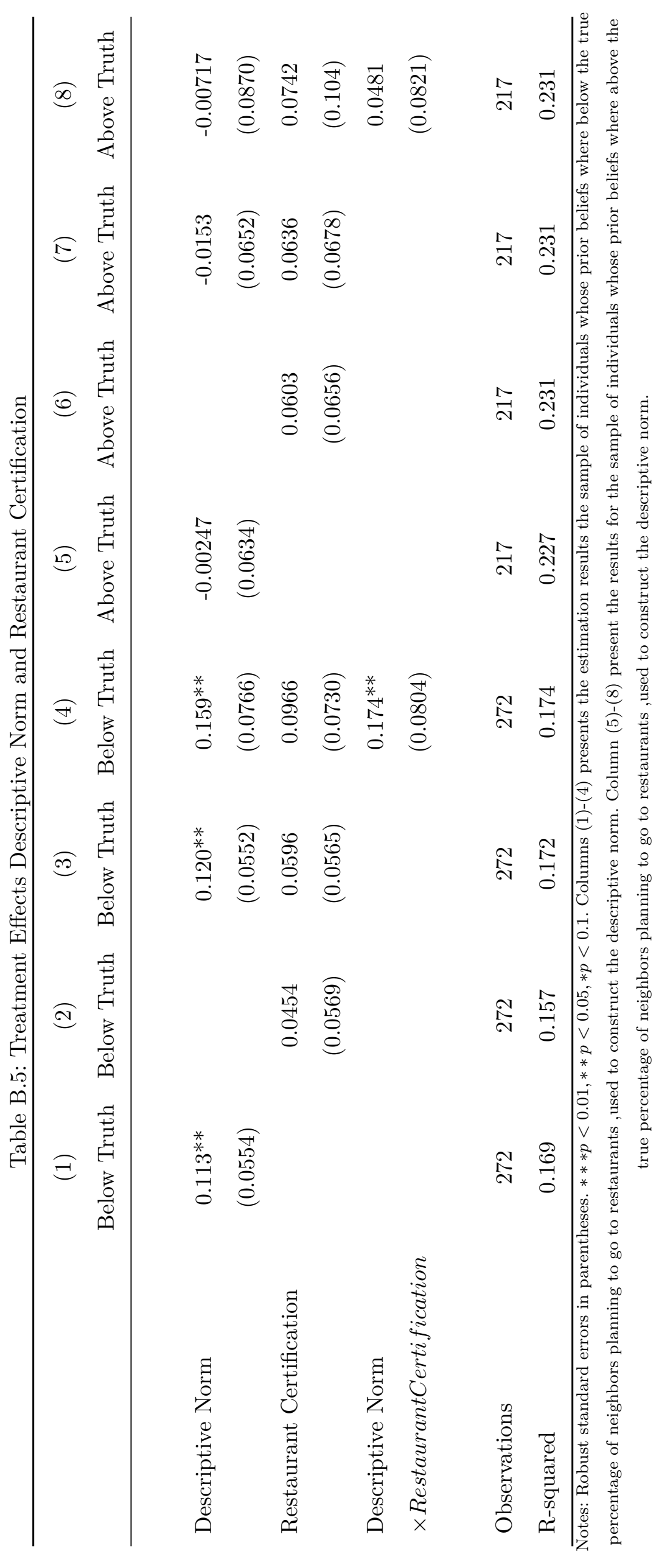




\section{Extra manipulation II: Social Preferences, Perceived Norms and Precautionary Behaviors}

We pre-registered (RCT ID: AEARCTR-0005644) an additional intervention that was not reported in the main text. For completeness, we included a description of the intervention and the main effects on behavior in this section.

In week 5 , we randomly relocated half of the individuals in experimental arm 2 and experimental arm 4 to a new treatment which expands the descriptive norm with information about the precautionary measures of neighbors to protect each other against the virus, and includes a message to encourage the participant to do the same.

In our moderator analysis, we show suggestive evidence that prosociality moderates the main treatment for the high-prior group (Figure A.8). In fact, beyond dining out, our prosociality measurements are generally predictive of other COVID-19 precautionary behaviors individuals undertake to protect others. In this section we present the results of how our measure of social preferences in the main analysis is associated with other social distancing behaviors and perceived norms associated with social distancing.

We included in our initial questionnaire a question asking participants for their perceived norms related to social distancing as civil duty, and their perception of social distancing as means to protect others (See Block 2 of Survey 1 in Questionnaire File for the complete question). In addition, we implemented a survey in week 5 of our experiment asking individuals for the frequency of adoption of three precautionary behaviors: Wearing face-masks in public spaces, maintaining safe distance to neighbors in the street, and temperature check before going to the street when feeling unwell.

Figure C.13 shows that participants with strong social preferences (i.e. above median stated altruism) have different beliefs and stated behaviors than the less prosocial ones, after controlling for treatment, urban district and socio-demographic characteristics. We standardized the belief indicators (Likert scale 1-5) and stated behavior indicators (Likert scale 1-7) for the analysis.

The results indicate that participants with strong social preferences are significantly more likely to perceive social distancing as a way to protect others, and judge it as civil duty. Prosocial people tend to report more frequent engagement in the social distancing behaviors like wearing face-mask in public spaces, ensuring sufficient distance to neighbors when walking in the street, and test temperature when they feel uncomfortable before going to the street.

\section{C.1 Manipulation perceived prosociality of neighbors}

In this subsection we present the estimated treatment effects of manipulating participants' knowledge about the precautionary measures that their neighbors are taking to protect oth- 
Figure C.13: Social Preferences, Perceived Norms, and Precautionary Behaviors

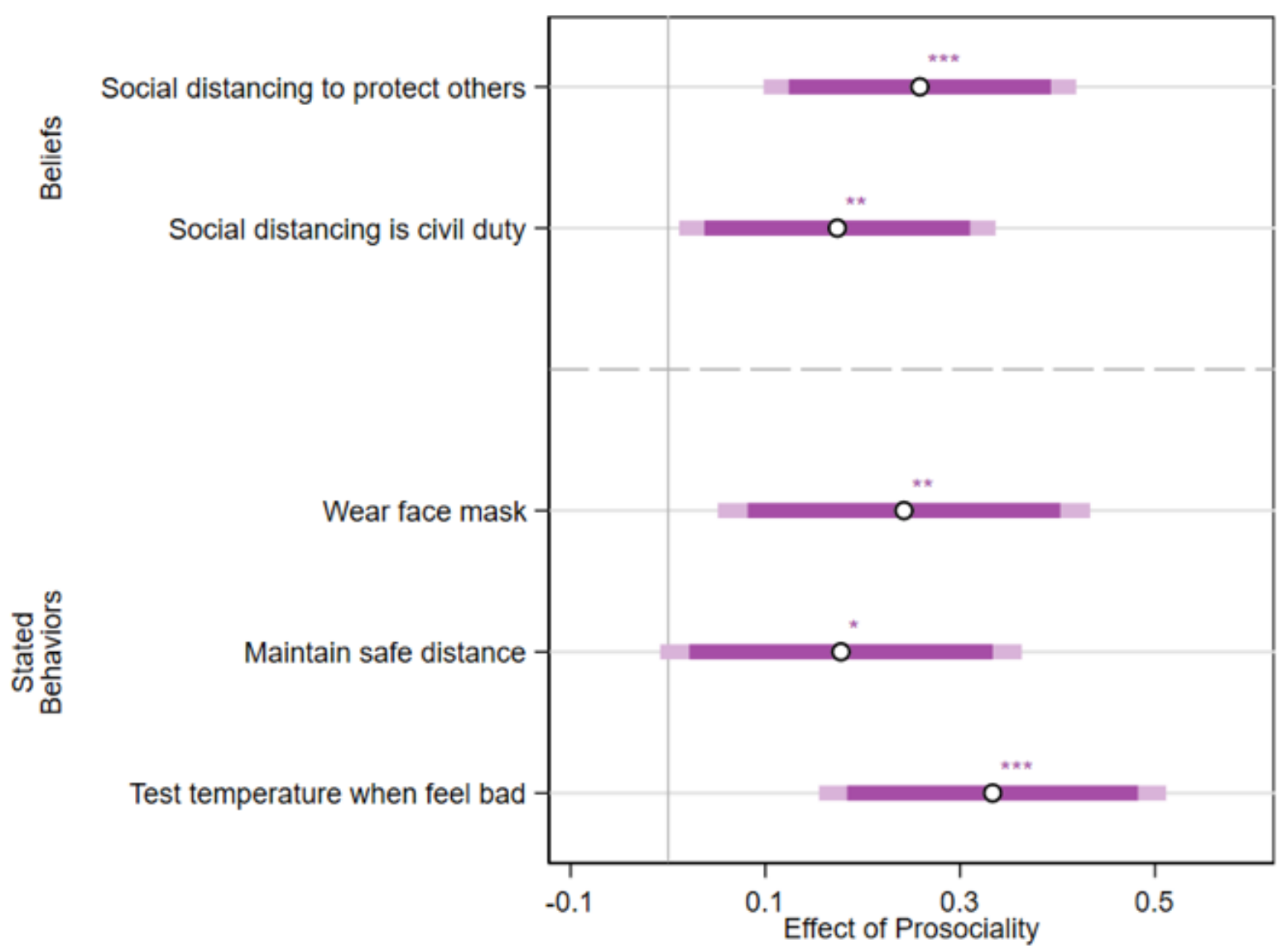

Note: The figure presents how prosocial people have different beliefs and stated behaviors than the less prosocial ones, after controlling for treatment, urban district and socio-demographic characteristics. The belief indicators (Likert scale 1-5) and stated behavior indicators (Likert scale 1-7) have been standardized. The dots describe the point estimates and the darker (lighter) bars describe the $90 \%$ (95\%) confidence intervals.

The results indicate that prosocial people are significantly more likely to perceive social distancing as a way to protect others and judge it as civil duty. Prosocial people tend to report more frequent engagement in the social distancing behaviors like wearing a face-mask, main safe distance, and test temperature when they feel uncomfortable.

ers. In the last week of the study, we expanded the original descriptive norm on the treatment group with a message describing the stated efforts that their neighbours were taking to protect each other (e.g., wearing face-masks and keeping safe distance in public spaces, and doing temperature checks before going out when feeling uncomfortable, see list of questions below).

The message made salient that the vast majority of their neighbors were executing important precautionary measures, emphasizing that they were doing so to protect others, and encouraging participants to do the same.

Questionnaire:

We asked both participants in our sample and 400 individuals recruited from the survey company WJX. All responses are based on a 7 point Likert scale from never to always.

(i). I wear a face-mask when I go to the restaurants and will only take it off when I am eating food. 
(ii). I use hand sanitiser before I touch anything in the supermarket, restaurant or street.

(iii). When I am in the street or parks and I encounter another person, I try to avoid being too close and keep a safe distance of 6 feet (1.5 meters).

(iv). I check my temperature whenever I feel uncomfortable, and I do not leave the house if I have fever.

(v). I try to go to the park or restaurant at a time when I expect few people to be there.

Table C.6: Summary statistics questions

\begin{tabular}{lcccc}
\hline & Mean & SD & \% Responses $\geq 5$ & $\mathrm{~N}$ \\
\hline Wearing face mask & 6.17 & 1.33 & $88.21 \%$ & 992 \\
Use hand sanitiser & 4.56 & 1.83 & $54.72 \%$ & 992 \\
Maintain safe distance & 5.41 & 1.48 & $72.58 \%$ & 992 \\
Test temperature and not go out & 6.19 & 1.18 & $89.72 \%$ & 992 \\
Change time going out & 5.67 & 1.34 & $79.94 \%$ & 992 \\
\hline
\end{tabular}


Wording Information Treatment. We added to our main treatment, the following text highlighting the prosociality of neighbors:

"The neighbors in your urban district are working together to protect each other from the Coronavirus so that everyone in the society can enjoy a normal leisure life. The statistics say virtually everyone confirms that they do not go out if they feel sick, and they wear face-masks whenever they are outside the house. The mass majority also report maintaining safe distance with others in public space, wearing face-masks in restaurants as long as not eating, and going out at a time when less people are expected to be there."

Figure C.14: Original treatment (left) and new treatment (right)

【假期计划】

在您前两天所填写的“假䐓计划_第四周”问卷中，您认为：与您 同城区参与者中，

- (D) 每 100 个人中大约有 1 人打算五一假期去督馆就督：

- 每 100 个人中大约有 2 人打算五一假期去公园踏青。

我们汇总了佨所在城区所有问卷参与者本周的假期计划，结果显 示:

- 每 100 个人中大约有 5 人打算五一假期去餐馆就督;

- 每 100 个人中大约有 6 人打算五一假期去公园踏青。
【假期计划]

在恷前两天所填写的“假期计划_第四周”问巻中，佨认为：与忽 同城区络与者中,

- (D) 每 100 个人中大约有 1 人打算五一假期去铬馆就格;

- 每 100 个人中大约有 2 人打算五一假期去公园䠰青。

我们汇总了您所在城区所有问䊁参与者本周的假期计划，结果显 示:

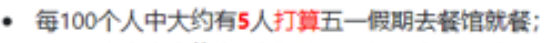

- 每 100 个人中大约有 6 人打算五一假期去公园踏青。

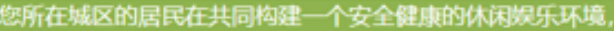

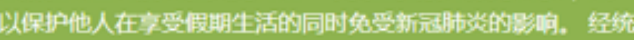

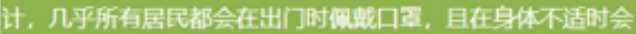

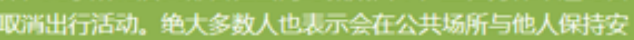

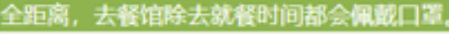


We estimate the effects of the information treatment using two specifications, separately for parks and restaurants:

$$
Y_{i 5}=\alpha_{C} \text { TProsocial }_{i}+\delta \text { AboveTruth }_{i 5}+\mu \text { Plan }_{i 5}+X_{i} \Gamma+\epsilon_{i t}
$$

where $Y_{i 5}$ takes the value of one if individual $i$ reported in our end-week questionnaire to have visited a park or restaurant over the weekend of our last experimental week (i.e. week 5),

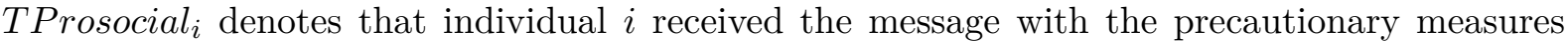
of neighbors, AboveTruth ${ }_{i 5}$ takes the value of one if individual $i$ reported in our mid-week questionnaire beliefs regarding the proportion of neighbors going to parks or restaurants over the last experimental weekend, correspondingly. $\operatorname{Plan}_{i 5}$ takes the value of one if an individual reports in our mid-week questionnaire to have plans to go to restaurants or parks over the weekend. $X_{i}$ includes individual controls. The parameter of interest in eq. 5 , $\alpha_{C}$, describes the differences in restaurant visitation in the last experimental week between individuals receiving the prosocial information treatment together with the descriptive norm and those receiving only the original descriptive norm.

Besides cross subject comparisons, we estimate the following model using the within-subject variation separately for restaurants and parks over the weeks of the experiment:

$$
Y_{i t}=\alpha_{W} \text { TProsocial }_{i}+\delta \text { AboveTruth }_{i t}+\mu \text { Plan }_{i t}+\lambda_{i}+\epsilon_{i t}
$$

where $Y_{i t}$ describes whether individual $i$ visited a restaurant or park in experimental week $t$, and , TProsocial $i$ denotes that individual $i$ received in the last week of the experiment the message with the precautionary measures of neighbors. Plan $i t$ takes the value of one if individual $i$ reports in our mid-week questionnaire to have plans to go to restaurants or parks over the

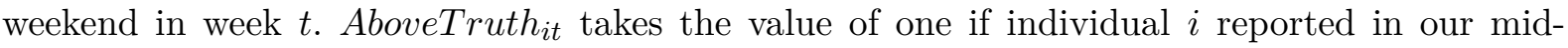
week questionnaire beliefs regarding the proportion of neighbors going to parks or restaurants, correspondingly, over the weekend in week $t$. The regression includes individual fixed effects, $\lambda_{i}$, controlling for any time invariant characteristic of individuals. Equation 6 exploits the differences in visits over time associated with the change in treatment status for individuals in the prosocial treatment, who switched in the last experimental week (i.e. week 5) from the original descriptive norm treatment to the expanded version included the precautionary measures of their neighbors to protect others. Robust standard errors are clustered at the individual level.

While non-significant for those subjects with stronger social preferences (above median) [95\% CI: -8.33, 62.36, $P=0.129$ ], participants with weaker social preferences (below median) significantly reduced dining out [95\% CI: -67.01 to $-7.57, P=0.015]$ after receiving the manipulation. 
These individuals are those who were initially non-responsive when learning that fewer neighbors than expected were going to restaurants in our main treatment, and were doing less social distancing measures in public space (Supplementary Fig. C.13).

Table C.7: Panel a. Treatment Effects on restaurant visitation. Manipulation perceived prosociality. All sample

(3)

$(4)$

(5)

(6)

CROSS WITHIN CROSS WITHIN CROSS WITHIN

\begin{tabular}{lcccccc} 
Prosocial Treatment & -0.0632 & -0.0709 & $-0.224^{*}$ & -0.147 & 0.0810 & 0.000291 \\
& $(0.0780)$ & $(0.0906)$ & $(0.114)$ & $(0.138)$ & $(0.118)$ & $(0.118)$ \\
Observations & 138 & 969 & 65 & 461 & 73 & 508 \\
Low Prosoc. Sample & YES & YES & YES & YES & NO & NO \\
High Prosoc. Sample & YES & YES & NO & NO & YES & YES \\
\hline
\end{tabular}

Tabel C.7. Panel b. Treatment effects on restaurant visitation. Manipulation perceived prosociality. Only subsample that did not receive risk manipulation

(3)

(4)

(5)

CROSS. WITHIN CROSS. WITHIN CROSS. WITHIN

\begin{tabular}{lcccccc}
\hline & & & & & & \\
Prosocial Treatment & -0.0883 & -0.176 & $-0.373^{* *}$ & $-0.414^{* *}$ & 0.270 & 0.0841 \\
& $(0.120)$ & $(0.132)$ & $(0.147)$ & $(0.187)$ & $(0.174)$ & $(0.169)$ \\
Observations & 72 & 488 & 38 & 244 & 34 & 244 \\
Low Prosoc. Sample & YES & YES & YES & YES & NO & NO \\
High Prosoc. Sample & YES & YES & NO & NO & YES & YES \\
\hline
\end{tabular}


Tabel C.7. Panel c. Treatment effects on restaurant visitation. Manipulation perceived prosociality. Only subsample that received risk manipulation

\section{CROSS WITHIN CROSS WITHIN CROSS WITHIN}

$\begin{array}{ccccccc}\text { Prosocial Treatment } & 0.0439 & 0.0314 & -0.222 & 0.272 & 0.164 & -0.0930 \\ & (0.138) & (0.123) & (0.309) & (0.166) & (0.192) & (0.165)\end{array}$

Observations

66

481

27

217

39

Low Prosoc. Sample YES

YES

YES

YES

$\mathrm{NO}$

YES NO

NO

YES
individual fixed effects. The controls in the CROSS models include district fixed effects, week fixed effects and a dummy variable indicating that the participant went at least once a week to a restaurant in the pre-COVID period, age, age squared, gender, a dummy indicating the subject does not have a college degree, a dummy indicating the participant's income is below the median level, a dummy variable indicating that the individual stated that he was planning to go to a restaurant in our Wednesday questionnaire, and 7-point Likert scale indicating the confidence in the plan. The controls in the WITHIN models include a dummy variable indicating that the individual stated that he was planning to go to a restaurant in our Wednesday questionnaire, a dummy variable indicating whether individuals' beliefs regarding the number of neighbors going to parks over the weekend was above the truth, and 7-point Likert scale indicating the confidence in the plan. The last rows indicate the number of observations, whether the sample included the sample of participants with weak (below median), and strong (above median) social preferences.

Table C.8: Panel a. Treatment Effects on park visitation. Manipulation perceived prosociality. All sample

(4)

(5)

(6)

CROSS WITHIN CROSS WITHIN CROSS WITHIN

\begin{tabular}{lcccccc}
\hline Prosocial Treatment & 0.0942 & 0.0982 & 0.101 & 0.162 & 0.163 & 0.0671 \\
& $(0.0812)$ & $(0.0764)$ & $(0.123)$ & $(0.105)$ & $(0.130)$ & $(0.103)$ \\
Observations & 130 & 961 & 60 & 456 & 70 & 505 \\
Low Prosoc. Sample & YES & YES & YES & YES & NO & NO \\
High Prosoc. Sample & YES & YES & NO & NO & YES & YES \\
\hline
\end{tabular}


Tabel C.8. Panel b. Treatment effects on park visitation. Manipulation perceived prosociality. Only subsample that did not receive risk manipulation

\begin{tabular}{lcccccc}
\hline & $(1)$ & $(2)$ & $(3)$ & $(4)$ & $(5)$ & $(6)$ \\
& CROSS & WITHIN & CROSS & WITHIN & CROSS & WITHIN \\
\hline Prosocial Treatment & -0.0421 & 0.146 & -0.0135 & $0.203^{*}$ & 0.00215 & 0.116 \\
& $(0.111)$ & $(0.0964)$ & $(0.167)$ & $(0.115)$ & $(0.216)$ & $(0.134)$ \\
Observations & 64 & 480 & 33 & 239 & 31 & 241 \\
Low Prosoc. Sample & YES & YES & YES & YES & YES & YES \\
High Prosoc. Sample & YES & YES & NO & NO & YES & YES \\
\hline
\end{tabular}

Table C.9: Panel a. Treatment Effects on park visitation. Manipulation perceived prosociality. All sample

(3)

(4)

CROSS WITHIN CROSS WITHIN CROSS WITHIN

\begin{tabular}{lcccccc}
\hline Prosocial Treatment & $0.210^{*}$ & 0.115 & $0.320^{* *}$ & 0.185 & 0.140 & 0.0546 \\
& $(0.122)$ & $(0.115)$ & $(0.125)$ & $(0.170)$ & $(0.189)$ & $(0.155)$ \\
Observations & 66 & 481 & 27 & 217 & 39 & 264 \\
Low Prosoc. Sample & YES & YES & YES & YES & NO & NO \\
High Prosoc. Sample & YES & YES & NO & NO & YES & YES \\
\hline Robust standard errors reported in parenthesis. $* P<0.10 ; * * P<0.05 ; * * * P<0.01$. & The sample includes only
\end{tabular}

individuals that received the descriptive norm first four weeks of the experiment. In this group of participants, half of them were re-assigned to the expanded treatment highlighting the precautionary measures of their neighbors. The $C R O S S$ columns display the estimation results of the cross sectional regression using only the observations from fifth week of the experiment. The WITHIN columns display the estimation results of regressions with individual fixed-effects including individual fixed effects. The controls in the CROSS models include district fixed effects, week fixed effects and a dummy variable indicating that the participant went at least once a week to a park in the pre-COVID period, age, age squared, gender, a dummy indicating the subject does not have a college degree, a dummy indicating the participant's income is below the median level, a dummy variable indicating that the individual stated that he was planning to go to a park in our Wednesday questionnaire, and 7-point Likert scale indicating the confidence in the plan. The controls in the WITHIN models include a dummy variable indicating that the individual stated that he was planning to go to a park in our Wednesday questionnaire, a dummy variable indicating whether individuals' beliefs regarding the number of neighbors going to parks over the weekend was above the truth, and 7-point Likert scale indicating the confidence in the plan. The last rows indicate the number of observations, whether the sample included the sample of participants with weak (below median), and strong (above median) social preferences. 
Changes in Risk Perception

In this section we examine how the descriptive norm impacted the level of risk perception of dining out. The question was included in our Friday survey, just after the elicitation of posterior beliefs. The results show the descriptive norm had a marginal impact on the risk perception of individuals. Those subjects with priors below the truth reported higher risk perception after receiving the descriptive norm intervention $(\mathrm{p}$-value $=0.093)$. We consider this as suggestive evidence that the intervention made individuals perceive restaurants as safer.

Table C.10 presents the estimations from the following regression models.

Column 1 presents the results restricting the sample to the first week of a participant in the experiment:

$$
\text { PostRisk }_{i 1}=\alpha T_{i}+\beta T_{i} \text { AboveTruth }_{i 1}+\delta \text { AboveTruth }_{i 1}+\text { PreRisk }_{i 1} \Lambda+X_{i} \Gamma+\epsilon_{i 1}
$$

Where PostRisk ${ }_{i 1}$ describes the reported risk level on the Friday of the first week that participant $i$ joined the experiment, after receiving the treatment information; PreRisk $k_{i 1}$ describes the level of risk that participant $i$ reported on Wednesday. $T_{i}$ is a dummy variable taking a value of one for people who receive the treatment information (i.e., the information of other neighbors' planned behaviors), and zero otherwise; AboveTruth ${ }_{i t}$ is a dummy variable indicating an individual reported on Wednesday beliefs regarding proportion of neighbors planning to go to restaurants (or parks) higher than the true percentage, based on the calculations by the research team; $X_{i}$ describes the set of control variables (district fixed effects, pre-COVID restaurant frequency, calendar week fixed effects, dummy indicating whether the individual received the information about the restaurant certification and a dummy variable indicating that the individual has a college degree). Sample is restricted to the week individuals joined the experiment. 
Table C.10: Treatment Effects on Risk Perception of dining out

(1)

(3)

Full Sample Below Truth Above Truth

\begin{tabular}{lccc}
\hline Descriptive Norm & $-0.160^{*}$ & $-0.156^{*}$ & 0.145 \\
& $(0.095)$ & $(0.094)$ & $(0.110)$ \\
& {$[0.093]$} & {$[0.098]$} & {$[0.188]$} \\
Prior Above Truth & $-0.187^{*}$ & & \\
& $(0.100)$ & & \\
& {$[0.063]$} & & \\
Descriptive Norm & $0.316^{* *}$ & & \\
$\times$ Prior AboveTruth & $(0.142)$ & & -0.129 \\
& {$[0.027]$} & & $(0.111)$ \\
Restaurant Certification & -0.108 & -0.078 & {$[0.248]$} \\
& $(0.070)$ & $(0.092)$ & 227 \\
Observations & {$[0.122]$} & {$[0.398]$} & 0.435 \\
\hline R-squared & 506 & 279 & \\
\hline Robust standard errors reported in parenthesis. *P<0.10;**P<0.05;***P<0.01.
\end{tabular}




\section{Supplementary Notes}

This section describes the communication with subjects during the experimental week. The individuals in the control group received the same information pieces as those in the treatment group, except for the descriptive norm information (i.e. percentage of neighbors planning to go to restaurants over the weekend). We included the original display in Chinese as well as the translated version in English (see next page).

In addition, we included the percentages included in the descriptive norm, and the wording of the scales to measure individual risk preferences and the rest of moderating scales included in the analysis. 


\section{D.1 Display Treatment Information}

Table D.1: tab: Display Messages for Each Experimental Arm

\begin{tabular}{ll}
\hline Text & Subsample \\
\hline
\end{tabular}

[Wechat]

Welcome screen: thank you for participating in this follow-up survey.

In this follow-up survey, we wish to update you on the plans of our survey participants in your urban district.

Recall that you guessed that for participants living in your urban district:

[emoji ] [[Wednesday Response]] out of 100 survey intend to go to the restauAll Sample rant this weekend;

[emoji ] [[Wednesday Response]]out of 100 survey participants intend to go to the park this weekend.

Find out the real: [Link]

We have analyzed all responses to the survey to give you the true number of people that intend to go to restaurants and parks this weekend.

Descriptive Norm Treatment Group For each 100 people filling the questionnaire living in your urban district, [[Information Descriptive Norm]] plan to the restaurant this weekend.

(Experimental arm For each 100 people filling the questionnaire, [[Information Descriptive Norm]] plan to the park this weekend.

The neighbors in your urban district are working together to protect each other from the Coronavirus so that everyone in the society can enjoy a normal leisure life.

The statistics say virtually everyone wears face masks whenever they are outside the house, and confirms that they do not go out if they feel sick. The mass majority also report maintaining safe distance with others in public spaces, and wearing face masks in restaurants as long as not eating. When you go out, please continue to protect your neighbours as they are doing for you.

\section{Manipulation}

Prosociality Treatment Group $(50 \%$ Descriptive Norm group in Week 5, Experimental arm 2 and 4, See Methods Section) 
Table D.1 cont.

Text

Subsample

Remember that we offered you:

All Sample

We offered you 2 RMB bonus payment for accurately guessing the survey par-

ticipants living in your urban district who would actually go to a restaurant and go to a park this weekend.

Remember that in the survey of Wednesday, you guessed that:

[embedded individual value] out of 100 survey participants living in your urban district would actually go to the restaurant this weekend;

[embedded individual value] out of 100 survey participants living in your urban district would actually go to the park this weekend;

Perhaps your views about otherâs behaviors change.

Please spend one minute to answer this questionnaire so that we can know your thoughts now: [Link to Survey]

[WJX Platform]

Perhaps your views about otherâs behaviors change.

Please guess for every 100 people living in your urban district that took our survey, how many will actually go to the restaurants and parks this weekend. (If your guess is within 2 people of the truth, you will earn a bonus payment of 2 RMB for each)

- Restaurant: [Answer] out of 100 respondents living in my urban district will go to restaurants

- Park: [Answer] out of 100 respondents living in my urban district will go to parks

Thank you for your sharing with us your beliefs. 
Figure D.1: Display descriptive norm treatment information and collection of posterior beliefs

\section{假期计划 - 跟进调研}

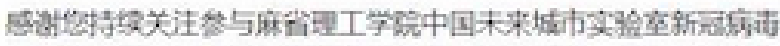

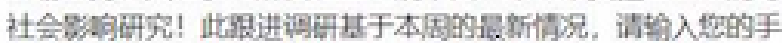

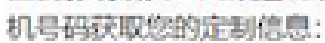

13810293640

\section{[expit划]}

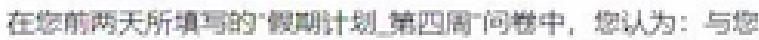
同缚区急与者中。

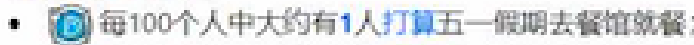

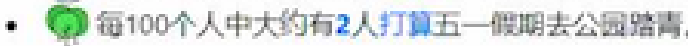

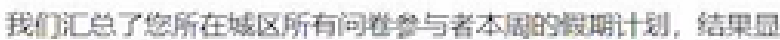
示:

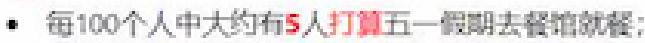

- 每100个人中大约有6人打算五一殿朋去公园踏青。

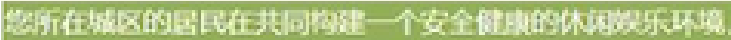

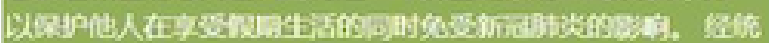

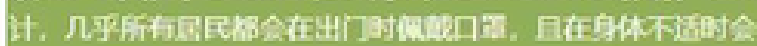

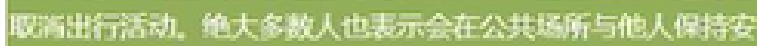

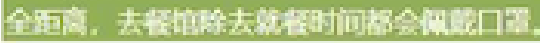

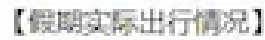

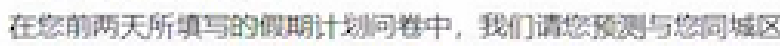

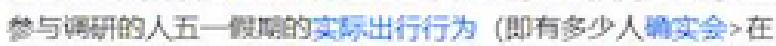

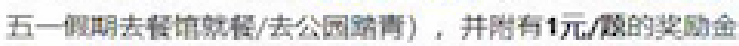
敦。

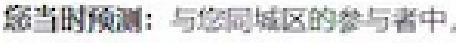

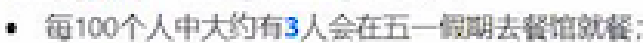

- 每100个人中大约有4人全在五一期朋去公国䠗青.

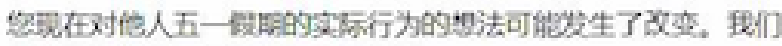

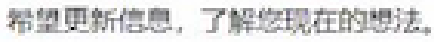

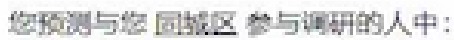

每100个人中大约有

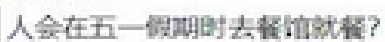

每100个人中右大约 人会在五一假䖧去公园踪青?

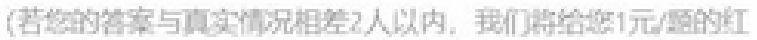
包然勀) 


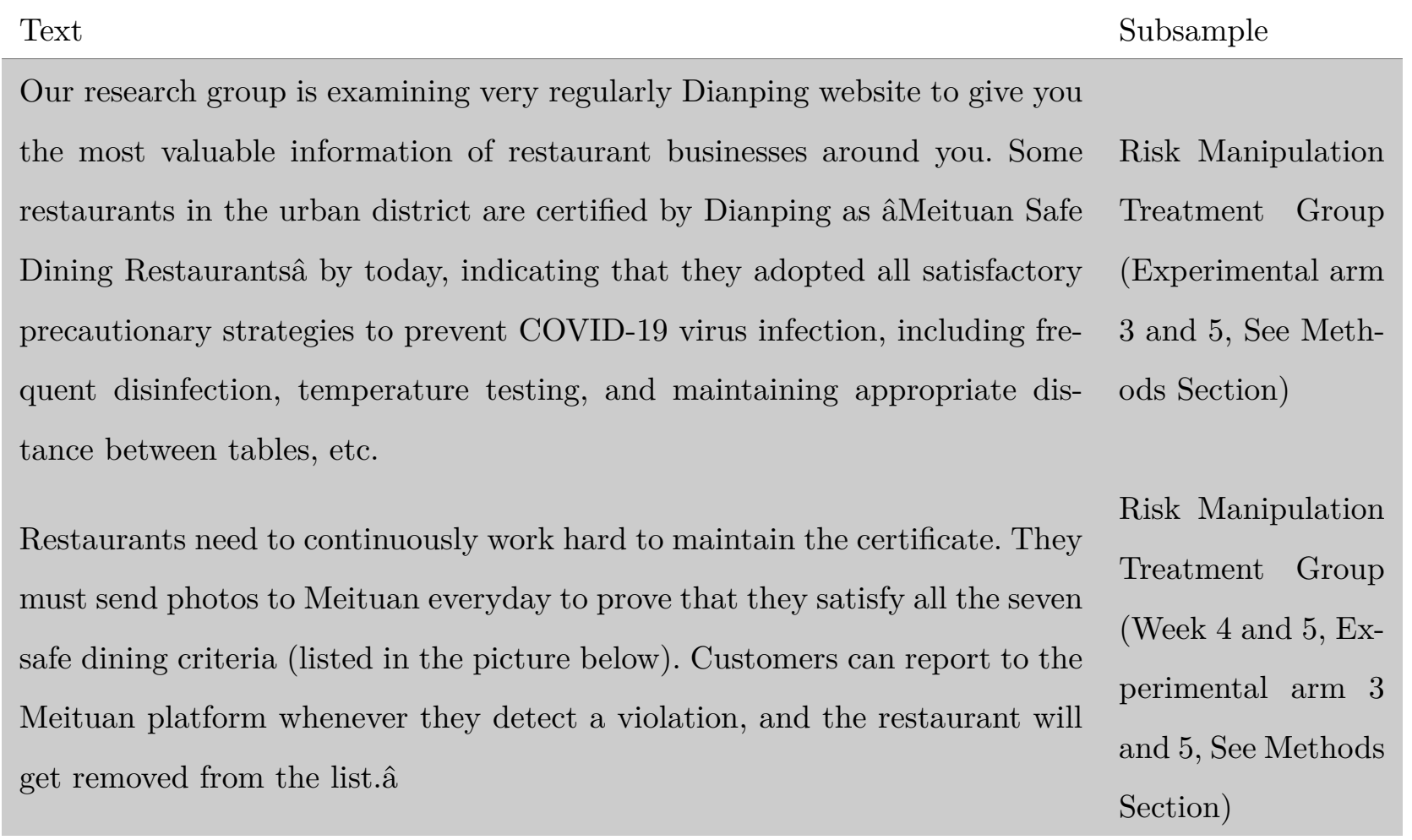

How risky do you feel about dining out at a nearby restaurant this weekend? (7-level Likert scale)

For the next questions, we would like you to think about the current situation in your urban district:

How risky do you feel about going to a nearby park this weekend? (7-level Likert scale)

We have created a list of restaurants with certification status of thousands of restaurants in the entire city.

$[[$ Screenshot Website $]]$ Figure + Screen

Do you want us to share the most updated information about the restaurants over the weekend?

Yes

No

Here is the link to the website. [Link]

Thank you very much for your participation. We will inform you about the total payment you have earned from Wednesday and todayâs surveys â the payment will be deposited to your virtual account via the SXCX APP.

We will also inform you about future study opportunities, and we look forward to seeing you again soon! Feel free to contact us via WeChat «Add WeChat ID» if you have questions regarding this study.

Have a good weekend and donât forget to set up your phone to participate in the weekend lottery! 


\section{D.2 Percentages used to construct descriptive norm}

Table D.2 displays the percentages used to construct the descriptive norm information treatment in the restaurant setting. Table D.3 displays the percentages used to construct the descriptive norm information treatment in the park setting. Table D.4 displays number of respondents in each of the five urban districts of Zhengzhou included in our sample.

Table D.2: Percentage individuals planning to visit restaurants in urban district in sample

\begin{tabular}{lccccc}
\hline & District 1 & District 2 & District 3 & District 4 & District 5 \\
\hline Week 1 & 30 & 45 & 29 & 32 & 40 \\
Week 2 & 36 & 35 & 37 & 32 & 39 \\
Week 3 & 39 & 47 & 25 & 40 & 39 \\
Week 4 & 38 & 51 & 41 & 32 & 40 \\
Week 5 & 41 & 33 & 30 & 51 & 49 \\
\hline
\end{tabular}

Table D.3: Percentage individuals planning to visit parks in urban district in sample

\begin{tabular}{lrrrrr}
\hline & District 1 & District 2 & District 3 & District 4 & District 5 \\
\hline Week 1 & 53 & 51 & 49 & 51 & 51 \\
Week 2 & 61 & 62 & 45 & 47 & 53 \\
Week 3 & 50 & 59 & 44 & 54 & 57 \\
Week 4 & 41 & 56 & 38 & 38 & 48 \\
Week 5 & 52 & 49 & 33 & 55 & 55 \\
\hline
\end{tabular}

Table D.4: Number respondents per urban district

\begin{tabular}{lrrrrr}
\hline & District 1 & District 2 & District 3 & District 4 & District 5 \\
\hline Week 1 & 51 & 39 & 11 & 131 & 218 \\
Week 2 & 55 & 43 & 9 & 134 & 246 \\
Week 3 & 54 & 44 & 10 & 143 & 270 \\
Week 4 & 53 & 42 & 9 & 136 & 268 \\
Week 5 & 38 & 25 & 9 & 101 & 203 \\
\hline
\end{tabular}


D.3 Description Moderating Scales 


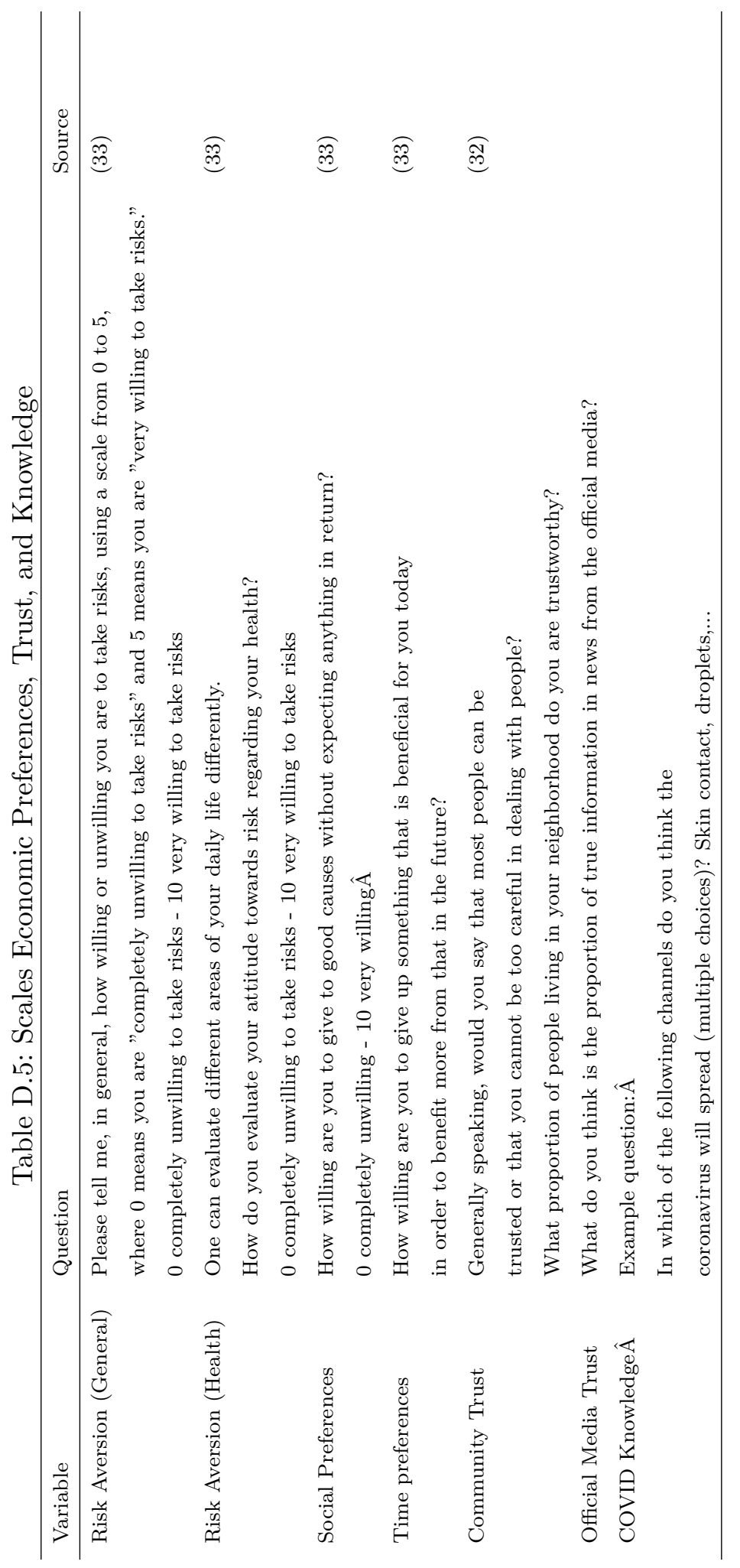




\section{E Summary Statistics And Balance tests}

This section presents the summary statistics and shows the balance tests across treatment arms by regressing baseline individual characteristics on indicators for the three treatment arms and the strata variables, and conduct F-tests that all treatment coefficients equal zero.

For the 38 variables analyzed, F-statistics are significant at 5 percent for only two variables, namely, a binary variable indicating whether the respondent had no college degree, and the trust in social media. Controlling for those variables do not change the significance nor the magnitude of our main estimates. As it is a key socio-demographic variable, we include education as a control in all regressions in our sample.

Finally, an overall F-test in a seemingly unrelated regression (SUR) specification across the 38 regressions yields a p-value on the F-statistic of 0.68 , indicating that we cannot reject the hypothesis of equality across all of the treatment arms and control group, indicating that the randomization created largely comparable groups.

Column 1 in E.1 reports mean values for the control group, with standard deviations in brackets. Columns 2 to 4 report the coefficients from separate regressions in which a dependent variable is regressed on the full set of treatment indicators and stratification variables (i.e., district, and a dummy variable that indicates that the individual went to the restaurant at least once a week in the pre-pandemic period on average). Column 5 reports the p-values of F-tests of whether the treatment coefficients are jointly equal to zero. An overall F-test in an SUR specification across the 38 regressions yields a p-value on the F-statistic of 0.68 , indicating that we cannot reject the hypothesis of baseline equality across all of the treatment arms and control group. 
Table E.1: Balance Tests

\begin{tabular}{|c|c|c|c|c|c|}
\hline & $\begin{array}{c}(1) \\
\text { Control }\end{array}$ & $\begin{array}{c}(2) \\
\text { Descriptive } \\
\text { Norm }\end{array}$ & $\begin{array}{c}\quad(3) \\
\text { Restaurant. } \\
\text { Certificate }\end{array}$ & $\begin{array}{c}(4) \\
\text { Desc. Norm } \\
\text { AND Rest. Cert }\end{array}$ & $\begin{array}{c}(5) \\
\text { p-value } \\
\text { F-test }\end{array}$ \\
\hline Age & $\begin{array}{l}31.12 \\
{[7.12]}\end{array}$ & $\begin{array}{c}0.91 \\
(0.81)\end{array}$ & $\begin{array}{c}1.38 \\
(0.83)\end{array}$ & $\begin{array}{c}0.09 \\
(0.75)\end{array}$ & 0.26 \\
\hline Working $(1=$ Yes $)$ & $\begin{array}{c}0.92 \\
{[0.27]}\end{array}$ & $\begin{array}{c}0.04 \\
(0.03)\end{array}$ & $\begin{array}{c}0.02 \\
(0.03)\end{array}$ & $\begin{array}{c}0.06 \\
(0.03)\end{array}$ & 0.25 \\
\hline Low Education (1=Yes) & $\begin{array}{c}0.27 \\
{[0.45]}\end{array}$ & $\begin{array}{c}0.11^{* *} \\
(0.05)\end{array}$ & $\begin{array}{l}-0.03 \\
(0.05)\end{array}$ & $\begin{array}{c}0.02 \\
(0.05)\end{array}$ & $0.07^{*}$ \\
\hline Low Income (1=Yes) & $\begin{array}{c}0.56 \\
{[0.50]}\end{array}$ & $\begin{array}{l}-0.01 \\
(0.06)\end{array}$ & $\begin{array}{c}0.02 \\
(0.06)\end{array}$ & $\begin{array}{c}0.05 \\
(0.06)\end{array}$ & 0.70 \\
\hline Owns Car (1=Yes) & $\begin{array}{c}0.77 \\
{[0.42]}\end{array}$ & $\begin{array}{l}-0.01 \\
(0.05)\end{array}$ & $\begin{array}{c}0.03 \\
(0.06)\end{array}$ & $\begin{array}{l}-0.05 \\
(0.06)\end{array}$ & 0.52 \\
\hline Prior Proportion Rest. Visitors & $\begin{array}{c}37.58 \\
{[23.79]}\end{array}$ & $\begin{array}{l}-2.52 \\
(2.67)\end{array}$ & $\begin{array}{c}-10.96^{* * *} \\
(2.55)\end{array}$ & $\begin{array}{l}-0.73 \\
(2.76)\end{array}$ & $0.00^{* * *}$ \\
\hline Prior Proportion Park Visitors & $\begin{array}{c}51.62 \\
{[24.43]}\end{array}$ & $\begin{array}{l}-1.39 \\
(2.69)\end{array}$ & $\begin{array}{c}-6.05^{* * *} \\
(2.90)\end{array}$ & $\begin{array}{c}0.82 \\
(2.77)\end{array}$ & $0.08^{*}$ \\
\hline Planning Visit Park (1=Yes) & $\begin{array}{c}0.56 \\
{[0.50]}\end{array}$ & $\begin{array}{c}0.04 \\
(0.06)\end{array}$ & $\begin{array}{c}0.03 \\
(0.06)\end{array}$ & $\begin{array}{l}-0.08 \\
(0.06)\end{array}$ & 0.14 \\
\hline Planning Visit Rest. (1=Yes) & $\begin{array}{c}0.35 \\
{[0.48]}\end{array}$ & $\begin{array}{c}0.08 \\
(0.05)\end{array}$ & $\begin{array}{l}-0.00 \\
(0.05)\end{array}$ & $\begin{array}{c}0.00 \\
(0.05)\end{array}$ & 0.35 \\
\hline Risk Shopping & $\begin{array}{c}3.66 \\
{[0.96]}\end{array}$ & $\begin{array}{c}0.05 \\
(0.11)\end{array}$ & $\begin{array}{c}0.08 \\
(0.11)\end{array}$ & $\begin{array}{c}0.02 \\
(0.11)\end{array}$ & 0.90 \\
\hline Office Risk & $\begin{array}{c}2.98 \\
{[0.94]}\end{array}$ & $\begin{array}{c}0.11 \\
(0.10)\end{array}$ & $\begin{array}{c}0.04 \\
(0.11)\end{array}$ & $\begin{array}{c}0.01 \\
(0.11)\end{array}$ & 0.68 \\
\hline Movie Risk & $\begin{array}{c}4.34 \\
{[0.74]}\end{array}$ & $\begin{array}{l}-0.02 \\
(0.09)\end{array}$ & $\begin{array}{c}0.09 \\
(0.08)\end{array}$ & $\begin{array}{c}0.00 \\
(0.08)\end{array}$ & 0.59 \\
\hline Taxi Risk & $\begin{array}{c}3.18 \\
{[0.91]}\end{array}$ & $\begin{array}{c}0.17 \\
(0.10)\end{array}$ & $\begin{array}{c}0.16 \\
(0.11)\end{array}$ & $\begin{array}{c}0.04 \\
(0.10)\end{array}$ & 0.23 \\
\hline Park Risk & $\begin{array}{c}2.72 \\
{[0.93]}\end{array}$ & $\begin{array}{c}0.07 \\
(0.10)\end{array}$ & $\begin{array}{c}0.13 \\
(0.11)\end{array}$ & $\begin{array}{l}-0.01 \\
(0.10)\end{array}$ & 0.55 \\
\hline Restaurant Risk & $\begin{array}{c}4.10 \\
{[0.81]}\end{array}$ & $\begin{array}{c}0.12 \\
(0.09)\end{array}$ & $\begin{array}{c}0.24^{* * *} \\
(0.09)\end{array}$ & $\begin{array}{c}0.11 \\
(0.09)\end{array}$ & $0.07^{*}$ \\
\hline Trust General & $\begin{array}{c}1.67 \\
{[0.62]}\end{array}$ & $\begin{array}{c}0.02 \\
(0.07)\end{array}$ & $\begin{array}{c}0.04 \\
(0.07)\end{array}$ & $\begin{array}{c}0.01 \\
(0.07)\end{array}$ & 0.95 \\
\hline Trust Family & $\begin{array}{c}4.74 \\
{[0.54]}\end{array}$ & $\begin{array}{l}-0.10 \\
(0.06)\end{array}$ & $\begin{array}{l}-0.07 \\
(0.05)\end{array}$ & $\begin{array}{c}-0.15^{* *} \\
(0.06)\end{array}$ & $0.09 *$ \\
\hline Trust Colleagues & $\begin{array}{c}3.64 \\
{[0.63]}\end{array}$ & $\begin{array}{l}-0.04 \\
(0.07)\end{array}$ & $\begin{array}{l}-0.02 \\
(0.07)\end{array}$ & $\begin{array}{l}-0.07 \\
(0.07)\end{array}$ & 0.79 \\
\hline Trust Neighborhood & $\begin{array}{c}2.94 \\
{[0.67]}\end{array}$ & $\begin{array}{l}-0.04 \\
(0.07)\end{array}$ & $\begin{array}{c}0.03 \\
(0.08)\end{array}$ & $\begin{array}{l}-0.07 \\
(0.08)\end{array}$ & 0.60 \\
\hline Trust Strangers & $\begin{array}{c}2.19 \\
{[0.82]}\end{array}$ & $\begin{array}{l}-0.14 \\
(0.09)\end{array}$ & $\begin{array}{l}-0.18 \\
(0.09)\end{array}$ & $\begin{array}{l}-0.03 \\
(0.10)\end{array}$ & 0.16 \\
\hline
\end{tabular}


Table E.1 (cont.). Balance Tests

\begin{tabular}{|c|c|c|c|c|c|}
\hline & $\begin{array}{c}\text { (1) } \\
\text { Control }\end{array}$ & $\begin{array}{c}(2) \\
\text { Descriptive } \\
\text { Norm }\end{array}$ & $\begin{array}{c}\quad(3) \\
\text { Restaurant. } \\
\text { Certificate }\end{array}$ & $\begin{array}{c}(4) \\
\text { Desc. Norm } \\
\text { AND Rest. Cert }\end{array}$ & $\begin{array}{c}(5) \\
\text { p-value } \\
\text { F-test }\end{array}$ \\
\hline Prop. Neighbors Trustworthy & $\begin{array}{c}3.56 \\
{[1.08]}\end{array}$ & $\begin{array}{c}0.01 \\
(0.12)\end{array}$ & $\begin{array}{c}0.06 \\
(0.12)\end{array}$ & $\begin{array}{c}0.02 \\
(0.13)\end{array}$ & 0.96 \\
\hline Trust Money Neighbors & $\begin{array}{c}1.71 \\
{[0.63]}\end{array}$ & $\begin{array}{l}-0.15 \\
(0.07)\end{array}$ & $\begin{array}{l}-0.08 \\
(0.07)\end{array}$ & $\begin{array}{l}-0.01 \\
(0.08)\end{array}$ & 0.17 \\
\hline Trust Money Stranger & $\begin{array}{c}1.25 \\
{[0.50]}\end{array}$ & $\begin{array}{l}-0.08 \\
(0.06)\end{array}$ & $\begin{array}{l}-0.06 \\
(0.06)\end{array}$ & $\begin{array}{c}0.05 \\
(0.06)\end{array}$ & 0.14 \\
\hline Trust TV & $\begin{array}{c}4.41 \\
{[0.98]}\end{array}$ & $\begin{array}{c}0.04 \\
(0.10)\end{array}$ & $\begin{array}{l}-0.05 \\
(0.12)\end{array}$ & $\begin{array}{c}0.04 \\
(0.11)\end{array}$ & 0.84 \\
\hline Trust Official Media & $\begin{array}{c}4.41 \\
{[0.93]}\end{array}$ & $\begin{array}{c}0.03 \\
(0.10)\end{array}$ & $\begin{array}{l}-0.02 \\
(0.11)\end{array}$ & $\begin{array}{c}0.03 \\
(0.10)\end{array}$ & 0.97 \\
\hline Trust Websites & $\begin{array}{c}2.90 \\
{[0.97]}\end{array}$ & $\begin{array}{c}0.08 \\
(0.11)\end{array}$ & $\begin{array}{c}0.06 \\
(0.11)\end{array}$ & $\begin{array}{c}0.07 \\
(0.11)\end{array}$ & 0.88 \\
\hline Trust Weibo & $\begin{array}{c}3.16 \\
{[1.08]}\end{array}$ & $\begin{array}{l}-0.05 \\
(0.12)\end{array}$ & $\begin{array}{l}-0.13 \\
(0.13)\end{array}$ & $\begin{array}{l}-0.01 \\
(0.12)\end{array}$ & 0.76 \\
\hline Trust Wechat & $\begin{array}{c}2.72 \\
{[0.97]}\end{array}$ & $\begin{array}{c}0.33^{* * *} \\
(0.11)\end{array}$ & $\begin{array}{c}0.20 \\
(0.11)\end{array}$ & $\begin{array}{c}0.23 \\
(0.11)\end{array}$ & $0.02^{* *}$ \\
\hline Trust Wechat Official Account & $\begin{array}{c}3.26 \\
{[1.11]}\end{array}$ & $\begin{array}{l}0.23^{*} \\
(0.12)\end{array}$ & $\begin{array}{c}0.05 \\
(0.13)\end{array}$ & $\begin{array}{c}0.05 \\
(0.12)\end{array}$ & 0.26 \\
\hline Trust Zhihu & $\begin{array}{c}3.01 \\
{[1.09]}\end{array}$ & $\begin{array}{l}-0.03 \\
(0.12)\end{array}$ & $\begin{array}{l}-0.15 \\
(0.12)\end{array}$ & $\begin{array}{l}-0.13 \\
(0.12)\end{array}$ & 0.54 \\
\hline COVID Quiz Score & $\begin{array}{c}9.14 \\
{[2.03]}\end{array}$ & $\begin{array}{l}-0.01 \\
(0.23)\end{array}$ & $\begin{array}{c}0.36 \\
(0.22)\end{array}$ & $\begin{array}{c}0.18 \\
(0.24)\end{array}$ & 029 \\
\hline Norm Distancing & $\begin{array}{c}3.36 \\
{[1.12]}\end{array}$ & $\begin{array}{c}0.07 \\
(0.12)\end{array}$ & $\begin{array}{l}0.23^{*} \\
(0.12)\end{array}$ & $\begin{array}{l}0.25^{* *} \\
(0.12)\end{array}$ & 0.11 \\
\hline Norm Protect Others & $\begin{array}{c}4.77 \\
{[0.50]}\end{array}$ & $\begin{array}{l}-0.03 \\
(0.06)\end{array}$ & $\begin{array}{l}-0.02 \\
(0.06)\end{array}$ & $\begin{array}{c}0.02 \\
(0.06)\end{array}$ & 0.81 \\
\hline Risk Preference General & $\begin{array}{c}3.45 \\
{[2.81]}\end{array}$ & $\begin{array}{l}-0.12 \\
(0.31)\end{array}$ & $\begin{array}{c}0.28 \\
(0.32)\end{array}$ & $\begin{array}{l}-0.29 \\
(0.32)\end{array}$ & 0.39 \\
\hline Risk Preference Health & $\begin{array}{c}3.24 \\
{[2.65]}\end{array}$ & $\begin{array}{l}-0.25 \\
(0.30)\end{array}$ & $\begin{array}{c}0.10 \\
(0.30)\end{array}$ & $\begin{array}{l}-0.02 \\
(0.30)\end{array}$ & 0.71 \\
\hline Time Preference Long Reward & $\begin{array}{c}7.03 \\
{[2.59]}\end{array}$ & $\begin{array}{c}0.06 \\
(0.29)\end{array}$ & $\begin{array}{l}-0.08 \\
(0.30)\end{array}$ & $\begin{array}{c}0.02 \\
(0.29)\end{array}$ & 0.97 \\
\hline Charity Preference & $\begin{array}{c}6.43 \\
{[2.68]}\end{array}$ & $\begin{array}{l}-0.15 \\
(0.30)\end{array}$ & $\begin{array}{c}0.00 \\
(0.30)\end{array}$ & $\begin{array}{c}0.00 \\
(0.30)\end{array}$ & 0.95 \\
\hline Time Preference Delay & $\begin{array}{c}3.67 \\
{[3.16]}\end{array}$ & $\begin{array}{l}-0.31 \\
(0.35)\end{array}$ & $\begin{array}{l}-0.14 \\
(0.35)\end{array}$ & $\begin{array}{l}-0.01 \\
(0.36)\end{array}$ & 0.80 \\
\hline
\end{tabular}

Asterisks indicate coefficient statistical significance level: ${ }^{*} \mathrm{P}<0.10 ;{ }^{*} \mathrm{P}<0.05$; ${ }^{* *} \mathrm{P}<0.01$. 


\section{F Recruitment and sample attrition}

This section describes the procedure to recruit subjects, and provides an overview of the refreshment samples collected over the experimental weeks. In the main text, we report the results based on the first week individuals are in the sample (i.e. column (1)), where individuals' priors are not being shaped by the descriptive norms in previous weeks.

The majority of individuals in our initial contact lists were extracted from a list of participants in a survey conducted in Zhengzhou July 2019 by the research team on air pollution and commuting behavior. Individuals voluntarily left their cell phone number for future research projects.

In addition, we complemented the list with a series of ads in the Chinese social network Wechat, which broadly advertised the research project as studying the "impact of Covid-19". We sent out recruitment text messages with an APP installation link and rewards for participating illustrated. If they agree to participate, the screening questionnaires and informed consent are included during the APP registration.

Out of 5,047 phone calls, 475 individuals never responded to the call. 1228 accepted to install the app and participate in the experiment. 609 individuals did not fill any questionnaire, leaving a total of 619 valid participants. Table F.1 for the number of individuals in the sample in each week of the experiment

Table F.1: Number participants in experimental weeks

\begin{tabular}{lccc} 
Experimental Week & New Comers & Return Sample & Total \\
\hline Week 1 & 450 & 0 & 450 \\
Week 2 & 81 & 406 & 487 \\
Week 3 & 47 & 474 & 521 \\
Week 4 & 12 & 496 & 508 \\
Week 5 & 32 & 344 & 376 \\
\hline
\end{tabular}




\section{G Compensation Participants}

Table G.2: Compensation for participants

\begin{tabular}{|c|c|c|c|}
\hline Item & $\begin{array}{l}\text { Monetary } \\
\text { Compensation }\end{array}$ & $\begin{array}{l}\text { Payment } \\
\text { Condition }\end{array}$ & $\begin{array}{l}\text { Payment } \\
\text { Time }\end{array}$ \\
\hline Survey 1 & $20 \mathrm{RMB}$ & Completed & Start from Mar 22 \\
\hline Survey 2 & $15 \mathrm{RMB}$ & Completed & Start from Mar 29 \\
\hline Prior belief (weekly) & $2 \mathrm{RMB}$ & $\begin{array}{l}\text { Completed by Thurs- } \\
\text { day night }\end{array}$ & Weekly Wed-Thurs \\
\hline $\begin{array}{l}\text { Treatment and posterior } \\
\text { belief (weekly) }\end{array}$ & $2 \mathrm{RMB}$ & $\begin{array}{l}\text { Completed by Friday } \\
\text { night }\end{array}$ & Weekly Friday \\
\hline $\begin{array}{l}\text { Weekend actual behavior } \\
\text { (weekly) }\end{array}$ & $2 \mathrm{RMB}$ & Completed & Weekly Sunday night \\
\hline Pop-up happiness questions & $1 \mathrm{RMB}$ & Completed & Weekly on Saturday \\
\hline End survey & $10 \mathrm{RMB}$ & Completed & Start from May 11 \\
\hline Correct belief rewards & $1 \mathrm{RMB}$ & $\begin{array}{l}\text { Correctly } \\
\text { neighbor } \\
\text { (within } 2 \text { percentage } \\
\text { points to the truth) }\end{array}$ & $\begin{array}{l}\text { Start from March } 30 . \\
\text { All rewards for correct } \\
\text { guesses were given at } \\
\text { the end of the experi- } \\
\text { ment. }\end{array}$ \\
\hline GPS data provision & $2 \mathrm{RMB} /$ day & $\begin{array}{l}\text { If a user provide any } \\
\text { data, money will be } \\
\text { top up to his account }\end{array}$ & Since March 16th \\
\hline GPS Weekend Lottery & $\begin{array}{l}1000 \text { RMB for two } \\
\text { participants that } \\
\text { provide valid GPS } \\
\text { over the weekend }\end{array}$ & $\begin{array}{l}\text { Participants who pro- } \\
\text { vide enough data for } \\
\text { Friday night( } 30 \text { mins }) \text {, } \\
\text { Saturday noon and } \\
\text { night(30 mins each, } \\
60 \text { mins in total) and } \\
\text { Sunday noon and } \\
\text { night(30 mins each, } \\
60 \text { mins in total) can } \\
\text { enter the lottery. }\end{array}$ & Since March 30th \\
\hline
\end{tabular}




\section{H Comparison Parks and Restaurants}

In the main text, we describe the different impacts of the descriptive norm intervention in restaurants and parks. In this section, we describe in detail the differences in average visits and risk perception.

\section{H.1 Comparison restaurant and park visits relative to Pre-COVID}

Table H.1 presents the percentage of individuals in our control group, receiving no descriptive norms nor the restaurant certification, that reported going to restaurants and and parks over the weekend, together with the percentage of individuals reporting planning to go to these two places, and their reported visit frequency in pre-COVID. In our control sample, the percentage of individuals going to restaurants went down by 36.5 percent $(1-31.18 / 49.10)$ in our first experimental week, relative to the the reported pre-COVID normal visitation patterns. In parks, the percentage went up by 13.9 percent $(37.63 / 33.04-1)$ in our first experimental week, relative to the the reported pre-COVID normal visitation patterns.

\section{Table H.1: Comparison visits to parks and restaurant with pre-COVID rates}

\begin{tabular}{lcc} 
& Observations & Percentage \\
\hline Restaurant & 93 & 31.18 \\
Went over the weekend & 112 & 31.25 \\
Planned to go & 112 & 49.10 \\
Went at least once a week before COVID-19 & & \\
Park & 93 & 37.63 \\
Went over the weekend & 112 & 59.82 \\
Planned to go & 112 & 33.04 \\
Went at least once a week before COVID-19 & & \\
\hline Notes: The figures in the table are based on data for the first experimental week 1 for the group
\end{tabular}

receiving no information treatment (no descriptive norm, and no information about the restaurant certification).

\section{H.2 Initial Risk Perception to Visit Public Spaces}

In the initial questionnaire, participants were asked to state their perceived risk of visiting 7 different places on a 5-point Likert scale from low to high risk: parks, restaurants, public transport, office, taxi, and cinema. Panel a in Figure shows the average risk perception in our sample for each place included in our initial questionnaire.

Panel $b$ in Figure shows the proportion of individuals that state a strictly higher value in the risk scale for restaurants than for the corresponding place, indicating that going to restaurants 
is riskier than going to the place described in the bar in the initial questionnaire.

Figure H.1: Initial Perceived Risk to Visit Public Spaces

Panel a. Average Risk

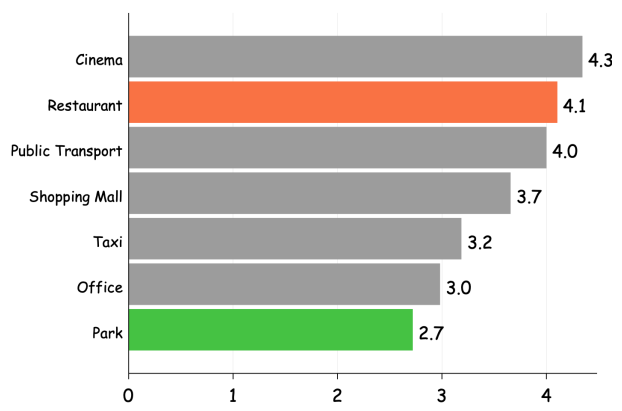

Panel b. Percentage Participants Perceiving

Restaurants Riskier than Space

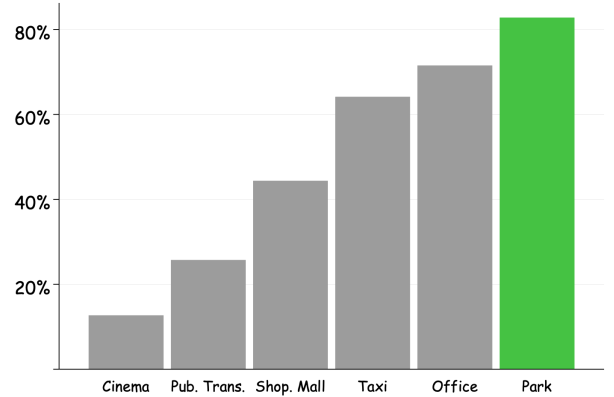

Notes:

i) Panel a: Bars indicate the average risk perception in our sample for each place included in our initial questionnaire. The scales rank from 1 (lowest risk) to 5 (highest risk).

ii) Panel b: Bars indicate the proportion of individuals that state a strictly higher value in the risk scale for restaurants than for the corresponding place, indicating that going to restaurants is riskier than going to the place described in the bar. 


\section{Prior beliefs over weeks}

In the main text, we describe that individuals stayed in the sample for several weeks reporting their beliefs and behaviors. Here, we show how the influence of the descriptive norm intervention in the prior beliefs (reported in our Wednesday survey) of the treatment group in subsequent weeks.

Figure I.1: Changes in prior beliefs over experimental weeks

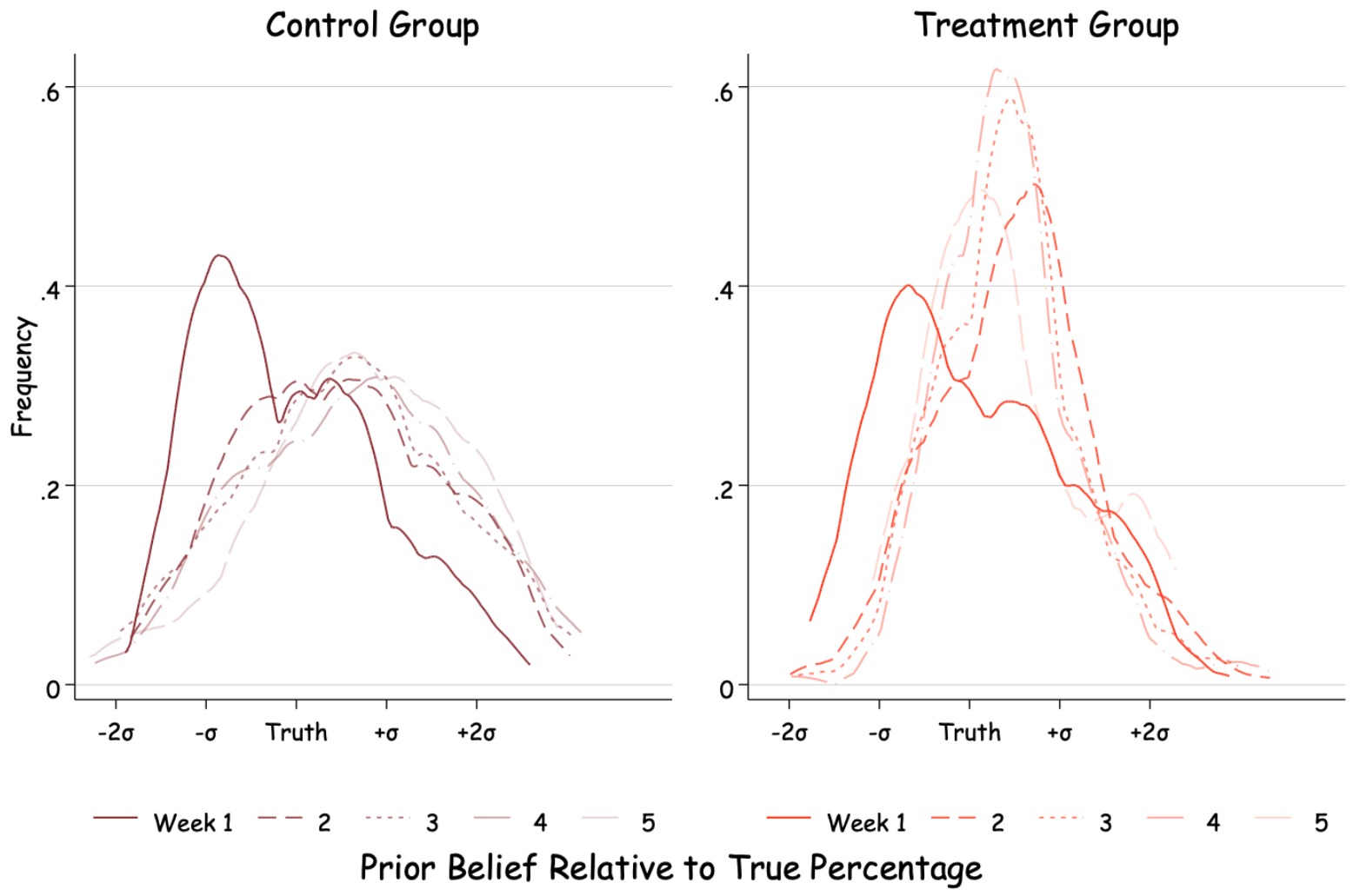

Notes: Figure displays the distribution of beliefs regarding the percentage of neighbors planning to go to restaurants over the weekend reported on our Wednesdays surveys separately for control (left) and treatment (right) group, in every week of the experiment. The figure shows how the beliefs of the treatment group are more concentrated around the true percentage of neighbors for the week after week 1. On the contrary, the distribution of beliefs of the control group is wider and not center around the truth. This suggests that prior beliefs are influenced by the descriptive norm information in previous weeks. 


\section{J Supplementary Methods: Validation Survey Responses with GPS Data}

During the experiment, we collected the GPS data thorough participants' daytime with the app. In this section we present the different tests that we undertook to confirm the validity of our survey measures. The results show: (1) the GPS coordinates of participants correspond to the restaurant that they reported in our Sunday questionnaire; (2) the proportion of time the GPS coordinates of participants are at the home of participants is lower for those individuals who report being at a restaurant at that day/time.

In order to save the battery of our participants while ensuring high quality of data, we have two sampling frequencies, see Table J.1

Table J.1: GPS Sampling Frequency

\begin{tabular}{lcc}
\hline Time of the day & Proportion of minutes sampled & Sample Frequency \\
\hline 7 am to $9 \mathrm{am}$ & 10 out of $10 \mathrm{mins}$ & 2 seconds \\
9 am to $5 \mathrm{pm}$ & 2 out of $10 \mathrm{mins}$ & 2 seconds \\
$5 \mathrm{pm}$ to $7 \mathrm{pm}$ & 10 out of $10 \mathrm{mins}$ & 2 seconds \\
$7 \mathrm{pm}$ to $8 \mathrm{pm}$ & 2 out of $10 \mathrm{mins}$ & 2 seconds \\
\hline
\end{tabular}

The GPS data records are stored in a Mongodb database together with a user's ID, to connect the records to the survey responses and treatment status of the participant.

\section{J.1 Restaurant Validation}

We first validate whether we can observe participant's phone GPS coordinates near (200 meters) the restaurant they reported in their weekend report. It is important to note that participants who voluntarily activate the app GPS sharing option are collected during the experiment. Thus, we only validate the performance of GPS data with participants who provided good quality survey entries and GPS data.

From our survey, we constructed a dataset with 2,968 survey entries containing whether a participant went to a restaurant over the weekend, the name of the restaurant, the dates, and for some cases time of day (evening or noon) the restaurant was visited. We implemented different filters to the GPS data to ensure the data quality and the correspondence with the time the participant reported he visited the restaurant. To ensure, data quality we applied the following filters to the row GPS data:

- The percentage of GPS data points in a single day for a participant should be larger than $80 \%$. There are several ways for the cellphone to generate a GPS point: receiving 
signals from satellites, receiving signal from WIFI, and using inertia measurement unit to infer the location based on the last precise position. These generated discrepancies in precision. According to the description from AMAP (The provider of the cellphone positioning API), satellites usually provide the highest precision since WIFI tend not to be of sufficient quality. To ensure the precision of the data, we included only data that were generated by satellites. We set a quality threshold of $80 \%$ to extract the data from days that users provided which contains enough high quality data points to ensure accuracy of latter analysis.

- Number of data points provided for each period should be more than $50 \%$ of the maximum data points that can be provided. We defined 3 periods based on the time in a day: 7AM9AM (Morning), 9AM-17PM (Noon), 17PM-19PM (Evening). During each time, the data collection frequency are different due to the power consumption issue (Supplementary table J.1). In the morning and evening, the maximum data points we could collect is $3,600(1,800$ records per hour). During noon period, we set down the frequency for battery conservation purposes, so the maximum data points we could collect is 2,880 (360 records/hour). We process each period separately to check their reliability.

The low quality of GPS data makes that the total entries that we can validate goes down to 88 entries. The final results were categorized into two groups: participants who provided a restaurant name within 200 meters of their GPS coordinates, and those who did not. In the end, 55 entries had a GPS location within 200 meters of the reported location and 3 that did not. The results show that $95 \%$ of the entries that we can validate show that the participant was within 200 meters of the restaurant they claim to visit.

\section{J.2 Time at Home}

Individuals in our sample were asked to provide their home address in the initial questionnaire. Every noon and evening over the weekend, we calculated the share of time at home of a participant by calculating the proportion of GPS data points within 200 meters of their home coordinates. For the analysis, we focused on the evening time (5 pm to $7 \mathrm{pm}$ ) when participants are expected not to be at the office. Table J.2 describes the correspondence between our survey and the GPS data. The results show the time at home is $11 \mathrm{pp}[\mathrm{P}<0.05]$ lower when participants reported going to restaurants. 
Table J.2: Correspondence survey reports with time at home measured from GPS data

$(1)$

$(2)$

(3)

(4)

$(5)$

(6)

Time at home

$\begin{array}{lllll}\text { Reported Rest. Visit }(1=\text { YES }) & -0.109^{* *} & -0.103^{* *} & -0.112^{* *} & -0.114^{* *} \\ & (0.0467) & (0.0457) & (0.0530) & (0.0538)\end{array}$

$\begin{array}{lcccccc}\text { Observations } & 549 & 549 & 549 & 549 & 549 & 549 \\ \text { R-squared } & 0.094 & 0.085 & 0.099 & 0.118 & 0.106 & 0.118 \\ \text { Day FE } & \text { YES } & \text { YES } & \text { YES } & \text { YES } & \text { YES } & \text { YES } \\ \text { Individual FE } & \text { NO } & \text { NO } & \text { NO } & \text { YES } & \text { YES } & \text { YES } \\ \text { Strata Controls } & \text { NO } & \text { YES } & \text { YES } & \text { NO } & \text { YES } & \text { YES } \\ \text { Extra Controls } & \text { NO } & \text { NO } & \text { YES } & \text { NO } & \text { NO } & \text { YES }\end{array}$

Notes: Robust standard errors are in parentheses. Asterisks indicate coefficient statistical significance level:

$* P<0.10 ; * * P<0.05 ; * * * P<0.01$. All estimations include day fixed effects. The Strata controls include district fixed effects, a dummy variable showing whether the individual went to restaurants at least once a week before the COVID-19 pandemic. The regression include as "Extra" controls the education level of individuals, age, age square, district fixed effects, a dummy variable showing whether the individual went to restaurants at least once a week before the COVID-19 pandemic, a dummy variable indicating that participants' income is below median ,experimental week fixed effects, whether the individual received the information treatment about the precautionary measures of restaurants. Sampling time restricted to the evening time on Friday, Saturday and Sunday. 
Limitations. We face data limitations in the GPS data analysis. The GPS data records provided by participants was low due to the lack of permission from participants to access their GPS records, technical difficulties (i.e. low battery) or not opening the App to transmit the data. The low number of observations hinders the power of our tests, with the consequent reduction in the significance level. 


\section{References}

[1] Solomon Hsiang, Daniel Allen, Sebastien Annan-Phan, Kendon Bell, Ian Bolliger, Trinetta Chong, Hannah Druckenmiller, Andrew Hultgren, Luna Yue Huang, Emma Krasovich, Peiley Lau, Jaecheol Lee, Esther Rolf, Jeanette Tseng, and Tiffany Wu. The Effect of LargeScale Anti-Contagion Policies on the Coronavirus (COVID-19) Pandemic. Nature, page 2020.03.22.20040642, jan 2020.

[2] Seth Flaxman, Swapnil Mishra, Axel Gandy, H Juliette T Unwin, Thomas A Mellan, Helen Coupland, Charles Whittaker, Harrison Zhu, Tresnia Berah, Jeffrey W Eaton, Christl A Donnelly, Steven M Riley, Michaela A C Vollmer, Neil M Ferguson, and Lucy C Okell. Estimating the effects of non-pharmaceutical interventions on COVID-19 in Europe. Nature, 2020 .

[3] World Bank. Global Economic Prospects. Technical Report June, Washington, DC, 2020.

[4] BEA. Gross Domestic Product, 2nd Quarter 2020 (Advance Estimate) and Annual Update, 2020.

[5] Austan Goolsbee and Chad Syverson. Fear, lockdown, and diversion: Comparing drivers of pandemic economic decline 2020. Journal of Public Economics, 193:104311, 2021.

[6] Raj Chetty, John N Friedman, Nathaniel Hendren, and Michael Stepner. How did covid-19 and stabilization policies affect spending and employment? a new real-time economic tracker based on private sector data. Technical report, National Bureau of Economic Research, 2020 .

[7] Kathleen Dooling. The advisory committee on immunization practicesâ updated interim recommendation for allocation of covid-19 vaccineâunited states, december 2020, 2020.

[8] The Times of Israel. Israel aims to vaccinate $25 \%$ of population in a month; 250,000 had shots so far, 2020.

[9] Melissa Eddy and Marc Santora. E.U. Starts Effort to Vaccinate 450 Million, 2020.

[10] Biden-Harris Transition. The Biden-Harris plan to beat COVID-19, 2020.

[11] Thiemo Fetzer, Lukas Hensel, Johannes Hermle, and Christopher Roth. Coronavirus perceptions and economic anxiety. The Review of Economics and Statistics, pages 1-36, 2021.

[12] Jeffrey V Lazarus, Scott C Ratzan, Adam Palayew, Lawrence O Gostin, Heidi J Larson, Kenneth Rabin, Spencer Kimball, and Ayman El-Mohandes. A global survey of potential acceptance of a covid-19 vaccine. Nature medicine, pages 1-4, 2020.

[13] Thiemo Fetzer, Marc Witte, Lukas Hensel, Jon Jachimowicz, Johannes Haushofer, Andriy Ivchenko, Stefano Caria, Elena Reutskaja, Christopher Roth, Stefano Fiorin, et al. Perceptions of an insufficient government response at the onset of the covid-19 pandemic are associated with lower mental well-being. PREPRINT, 2020.

[14] Austan Goolsbee. Twitter. https://twitter.com/austangoolsbee/ status/ 1347548098978062336, 08-January 2021.

[15] Nancy H.L. Leung, Daniel K.W. Chu, Eunice Y.C. Shiu, Kwok Hung Chan, James J. McDevitt, Benien J.P. Hau, Hui Ling Yen, Yuguo Li, Dennis K.M. Ip, J. S.Malik Peiris, Wing Hong Seto, Gabriel M. Leung, Donald K. Milton, and Benjamin J. Cowling. Respiratory virus shedding in exhaled breath and efficacy of face masks. Nature Medicine, 26(5):676-680, 2020.

[16] H. Wesley Perkins and Alan D Berkowitz. Perceiving the community norms of alcohol use among students: Some Research implications for campus alcohol education programming*. Substance Use and Misuse, 21(9-10):961-976, 1986.

[17] Michael Hallsworth, John A List, Robert D Metcalfe, and Ivo Vlaev. The behavioralist as tax collector: Using natural field experiments to enhance tax compliance. Journal of public economics, 148:14-31, 2017.

[18] Noah J Goldstein, Robert B Cialdini, and Vladas Griskevicius. A room with a viewpoint: Using social norms to motivate environmental conservation in hotels. Journal of consumer Research, 35(3):472-482, 2008. 
[19] Kimberly S. Wolske, Kenneth T. Gillingham, and P. Wesley Schultz. Peer influence on household energy behaviours. Nature Energy, 5(3):202-212, 2020.

[20] Robert C. Dempsey, John McAlaney, and Bridgette M. Bewick. A critical appraisal of the social norms approach as an interventional strategy for health-related behavior and attitude change. Frontiers in Psychology, 9(NOV):1-16, 2018.

[21] J.J.; et al VanBavel. Using social and behavioural science to support COVID-19 pandemic response. Nature Human Behaviour, pages 1-50, 2020.

[22] Michael Muthukrishna, Thomas J H Morgan, and Joseph Henrich. The when and who of social learning and conformist transmission. Evolution and Human Behavior, 37(1):10-20, 2016.

[23] John Beshears, James J Choi, David Laibson, Brigitte C Madrian, and Katherine L Milkman. The effect of providing peer information on retirement savings decisions. The Journal of finance, 70(3):1161-1201, 2015.

[24] Christina Annette Gravert and Linus Olsson Collentine. When nudges aren't enough: Incentives and habit formation in public transport usage. CEBI WORKING PAPER SERIES, Working Paper 10/19, ISSN 2596-44TX, 2019.

[25] Ariella S Kristal and Ashley V Whillans. What we can learn from five naturalistic field experiments that failed to shift commuter behaviour. Nature Human Behaviour, 4(2):169$176,2020$.

[26] Mark A Andor, Andreas Gerster, Jörg Peters, and Christoph M Schmidt. Social norms and energy conservation beyond the us. Journal of Environmental Economics and Management, $103,2020$.

[27] P Wesley Schultz, Jessica M Nolan, Robert B Cialdini, Noah J Goldstein, and Vladas Griskevicius. The constructive, destructive, and reconstructive power of social norms. Psychological science, 18(5):429-434, 2007.

[28] Eli P. Fenichel. Economic considerations for social distancing and behavioral based policies during an epidemic. Journal of Health Economics, 32(2):440-451, 2013.

[29] Eli P. Fenichel, Carlos Castillo-Chavezb, M. G. Ceddiac, Gerardo Chowellb, Paula A. Gonzalez Parrae, Graham J. Hickling, Garth Holloway, Richard Horan, Benjamin Morin, Charles Perrings, Michael Springborn, Leticia Velazquez, and Cristina Villalobos. Adaptive human behavior in epidemiological models. Proceedings of the National Academy of Sciences of the United States of America, 108(15):6306-6311, 2011.

[30] Seth Benzell, Avinash Collis, and Christos Nicolaides. Rationing Social Contact During the COVID-19 Pandemic: Transmission Risk and Social Benefits of US Locations. Proceedings of the National Academy of Sciences, pages 2-4, 2020.

[31] Daisy Dai and Michael Luca. Digitizing Disclosure: The Case of Restaurant Hygiene Scores. American Economic Journal: Microeconomics, 12(2):41-59, 2020.

[32] Jon M. Jachimowicz, Salah Chafik, Sabeth Munrat, Jaideep C. Prabhu, and Elke U. Weber. Community trust reduces myopic decisions of low-income individuals. Proceedings of the National Academy of Sciences of the United States of America, 114(21):5401-5406, 2017.

[33] Armin Falk, Anke Becker, Thomas Dohmen, Benjamin Enke, David Huffman, and Uwe Sunde. Global evidence on economic preferences. The Quarterly Journal of Economics, 133(4):1645-1692, 2018.

[34] Davide Cantoni, David Yang, Noam Yuchtman, and Jane Zhang. Protests as strategic games: Experimental Evidence from Hong Kong's Authoritarian Movement. The Quarterly Journal of Economics, 134(2):1021-1077, 2019.

[35] John A. List, Azeem M. Shaikh, and Yang Xu. Multiple hypothesis testing in experimental economics. Experimental Economics, 22(4):773-793, 2019.

[36] George Loewenstein, Cass R. Sunstein, and Russell Golman. Disclosure: Psychology Changes Everything. Annual Review of Economics, 6(1):391-419, 2014. 